Camila Shirota

\title{
Ondaletas no Processamento de Potenciais Evocados Somato-Sensitivos
}

Dissertação apresentada à Escola Politécnica da Universidade de São Paulo para obtenção do Título de Mestre em Engenharia. 
Camila Shirota

\section{Ondaletas no Processamento de Potenciais Evocados Somato-Sensitivos}

Dissertação apresentada à Escola Politécnica da Universidade de São Paulo para obtenção do Título de Mestre em Engenharia.

Área de concentração:

Sistemas Eletrônicos

Opção Engenharia Biomédica

Orientadora:

Prof ${ }^{\mathrm{a}} \mathrm{Dr}^{\mathrm{a}}$ Cinthia Itiki 


\section{FICHA CATALOGRÁFICA}

\section{Shirota, Camila}

Ondaletas no processamento de potenciais evocados somato-sensitivos / C. Shirota. -- São Paulo, 2008.

$122 \mathrm{p}$.

Dissertação (Mestrado) - Escola Politécnica da Universidade de São Paulo. Departamento de Engenharia de Telecomunicações e Controle.

1. Processamento de sinais biomédicos 2. Potenciais evocados de curta latência 3. Análise de ondaletas (wavelet) 4. Filtros digitais I. Universidade de São Paulo. Escola Politécnica. Departamento de Engenharia de Telecomunicações e Controle II. t. 
Aos meus pais. 


\section{Agradecimentos}

Agradeço à minha família, que sempre me apoiou e me incentivou. Aos meus irmãos, pela ajuda, companhia, cumplicidade, paciência e compreensão desde que saímos de casa.

À Prof ${ }^{a}$. Cinthia Itiki, minha 'mãe' acadêmica e 'tia' de coração, pela orientação, amizade e tantas outras coisas que passamos nesses anos de convivência.

Aos professores do Laboratório de Engenharia Biomédica, Prof. André F. Kohn, Prof. José Carlos T.B. Moraes e Prof. Henrique T. Moriya, que sempre me acolheram tão bem.

Ao Prof. Gilberto M. Manzano pelo auxílio com os potenciais evocados e, junto com o Prof. André, pelas sugestões apresentadas durante este trabalho.

Aos técnicos e colegas do LEB, pela ajuda e pelo convívio diário.

Ao Diego, Mateus, Paulo e Bruno, que fizeram o trabalho ser mais divertido.

Aos meus amigos, que sempre estiveram ao meu lado.

Aos voluntários dos experimentos realizados durante este mestrado.

À Fapesp, pelo apoio financeiro (processo 05/57428-6).

A todas as pessoas que colaboraram diretamente ou indiretamente na realização deste trabalho. 


\section{Resumo}

Os potenciais evocados somato-sensitivos são úteis para detectar e localizar lesões nas vias sensoriais. Sua obtenção exige a média síncrona de mais de mil respostas individuais. A redução do número de estímulos elétricos para obter o potencial evocado resulta na diminuição do tempo do exame e do desconforto do paciente.

O objetivo desta dissertação foi o de estudar o potencial de contribuição de duas técnicas de tempo-freqüência (ondaletas e filtros associados a trechos temporais específicos) à estimação de potenciais evocados somato-sensitivos, quando se utilizam apenas 100 respostas individuais.

Quanto aos filtros, sugere-se o uso de dois passa-baixas. O primeiro, com freqüência de corte em $900 \mathrm{~Hz}$, deve ser utilizado no trecho inicial de $3 \mathrm{~ms}$ a $35 \mathrm{~ms}$ e o segundo, com freqüência de corte em $200 \mathrm{~Hz}$, no trecho final de $25 \mathrm{~ms}$ a $60 \mathrm{~ms}$.

Em relação aos parâmetros da técnica baseada em ondaletas, recomenda-se a utilização da ondaleta-mãe biortogonal 5.5, pois ela fornece erros menores e apresenta curvas visualmente boas. Além disso, ela apresenta a vantagem de ter fase linear, que é mais adequada ao processamento de potenciais evocados. Os 20\% maiores coeficientes das escalas D3, D4 e D5 e os 50\% maiores coeficientes da escala D6 que se encontram em trechos temporais específicos, além de todos os coeficientes de aproximação da escala 6 , reconstroem adequadamente o potencial evocado.

A análise estatística dos erros quadráticos normalizados indicou que a estimação por ondaletas é a melhor dentre as técnicas testadas. Também se verificou que ambas as técnicas resultaram na redução do erro quadrático normalizado, quando comparadas à média síncrona de 100 respostas individuais.

Conclui-se que tanto as ondaletas quanto os filtros contribuem de forma positiva à obtenção de melhores estimativas do potencial evocado, mesmo quando um número reduzido de respostas individuais é utilizado.

Palavras-chave: Processamento de sinais biomédicos. Potenciais evocados de curta latência. Análise de ondaletas (wavelet). Filtros digitais. 


\section{Abstract}

Somatosensory evoked potentials are useful to detect and locate lesions in sensory pathways. In order to obtain somatosensory evoked potentials, more than one thousand single sweeps must be synchronously averaged. The smaller the number of electrical stimuli used for evoked potentials, the lower is the examination length and the patient discomfort.

The objective of this thesis is to study the contribution potential of two time-frequency techniques (wavelets and filters associated to specific time intervals) to the estimation of somatosensory evoked potentials, when only one hundred individual responses are used.

For the filtering technique, it is suggested that two low-pass filters be used. The first filter has a $900 \mathrm{~Hz}$ cutoff frequency and must be used in the $3 \mathrm{~ms}-35 \mathrm{~ms}$ time interval. The second one has a $200 \mathrm{~Hz}$ cutoff frequency and should be applied to the $25 \mathrm{~ms}-60 \mathrm{~ms}$ section.

Regarding wavelet parameters, it is recommended that a biorthogonal 5.5 mother wavelet be used, because it provides smaller errors and the results are visually good. Besides it, this mother wavelet has linear phase, which is useful to the evoked potential processing. The $20 \%$ greatest coefficients in D3, D4, D5 scales, and the $50 \%$ greatest D6 coefficients are candidates to the reconstruction. Those that fall in specific time intervals are used together with all the A6 coefficients. They reconstruct evoked potentials in a satisfactory manner.

The statistical analysis of the normalized squared errors indicates that the wavelet estimation is the best technique among the tested ones. This work also shows that both techniques resulted in the reduction of the normalized squared errors, when compared to the synchronous averaging of 100 individual responses.

As a conclusion, both wavelets and filters contribute in a positive manner to improve evoked potential estimation, even when a reduced number of individual responses is used.

Keywords: Biomedical signal processing. Short-latency evoked potentials. Wavelet analysis. Digital filters. 


\section{Sumário}

\section{Lista de Figuras}

\section{Lista de Tabelas}

1 Introdução $\quad 17$

2 Potenciais Evocados 23

2.1 O sistema nervoso . . . . . . . . . . . . . . . . . 23

2.1.1 Neurônios . . . . . . . . . . . . . . . . . . . . . . . . . 24

2.1.2 Organização do sistema nervoso . . . . . . . . . . . . . 25

2.2 Considerações gerais . . . . . . . . . . . . . . . . . 30

2.3 PEs somato-sensitivos . . . . . . . . . . . . . . . . 33

2.3 .1 Estimulação . . . . . . . . . . . . . . . . . . . . 33

2.3.2 Captação . . . . . . . . . . . . . . . . . . . . . 35

2.3 .3 Aquisição . . . . . . . . . . . . . . . . . . 36

2.3 .4 Análise . . . . . . . . . . . . . . . . . . . . . . 37

3 Metodologia $\quad 39$

3.1 Obtenção de sinais . . . . . . . . . . . . . . . . . . . . 39

3.1 .1 Estimulação . . . . . . . . . . . . . . . . . . . 40 
3.1 .2 Captação . . . . . . . . . . . . . . . . . . . . . 40

3.1 .3 Aquisição . . . . . . . . . . . . . . . . . . . . . . . . . . . . 41

3.1 .4 Análise . . . . . . . . . . . . . . . . . . . . 41

3.2 Método de filtros seletivos no tempo f . . . . . . . . . . . . . . . 43

3.2.1 Método de Nishida, Nakamura e Shibasaki (1993) . . . . . . . . . . 45

3.2 .2 Método alternativo $1 \ldots \ldots$. . . . . . . . . . . . 47

3.2.3 Método alternativo $2 \ldots \ldots \ldots$. . . . . . . . . . . . 48

3.3 Ondaletas . . . . . . . . . . . . . . . . . . . . . . . . . . 49

3.3 .1 Decomposição . . . . . . . . . . . . . . . . . . 52

3.3.2 Relação entre as ondaletas e os filtros . . . . . . . . . . . . . 55

3.3 .3 Reconstrução . . . . . . . . . . . . . . . . . 56

3.4 Forma de análise dos resultados . . . . . . . . . . . . . . . . . . . 61

3.4 .1 Análise visual . . . . . . . . . . . . . . . . . . . . . . 61

3.4 .2 Erro quadrático . . . . . . . . . . . . . . . . 61

3.4.3 Análise estatística para duas técnicas . . . . . . . . . . . . . 61

3.4.4 Análise estatística para mais de duas técnicas . . . . . . . . . 63

4 Resultados $\quad 65$

4.1 Escolha dos coeficientes . . . . . . . . . . . . . . . . 65

4.1 .1 Contribuição de cada escala . . . . . . . . . . . . . . 66

4.1.2 Determinação das faixas de coeficientes relevantes . . . . . . . . . 76

4.1.3 Determinação das porcentagens de coeficientes relevantes . . . . . . 80

4.2 Outras ondaletas-mãe . . . . . . . . . . . . . . . . . 85 
4.3 Sinais experimentais . . . . . . . . . . . . . . . . . . 88

4.4 Aplicação da metodologia . . . . . . . . . . . . . . . . . . . . 90

5 Discussão e Conclusão 102

5.1 Escolha dos coeficientes . . . . . . . . . . . . . . . . . . 102

5.2 Seleção da ondaleta-mãe . . . . . . . . . . . . . . . . . . . . . . . . . 104

5.3 Métodos de estimação . . . . . . . . . . . . . . . . . 106

5.4 Avaliação das estimativas . . . . . . . . . . . . . . . . . . 108

5.5 Variação do número de respostas individuais por média síncrona . . . . . . 109

5.6 Conclusão . . . . . . . . . . . . . . . . . . . . 115

$\begin{array}{ll}\text { Referências Bibliográficas } & 117\end{array}$ 


\section{Lista de Figuras}

2.1 Sistemas nervosos central e periférico. . . . . . . . . . 26

2.2 Divisão do córtex em lobos. Observa-se que alguns sulcos delimitam as regiões. . . . . . . . . . . . . . . . . . . 27

2.3 Mapa somatotópico e ilustração do corpo humano com as partes proporcionais aos do mapeamento. . . . . . . . . . . . . . . . . . . . 28

2.4 Sistema coluna dorsal-lemnisco medial. Essa via é utilizada principalmente para sensações de pressão, vibração e propriocepção. . . . . . . . . . . . . . . 29

2.5 Localização do nervo mediano e as correspondentes regiões invervadas na

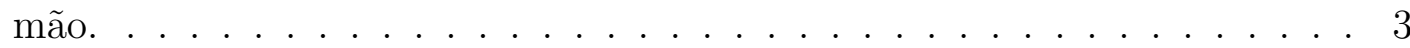

2.6 Potencial evocado somato-sensitivo cortical em resposta à estimulação do nervo mediano, média de 2000 respostas individuais. A1: amplitude a partir da linha de base; A2: amplitude pico-a-pico. . . . . . . . . . . 32

2.7 Tipos de eletrodo de estimulação: a) eletrodo de superfície; b) eletrodo de barra; c) eletrodo de anel.

2.8 Exemplo de estimulação de nervo misto. O limiar motor foi de $6,4 \mathrm{~mA}$, portanto o estímulo aplicado tinha intensidade de $9,6 \mathrm{~mA} \ldots$. . . . . . . . . 35

2.9 Sistema internacional 10-20 de posicionamento de eletrodos. . . . . . . . . 36

3.1 Esquema da montagem utilizada nos experimentos. . . . . . . . . . . . . . 39

3.2 Estrutras do punho, mão direita. O nervo mediano está em preto e os tendões dos músculos palmar longo e flexor radial do carpo estão em branco. 41 
3.3 Marcas e estruturas, no membro esquerdo, utilizados no posicionamento do eletrodo de estimulação. . . . . . . . . . . . . . . . . . . . . . . . . . 42

3.4 Sistema internacional 10-20 de posicionamento de eletrodos. Os pontos $C_{4}^{\prime}$ e $F_{p z}^{\prime}$ ficam $2 \mathrm{~cm}$ atrás, respectivamente, dos pontos $C_{4}$ e $F_{z}$. . . . . . . . 42

3.5 Exemplos de entrada e saída (coluna da direita) e ganho (coluna da esquerda) de filtros ideais a) passa-baixas, b) passa-altas, c) passa-faixa e d) rejeita-faixa. . . . . . . . . . . . . . . . . . . 44

3.6 Método de reconstrução a partir de respostas individuais. . . . . . . . . . . 45

3.7 Exemplo de aplicação dos filtros de Nishida, Nakamura e Shibasaki (1993): a) sinal original e b) saídas dos filtros 1 (componente inicial), 2 (componente médio) e 3 (componente final) . . . . . . . . . . . . . . . . . . . 46

3.8 Resposta em freqüência dos filtros 1 (linha escura) e 2 (linha clara) a) até centenas de hertz e b) até milhares de hertz. . . . . . . . . . . . . . . . . 47

3.9 Resposta em freqüência dos filtros 1 (linha escura) e 2 (linha clara) a) até centenas de hertz e b) até milhares de hertz. . . . . . . . . . . . . . . . 48

3.10 Sinais obtidos aplicando os filtros passa-faixas com a função filtfilt ao sinal 13 do sujeito 3: a) saída do filtro 1; b) saída do filtro 2; c) estimativa individual. As linhas verticais indicam os intervalos em que os trechos foram utilizados na reconstrução do sinal. A amplitude está em micro-volts. 49

3.11 Método alternativo de reconstrução a partir de respostas individuais. . . 49

3.12 Resposta em freqüência dos filtros 1 (linha escura) e 2 (linha clara) a) até centenas de hertz e b) até milhares de hertz. . . . . . . . . . . . . . . 50

3.13 Divisão do plano tempo-freqüência por a) STFT e b) ondaletas. . . . . . . 51

3.14 Exemplos de ondaletas-mãe usadas na decomposição: a) Haar; b) Daubechies 6 ; c) Biortogonal 5.5 e d) Symlet 2. . . . . . . . . . . . . 52 
3.15 Variação dos parâmetros das ondaletas: a) $k$, ondaleta biortogonal 5.5 e b) $j$, ondaleta daubechies $6 \ldots \ldots \ldots \ldots \ldots$

3.16 Decomposição em 3 escalas. . . . . . . . . . . . . . . . . . . 55

3.17 Reconstrução em 3 escalas. . . . . . . . . . . . . . . . . . . . . 58

3.18 Ganho das respostas em freqüência dos filtros passa-faixa (linha escura) e passa-baixas (linha clara) relacionados à ondaleta biortogonal 5.5: a) filtros de decomposição e b) filtros de reconstrução. . . . . . . . . . . . . . . . . . . 60

3.19 Fase das respostas em freqüência dos filtros passa-faixa (linha escura) e passa-baixas (linha clara) relacionados à ondaleta biortogonal 5.5: a) filtros de decomposição e b) filtros de reconstrução. . . . . . . . . . . . . . . . . . 60

4.1 Valores dos coeficientes da DWT: a) PE padrão, b) aproximação de escala 6, c) detalhe de escala 6, d) detalhe de escala 5. (continua) . . . . . . . 67

4.1 (continuação) e) detalhe de escala 4, f) detalhe de escala 3, g) detalhe de

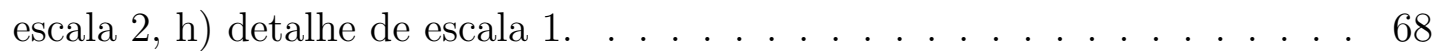

4.2 Contribuição de cada escala da DWT: a) PE padrão em linha pontilhada e reconstrução usando os coeficientes A6 e b) erro quadrático. . . . . . . . 69

4.3 Contribuição de cada escala da DWT: a) PE padrão em linha pontilhada e reconstrução usando os coeficientes A6 e D6 e b) erro quadrático. . . . . 70

4.4 Contribuição de cada escala da DWT: a) PE padrão em linha pontilhada e reconstrução usando os coeficientes A6, D6 e D5 e b) erro quadrático. . 71

4.5 Contribuição de cada escala da DWT: a) PE padrão em linha pontilhada e reconstrução usando os coeficientes A6, D6, D5 e D4 e b) erro quadrático. 72

4.6 Contribuição de cada escala da DWT: a) PE padrão em linha pontilhada e reconstrução usando os coeficientes A6, D6, D5, D4 e D3 e b) erro quadrático. 73 
4.7 Contribuição de cada escala da DWT: a) PE padrão em linha pontilhada e reconstrução usando os coeficientes A6, D6, D5, D4, D3 e D2 e b) erro

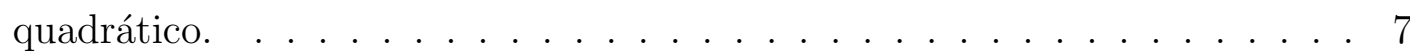

4.8 Contribuição de cada escala da DWT: a) PE padrão em linha pontilhada e reconstrução usando todos coeficientes e b) erro quadrático. . . . . . . . 75

4.9 Média dos valores quadráticos dos coeficientes da TWD: a) aproximação de escala 6, b) detalhe de escala 6 , c) detalhe de escala 5, d) detalhe de escala 4. (continua) . . . . . . . . . . . . . . . . . 7

4.9 (continuação) e) detalhe de escala 3, f) detalhe de escala 2, g) detalhe de escala 1. . . . . . . . . . . . . . . . . . . . . 78

4.10 Média dos valores quadráticos dos coeficientes da TWD. Os 20\% (ou 50\%) maiores valores são representados por hastes. As faixas de coeficientes relevantes são delimitadas pelas linhas pontilhadas e os números dos coeficientes que limitam a faixa estão indicados na parte superior do gráfico. São representados os detalhes das escalas: a) 6, b) 5, c) 4 e d) 3. . . . . .

4.11 Estimativa do potencial evocado padrão do sujeito 1 usando ondaletas: a) PE padrão (linha pontilhada) e estimativa (linha contínua), b) erro quadrático usando todos os coeficientes das faixas relevantes que também estejam entre os $20 \%$ maiores e c) erro quadrático usando todos os coeficientes das faixas relevantes. . . . . . . . . . . . . . . . 81

4.12 Estimativa do potencial evocado padrão do sujeito 2 usando ondaletas: a) PE padrão (linha tracejada) e estimativa (linha contínua), b) erro quadrático usando todos os coeficientes das faixas relevantes que também estejam entre os $20 \%$ (ou $50 \%$ ) maiores e c) erro quadrático usando todos os coeficientes das faixas relevantes. . . . . . . . . . . . . . . . . 82 
4.13 Estimativa do potencial evocado padrão do sujeito 3 usando ondaletas: a) PE padrão (linha tracejada) e estimativa (linha contínua), b) erro quadrático usando todos os coeficientes das faixas relevantes que também estejam entre os $20 \%$ (ou $50 \%$ ) maiores e c) erro quadrático usando todos os coeficientes das faixas relevantes. . . . . . . . . . . . . . . . . 83

4.14 Estimativa do potencial evocado padrão do sujeito 4 uusando ondaletas: a) PE padrão (linha tracejada) e estimativa (linha contínua), b) erro quadrático usando todos os coeficientes das faixas relevantes que também estejam entre os $20 \%$ (ou $50 \%$ ) maiores e c) erro quadrático usando todos os coeficientes das faixas relevantes. . . . . . . . . . . . . . . . . 84

4.15 PE padrão, média síncrona de 100 respostas e estimativas por ondaletas utilizando as ondaletas-mãe biortogonal 5.5, daubechies 6 , symlet 6 , coiflet 2 , daubechies 3 , symlet 3 e coiflet 1 . As estimativas estão deslocadas de $0,4 \mu V$ para facilitar a visualização e foram calculadas para o primeiro conjunto de 100 respostas do sujeito 3.

4.16 Médias das mil primeiras (linha contínua) e mil últimas (linha pontilhada) respostas inviduais, para os sujeitos a) 5, b) 6, c) 7, d) 8, e) 9, f) 10, g) 11,

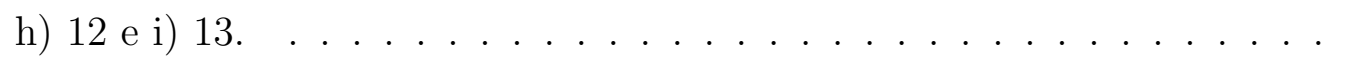

4.17 PE padrão e estimativas obtidas usando média síncrona, filtros e ondaletas (de cima para baixo, deslocadas de $4 \mu V$ ) para os conjuntos a) 1, b) 2, c) 3, d) 4 , e) 5 , f) 6 , g) 7 , h) 8 , i) 9 e j) 10 do sujeito $5 \ldots \ldots$. . . . . . . 92

4.18 PE padrão e estimativas obtidas usando média síncrona, filtros e ondaletas (de cima para baixo, deslocadas de $4 \mu V$ ) para os conjuntos a) 1, b) 2, c) 3, d) 4 , e) 5, f) 6 , g) 7 , h) 8 , i) 9 e j) 10 do sujeito 6 .

4.19 PE padrão e estimativas obtidas usando média síncrona, filtros e ondaletas (de cima para baixo, deslocadas de $4 \mu V$ ) para os conjuntos a) 1, b) 2, c) 3 , d) 4 , e) 5 , f) 6 , g) 7 , h) 8 , i) 9 e j) 10 do sujeito 7 . 
4.20 PE padrão e estimativas obtidas usando média síncrona, filtros e ondaletas (de cima para baixo, deslocadas de $4 \mu V$ ) para os conjuntos a) 1, b) 2, c) 3 , d) 4 , e) 5 , f) 6 , g) 7 , h) 8 , i) 9 e j) 10 do sujeito $8 \ldots \ldots . \ldots$

4.21 PE padrão e estimativas obtidas usando média síncrona, filtros e ondaletas (de cima para baixo, deslocadas de $4 \mu V$ ) para os conjuntos a) 1, b) 2, c) 3 , d) 4 , e) 5 , f) 6 , g) 7 , h) 8 , i) 9 e j) 10 do sujeito $9 \ldots \ldots 6$

4.22 PE padrão e estimativas obtidas usando média síncrona, filtros e ondaletas (de cima para baixo, deslocadas de $4 \mu V$ ) para os conjuntos a) 1, b) 2, c) 3 , d) 4 , e) 5 , f) 6 , g) 7 , h) 8 , i) 9 e j) 10 do sujeito $10 \ldots$. . . . . . 97

4.23 PE padrão e estimativas obtidas usando média síncrona, filtros e ondaletas (de cima para baixo, deslocadas de $4 \mu V$ ) para os conjuntos a) 1, b) 2, c) 3 , d) 4 , e) 5, f) 6 , g) 7 , h) 8, i) 9 e j) 10 do sujeito 11.

4.24 PE padrão e estimativas obtidas usando média síncrona, filtros e ondaletas (de cima para baixo, deslocadas de $4 \mu V$ ) para os conjuntos a) 1, b) 2, c) 3 , d) 4 , e) 5, f) 6 , g) 7, h) 8, i) 9 e j) 10 do sujeito 12 .

4.25 PE padrão e estimativas obtidas usando média síncrona, filtros e ondaletas (de cima para baixo, deslocadas de $4 \mu V$ ) para os conjuntos a) 1, b) 2, c) 3 , d) 4 , e) 5 , f) 6 , g) 7 , h) 8 , i) 9 e j) 10 do sujeito $13 . \ldots 100$

5.1 Variação da média do erro quadrático normalizado com o inverso do número de respostas individuais, para as estimativas por a) média síncrona, b) filtros e c) ondaletas, par ao sujeito $5 \ldots$. . . . . . . . . . . . . . 110

5.2 PE padrão e estimativas obtidas usando média síncrona, filtros e ondaletas (de cima para baixo, deslocadas de $4 \mu V$ ) para os primeiros conjuntos de a) 500 , b) 250 , c) 200 , d) 125 , e) 100, f) 50 , g) 40, h) 25, i) 20 e j) 10 respostas individuais do sujeito $6 \ldots \ldots$. . . . . . . . . . 111 
5.3 Variação da média do erro quadrático normalizado (da média síncrona) com o inverso do número de respostas individuais, para todos os sujeitos. . 113

5.4 PE padrão e média síncrona das 10 primeiras respostas individuais do su-

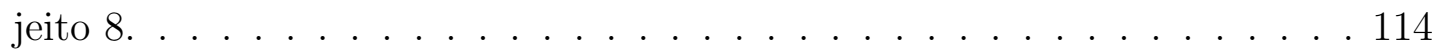




\section{Lista de Tabelas}

2.1 Latências e amplitudes dos picos de PE contralateral de nervo mediano, após estimulação unilateral (adaptado de (CRACCO; BODIS-WOLLNER, 1986) e (DELISA; MACKENZIE; BARAN, 1987)). . . . . . . . . . . 37

3.1 Coeficientes dos filtros $h[k]$ e $\tilde{h}[k]$ para a TWD e anti-transformada usando a ondaleta biortogonal 5.5. Os filtros têm simetria par, ou seja, $h[k]=$ $h[-k]$ e $\tilde{h}[k]=\tilde{h}[-k] \ldots \ldots \ldots \ldots \ldots \ldots$

3.2 Dados para o teste do sinal. . . . . . . . . . . . . . . . . . 62

3.3 Valores críticos para a distribuição nula da estatística do L de Page. São apresentados os valores de $\ell(\alpha, k, n)$ que satisfazem $P[L \geq \ell(\alpha, k, n)]=\alpha$, dados o número de técnicas $(k)$, o número de indivíduos $(n)$ e o nível de significância $(\alpha)$.

4.1 Erros quadráticos normalizados das estimativas de médias de 100 respostas individuais do sujeito 3 obtidas pelas ondaletas biortogonal 5.5 (bior5.5), daubechies 6 (db6), symlet 6 (sym6), coiflet 2 (coif2), daubechies 3 (db3), symlet 3 (sym3) e coiflet 1 (coif1), em porcentagem. . . . . . . . . . 86

4.2 Erros quadráticos normalizados percentuais das três estimativas para os conjuntos de 100 respostas individuais dos sujeitos 5 a 13. . . . . . . . . . 91

4.3 Média dos erros quadráticos normalizados das três estimativas para os sujeitos 5 a 13, em porcentagem, e postos de Friedman (entre parênteses). . . 101 


\section{Introdução}

A percepção do ambiente é fundamental para a sobrevivência. As informações do meio externo ao corpo indicam, por exemplo, a presença de predadores, as condições climáticas e a comestibilidade de um alimento. Essas informações são obtidas pelos sistemas sensoriais: gustativo, olfativo, visual, auditivo e somato-sensitivo. Este último sistema transmite informações como a temperatura, a dor, a pressão e a propriocepção ao encéfalo (BEAR; CONNORS; PARADISO, 2001).

O sinal elétrico resultante da resposta do sistema nervoso a estímulos sensoriais é denominado potencial evocado (PE) (KANDEL; SCHWARTZ; JESSELL, 2000; CHIAPPA, 1983). Os PEs são classificados pelo tipo de estímulo aplicado ao sistema nervoso (SPEHLMANN, 1985). Em clínica, são usados estímulos visuais, auditivos ou elétricos, dando origem a PEs visuais, auditivos e somato-sensitivos, respectivamente.

Os PEs consistem de uma seqüência de deflexões ou picos. A presença desses picos, suas amplitudes e latências (tempo decorrido entre a estimulação e a ocorrência do pico) são utilizadas na análise do sinal. Os PEs de curta latência são importantes em clínica pois são respostas que independem da atenção da pessoa ao estímulo apresentado e que podem ser obtidas até mesmo de pacientes que não conseguem se comunicar. Além disso, os PEs podem ser comparados de modo objetivo entre sujeitos diferentes (AMINOFF, 1986). Essa comparação é possível porque os valores considerados normais de amplitude e latência dos picos do PE são tabelados na literatura (CRACCO; BODIS-WOLLNER, 1986). O afastamento em relação a esses valores geralmente indica lesões nas vias sensoriais (ILKHANI et al., 2005; AMINOFF; EISEN, 1998). Também se pode acompanhar a variação 
desses parâmetros ao longo do tempo para observar o efeito do tratamento na progressão de doenças (FREYE, 2005).

Além das aplicações mencionadas acima, os PEs também são utilizados para monitorar as condições das vias sensoriais durante neurocirurgias (KRAFT et al., 1998; FREYE, 2005). Outra aplicação desses sinais é no acompanhamento do efeito de remédios que atuam sobre o sistema nervoso (SPRECKELSEN; BROMM, 1988; SCHELLER et al., 2006).

O PE pode ser captado no escalpo, mas a sua amplitude é pequena frente ao sinal de eletroencefalografia (EEG), resultante da atividade normal do encéfalo, e a outros sinais de origem biológica (CHIAPPA, 1983). Por isso, o potencial evocado é obtido a partir da média síncrona de várias respostas individuais (cada resposta é obtida pela aplicação de um estímulo de amplitude e duração pré-determinadas). Em clínica, cerca de 1000 respostas individuais são necessárias para se obter uma estimativa (media síncrona) confiável do PE somato-sensitivo. Além disso, duas médias síncronas são necessárias para se validar a estimativa do PE (DELISA; MACKENZIE; BARAN, 1987; SPEHLMANN, 1985). Dessa forma, o exame tem uma duração longa, e a inquietação e o desconforto do paciente podem provocar artefatos no sinal captado, dificultando ainda mais a estimação do potencial evocado. Por isso, seria interessante diminuir o número de respostas necessárias para se calcular a média síncrona, mas que, ainda assim, preservasse as características do PE.

Essa melhoria na obtenção de PEs tem sido abordada de diversas formas. Por exemplo, tem-se procurado aumentar a relação sinal-ruído (DAVILA; MOBIN, 1992; HOPPE et al., 2002; CAUSEVIC et al., 2005), remover artefatos de estímulo (PARSA; PARKER; SCOTT, 1998) e interferências (CERUTTI et al., 1988; LANGE; INBAR, 1996), detectar os picos relevantes do potencial evocado e estimar suas latências e amplitudes (QUIROGA, 2000). Isso tem sido feito em sinais captados por um único canal ou por diversos canais (KLEIN et al., 2006; LEMM et al., 2006; DROZD et al., 2005); para sinais de longa, média ou curta latência; em sinais eletroencefalográficos (BOSTANOV, 2004), magnetoencefalográficos (NORTON et al., 2004) ou ambos (MAKINEN; MAY; TIITINEN, 2005); e em médias síncronas de números variados de respostas (ZHANG et al., 2004) ou em uma única resposta a estímulo (CERUTTI 
et al., 1988; LEMM et al., 2006).

Alguns autores também tentaram melhorar o próprio cálculo da média síncrona. Davila e Mobin (1992) atribuíram pesos a cada resposta a um estímulo auditivo procurando maximizar a relação sinal-ruído da média ponderada de um número reduzido de respostas. Já Nait-Ali e Siarry (2006) consideraram que o PE auditivo sofre atrasos aleatórios em cada resposta individual, e usaram um método metaheurístico para obter melhores formatos de onda. Para potenciais evocados relacionados a eventos, Gibbons e Stahl (2007) corrigiram as variações do tempo de resposta de cada sujeito pela dilação temporal das respostas rápidas e a compressão das respostas lentas antes do cálculo da média.

Em outros trabalhos, procurou-se modelar tanto o potencial evocado quanto o sinal de EEG. Thakor et al. (1993a) decompuseram os PEs em séries de Fourier e funções de Walsh e estudaram as conseqüências dos danos neurológicos causados pela hipóxia no PE. Bai et al. (2001) procuraram melhorar a relação sinal-ruído representando a transformada discreta de cosseno do PE somato-sensitivo como uma soma de cossenos amortecidos. Lange e Inbar (1996) e Cerutti et al. (1988) usaram modelos paramétricos auto-regressivos com entrada exógena (ARX, do inglês Auto Regressive with eXogenous input), cujas entradas exógenas representavam os sinais biológicos indesejados (eletroencefalográfico ou eletrooculográfico), para obter estimativas menos ruidosas dos potenciais evocados. Por outro lado, Jacobs, Rao e Jose (1989) usaram um modelo auto-regressivo de média móvel (ARMA, do inglês Auto Regressive Moving Average) para representar o PE. Já Fung et al. (1999) e Yin et al. (2004) utilizaram redes neurais para estimar PEs auditivos. Zhang e Böhme (2007) também usaram redes neurais para modelar o potencial evocado visual e o EEG. Por outro lado, Lange, Pratt e Inbar (1997) representaram o EEG por um modelo AR e consideraram o PE relacionado a evento como uma soma de componentes de amplitude e latência variáveis. De forma semelhante, Spreckelsen e Bromm (1988) também usaram um modelo AR para o EEG e outro modelo AR para o PE somato-sensitivo, além de construirem um filtro de Kalman para estimar o potencial evocado a partir de respostas individuais. 
Vários autores procuram melhorar a obtenção dos potenciais evocados empregando filtros. Parsa, Parker e Scott (1998) utilizaram filtros adaptativos lineares e não-lineares para retirar os artefatos de estímulo de PEs somato-sensitivos. Laguna et al. (1992) também usaram filtros adaptativos, mas para aumentar a relação sinal-ruído. Qiu et al. (2006) acompanharam a variação das amplitudes e latências dos picos de potenciais evocados auditivos por meio de uma filtragem não-linear e adaptativa que empregava redes neurais. Lange, Pratt e Inbar (1995) usaram filtros casados por trecho para aumentar a relação sinal-ruído de PEs relacionados a evento. Chan et al. (1998) também utilizaram filtros por trechos, mas adaptativos, para monitorar potenciais evocados auditivos. Além disso, Nishida, Nakamura e Shibasaki (1993) usaram filtros passa-faixa por trechos para detectar os picos do PE somato-sensitivo.

A observação de que trechos diferentes do PE apresentam características espectrais distintas tem levado à utilização de técnicas de análise de tempo-freqüência como, por exemplo, o espectrograma, que é a representação gráfica da STFT (do inglês Short Time Fourier Transform) (HU et al., 2003; HU et al., 2002) e de ondaletas, também conhecidas como wavelets. A grande diferença entre essas técnicas é a divisão do plano tempofreqüência: enquanto a STFT mantém fixas as bandas de freqüência e os intervalos de tempo, as ondaletas variam as suas proporções de forma inversa, analisando freqüências baixas em trechos mais longos e freqüências altas em trechos curtos. Essa característica das ondaletas tem-se mostrado apropriada para o processamento de sinais eletrofisiológicos (CAUSEVIC et al., 2005; KIYMIK; AKIN; SUBASI, 2004; KLEIN et al., 2006; MERLO; FARINA; MERLETTI, 2003; ADDISON, 2005; HOPPE et al., 2002; THAKOR et al., 1993b; UNSER; ALDROUBI, 1996).

Em particular, para o processamento dos potenciais evocados, os coeficientes da DWT (do inglês Discrete Wavelet Transform) são usados para compactar a quantidade de informação, reduzir o ruído ou obter parâmetros para detecção ou estimação dos PEs. Hoppe et al. (2002) selecionaram 16 coeficientes da DWT para representar um PE somatosensitivo, procurando minimizar a relação sinal-erro. Por outro lado, Bartnik, Blinowska 
e Durka (1992), Zhang et al. (2004) e Scheller et al. (2006) usaram os coeficientes da DWT para detectar PEs auditivos. Thakor et al. (1993b) usaram os coeficientes para detectar hipóxia e reoxigenação a partir de PEs somato-sensitivos. Quiroga (2000) escolheu heuristicamente coeficientes da DWT para estimar potenciais evocados visuais a partir de respostas individuais. Causevic et al. (2005) propuseram uma técnica para melhorar a relação sinal-ruído de potenciais evocados auditivos baseada na combinação sucessiva de sinais reconstruídos após a eliminação de ruído pela escolha de coeficientes da DWT. Heinrich et al. (1999) combinaram as ondaletas com as redes neurais na estimação do potencial evocado relacionado a evento, visando estudar o déficit de atenção em crianças. Especificamente para PEs auditivos, Bradley e Wilson (2004) compararam algumas técnicas de estimação utilizando ondaletas, e Wilson (2004) estudou a relação entre o potencial evocado e o sinal reconstruído a partir dos coeficientes da DWT.

Vê-se que as ondaletas têm sido empregadas para melhorar a obtenção de PEs há vários anos. No entanto, ainda há questões a serem estudadas. Um dos problemas na utilização de coeficientes da DWT é a seleção daqueles que melhor representam o PE. Os trabalhos acima mencionados abordaram esse problema específico e os bons resultados obtidos indicam que as ondaletas podem ser utilizadas no processamento de potenciais evocados. Mas muitos desses trabalhos não discutiram aspectos como a escolha da ondaleta-mãe usada, que é essencial para a aplicação da DWT. Além disso, grande parte dos resultados da literatura se aplicam a potenciais evocados visuais ou auditivos de longa latência, havendo poucos trabalhos visando a estimação de PEs somato-sensitivos.

Por isso, seria interessante estudar a aplicação das ondaletas no processamento de potenciais evocados somato-sensitivos. O objetivo desta dissertação é o de estudar o potencial de contribuição de duas técnicas de tempo-freqüência (ondaletas e filtros de trechos temporais específicos) à estimação de potenciais evocados somato-sensitivos, a partir de um número reduzido de respostas individuais. Aspectos metodológicos como a escolha de parâmetros (intervalos de tempo, limiares, freqüência de corte), a influência da ondaleta-mãe e a dependência ao número de respostas utilizadas também serão abordados 
neste trabalho.

Esta dissertação é dividida em 5 capítulos. Este primeiro capítulo apresentou uma introdução ao trabalho, incluindo a justificativa e os objetivos da dissertação. Uma breve introdução aos potenciais evocados é apresentada no capítulo 2. As metodologias de captação de sinais e de estimação dos PEs (média síncrona, filtros de trechos temporais específicos e ondaletas) são explicadas no capítulo 3, assim como os testes estatísticos aplicados ao trabalho. Os resultados obtidos por todos os métodos são apresentados no capítulo 4. E, por fim, o capítulo 5 apresenta a discussão e a conclusão do trabalho. 


\section{Potenciais Evocados}

Os potenciais evocados são sinais eletrofisiológicos muito conhecidos e utilizados na área médica. No entanto, como este trabalho possui enfoque na engenharia, não se espera que o leitor tenha conhecimento sobre o assunto. Por isso, neste capítulo é feita uma breve introdução a esses sinais. Inicialmente, são mostrados alguns tópicos do funcionamento e da organização do sistema nervoso. Em seguida, são apresentados os potenciais evocados em resposta à estimulação sensorial. Finalmente, restringe-se aos potenciais evocados somato-sensitivos, abordando aspectos relacionados à sua estimulação, captação, aquisição e análise. Em particular, são descritos os sinais evocados pela estimulação do nervo mediano e captados no escalpo, já que esse tipo de sinal foi utilizado neste trabalho.

\section{$2.1 \quad$ O sistema nervoso}

É fundamental conhecer um pouco mais sobre o sistema nervoso do ser humano para compreender melhor os potenciais evocados relacionados à estimulação sensorial. Serão abordados alguns aspectos básicos sobre a organização e o funcionamento da rede de neurônios, apresentando a via que leva algumas das sensações de tato até o cérebro. A abordagem escolhida se concentra no sinal utilizado neste trabalho, mas é interessante lembrar que, para os outros sentidos, há vias análogas, que dão origem aos outros tipos de potenciais evocados. 


\subsubsection{Neurônios}

O sistema nervoso é composto por dois tipos de células: os neurônios e as células gliais ou glia. Os neurônios são as unidades básicas do sistema nervoso, cujas atividades resultam do funcionamento dessas células. A glia, por outro lado, não transmite informações dentro do sistema nervoso. Contudo, ela desempenha funções importantes para a sobrevivência e o funcionamento dos neurônios, como o controle da concentração de íons no meio extracelular e o isolamento elétrico de partes dos neurônios por bainhas mielínicas.

Os neurônios podem apresentar algumas partes distintas quanto à função. $\mathrm{O}$ corpo celular é o centro metabólico da célula, e é onde se encontra o núcleo. Do corpo celular saem ramificações que servem para a comunicação do neurônio com outras células: os dendritos geralmente são em grande número e recebem as informações de outras células, e o axônio transmite sinais de forma rápida geralmente em direção a outras células. Por fim, os terminais pré-sinápticos transmitem informações do neurônio às células pós-sinápticas (outros neurônios ou fibras musculares).

Geralmente, o axônio conduz ativamente o potencial de ação (PA), pela movimentação de íons através da membrana celular. Em repouso, o meio intracelular do axônio apresenta um potencial negativo em relação ao meio extracelular. O potencial de ação é uma despolarização, de cerca de $100 \mathrm{mV}$, muito rápida da membrana celular. Essa despolarização é muitas vezes seguidas por uma hiperpolarização. Entre o início do PA e o retorno da membrana ao repouso, decorrem cerca de 2ms (BEAR; CONNORS; PARADISO, 2002). Assim, a informação é codificada pela freqüência e pelo padrão de disparo dos potenciais de ação. Os axônios podem conduzir os sinais por distâncias de até um metro (KANDEL; SCHWARTZ; JESSELL, 2000). A velocidade com que os potenciais de ação percorrem o axônio é variável, sendo maior nos axônios que apresentam bainhas mielínicas. Os nervos são conjuntos de axônios.

A informação que chega ao dendrito também pode causar uma mudança no potencial do meio intracelular em relação ao meio extracelular. No caso em que ocorre uma des- 
polarização, observa-se um potencial excitatório pós-sináptico (PEPS). Por outro lado, quando há uma hiperpolarização ou não há mudança no potencial da membrana (ocorre um aumento na permeabilidade da membrana celular a alguns íons), ocorre um potencial inibitório pós-sináptico (PIPS). Os potenciais pós-sinápticos recebem seus nomes segundo a sua contribuição para a despolarização necessária na zona de disparo para gerar um potencial de ação. Ao contrário do PA, os potenciais pós-sinápticos não possuem um formato padronizado. Além disso, têm duração mais longa e em geral são transportados passivamente, ou seja, vão se atenuando no seu percurso ao longo do neurônio. Dessa forma, vê-se que é necessária a soma de vários potenciais pós-sinápticos para haver o disparo de PAs, mostrando que o neurônio não funciona como um simples repetidor dos sinais recebidos das outras células.

\subsubsection{Organização do sistema nervoso}

O sistema nervoso é dividido em duas partes, denominadas sistema nervoso central e periférico. A Figura 2.1 ilustra essa divisão. O sistema nervoso central (SNC) é composto pelo encéfalo, que fica dentro da caixa craniana, e pela medula espinhal, que é protegida pela coluna vertebral. O sistema nervoso periférico é formado pelos nervos e gânglios que não pertencem ao SNC. Dentre os neurônios do sistema periférico, encontram-se aqueles com terminações especializadas para as sensações de tato e aqueles que fazem a comunicação do sistema nervoso central com as vísceras.

As informações provenientes do sistema nervoso periférico seguem em direção ao encéfalo pela medula espinhal. O encéfalo possui várias partes, dentre as quais o tronco cerebral, o cerebelo e os hemisférios cerebrais. O tronco cerebral é responsável pela regulação de funções vitais à sobrevivência do organismo, como a respiração. O cerebelo está relacionado com o controle de movimentos. Por fim, nos hemisférios cerebrais, encontram-se os centros relacionados a sensações, sentimentos, memória e linguagem, entre outros.

A parte mais externa dos hemisférios cerebrais, de aspecto irregular, é o córtex. No córtex, o processamento de informações é organizada em colunas perpendiculares à su- 


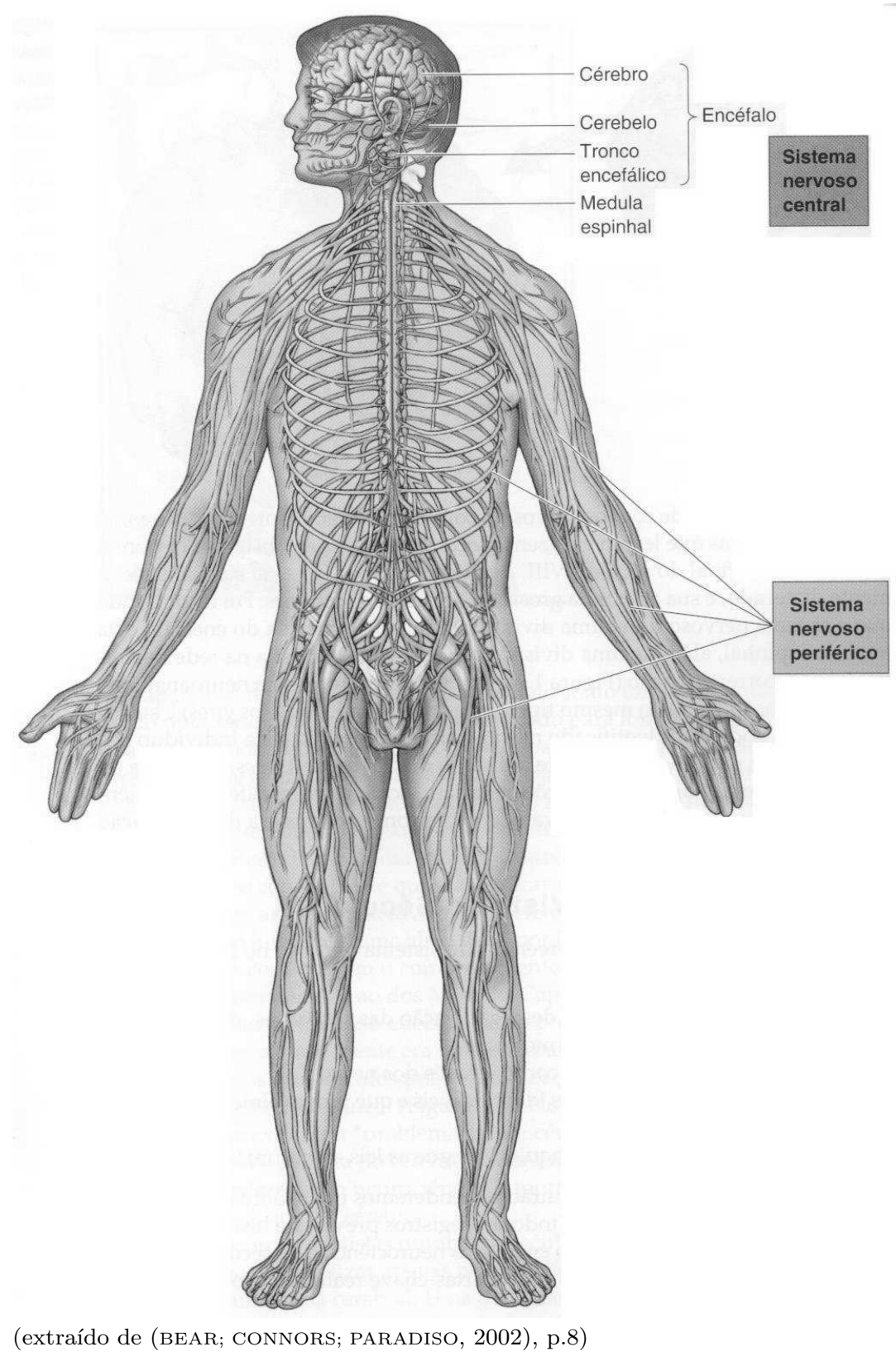

Figura 2.1: Sistemas nervosos central e periférico.

perfície, e as diferentes funções do córtex dividem a superfície em áreas. Com o desenvolvimento do córtex ao longo da evolução das espécies, o tecido cerebral foi se expandindo mais que o crânio. Assim, foram surgindo ondulações para que o tecido se mantivesse dentro da caixa craniana, dando origem aos sulcos e giros. Alguns dos sulcos do cérebro humano são característicos e servem para separar as regiões do córtex (KANDEL; SCHWARTZ; JESSELL, 2000). Essas regiões, também chamadas de lobos, levam o nome do osso sobrejacente: frontal, parietal, temporal e occipital. A Figura 2.2 ilustra essa divisão do córtex. Nos lobos, os neurônios relacionados a uma mesma função encontram-se reunidos em regiões 
denominadas áreas.

Nesses lobos encontram-se, entre outras, as áreas motora, somestésica (relacionada ao tato), auditiva e visual, respectivamente.

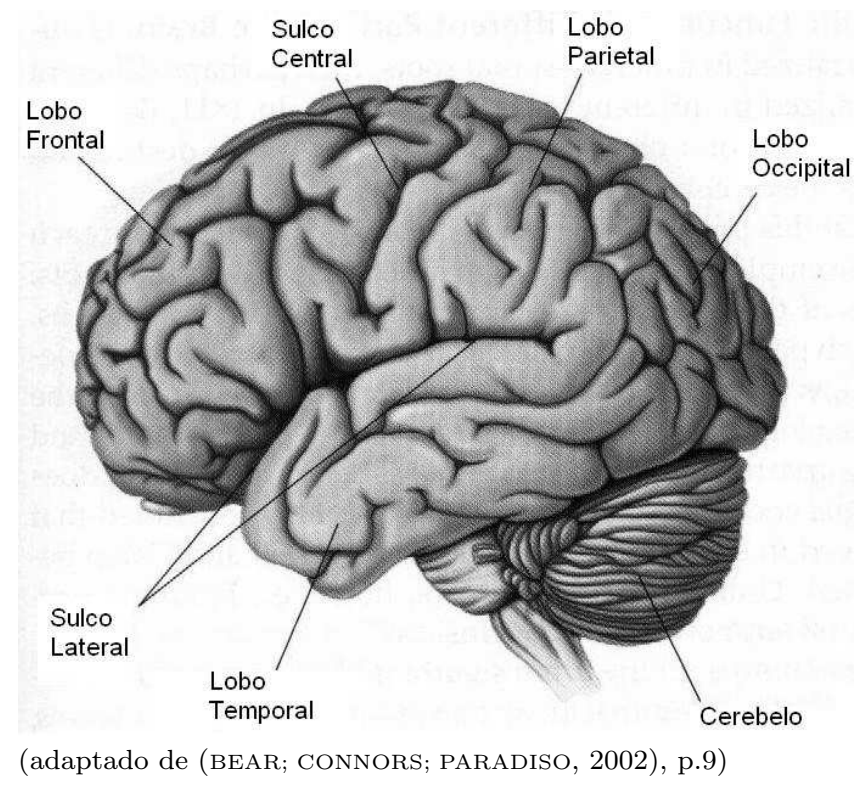

Figura 2.2: Divisão do córtex em lobos. Observa-se que alguns sulcos delimitam as regiões.

Na região parietal, existe uma representação do corpo que é chamado mapa somatotópico ou homúnculo, mostrado na Figura 2.3. Nesse mapa, o tamanho da área relacionada a determinada parte do corpo é proporcional à quantidade de informação proveniente daquela parte, ou seja, aquelas que apresentam maior número de terminações nervosas ocupam uma superfície maior. Esse mapeamento é importante, por exemplo, no caso em que se quer observar a atividade dos neurônios na região relacionada a determinada parte do corpo. A manifestação elétrica resultante, uma integração dos potenciais póssinápticos (KANDEL; SCHWARTZ; JESSELL, 2000), pode ser captada por meio de eletrodos posicionados adequadamente sobre o escalpo. É o que se faz para obter o tipo de potencial evocado usado neste trabalho.

O potencial evocado também pode ser captado ao longo da via sensorial utilizada para levar as informações ao córtex. A principal via das sensações de tato provenientes dos nervos periféricos (exceto dor e temperatura) é o sistema coluna dorsal-lemnisco me- 


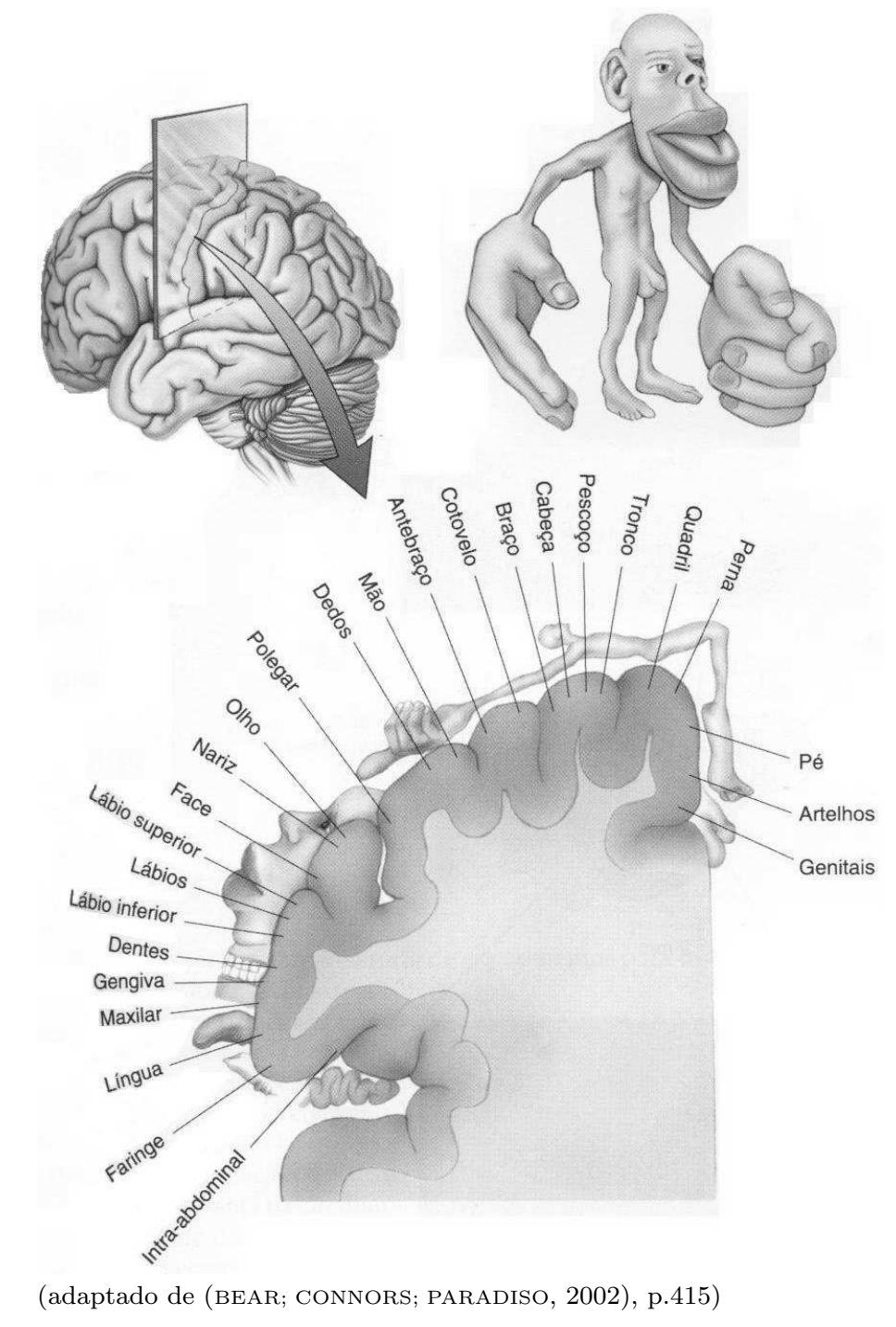

Figura 2.3: Mapa somatotópico e ilustração do corpo humano com as partes proporcionais aos do mapeamento.

dial, ilustrado na Figura 2.4. Nota-se que as informações são levadas ao córtex do lado contrário da estimulação (contralateral). Além disso, são necessários apenas três 'níveis' de neurônios para percorrer esse caminho.

Considere como exemplo o caso dos sinais utilizados neste trabalho, provenientes do nervo mediano. A Figura 2.5 ilustra a localização desse nervo no membro superior. Ele inerva alguns músculos do antebraço, os dedos polegar, indicador e médio e uma região da palma da mão. Seguindo em direção ao sistema nervoso central, o nervo mediano passa pelo plexo braquial, juntando-se com outros nervos e chegando na medula. A partir dali, pela coluna dorsal ipsilateral (do mesmo lado da estimulação), os sinais provenientes do 


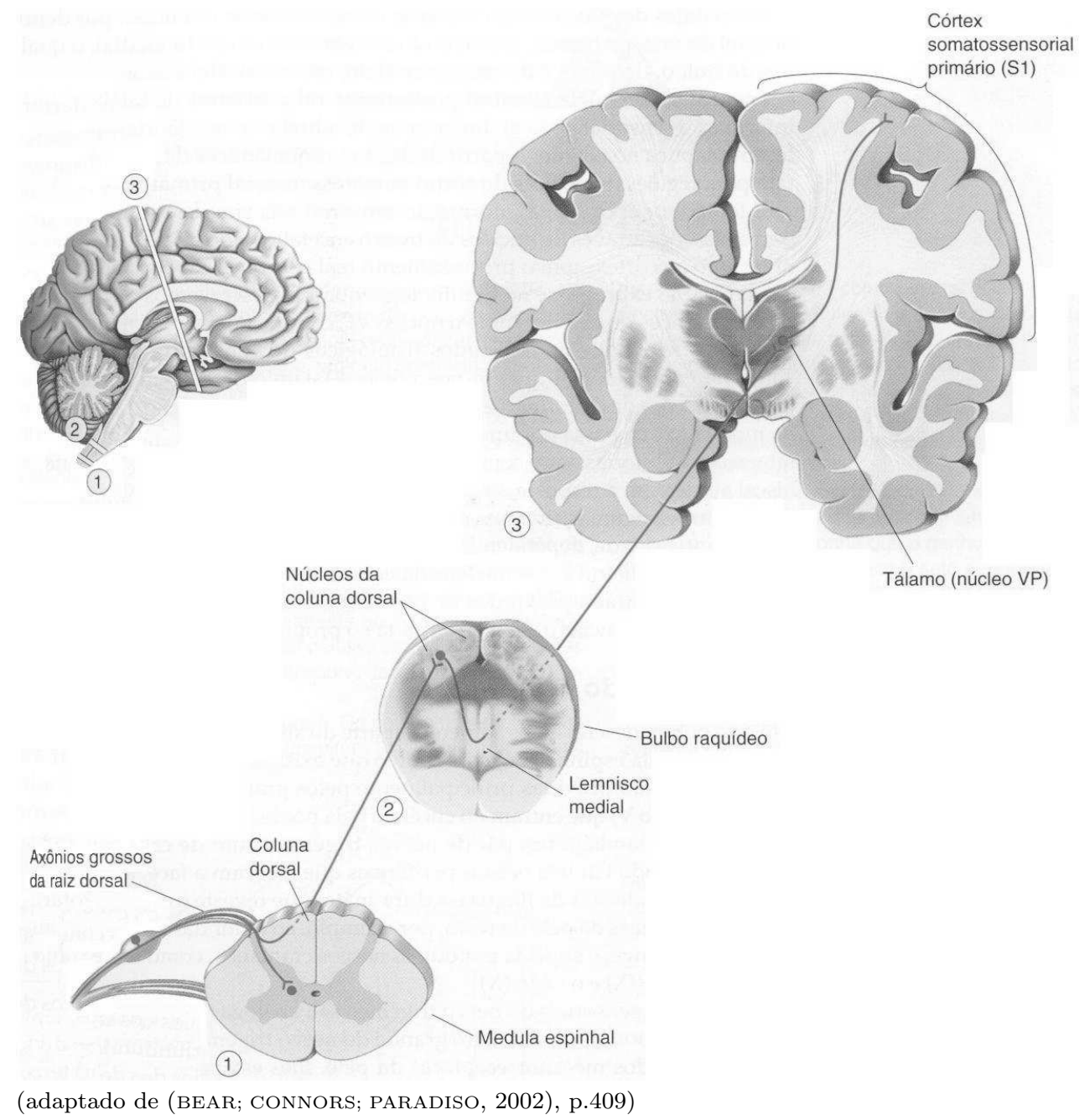

Figura 2.4: Sistema coluna dorsal-lemnisco medial. Essa via é utilizada principalmente para sensações de pressão, vibração e propriocepção.

nervo mediano seguem até o bulbo, onde passam para o lado contralateral e continuam até o núcleo ventral posterior do tálamo. Os sinais seguem, finalmente chegando ao córtex somato-sensitivo, que fica no lobo parietal.

Ao longo da via sensorial, são gerados potenciais pós-sinápticos nos neurônios das estruturas receptoras da informação. As conseqüentes correntes iônicas geradas na região da estrutura se propagam pelos tecidos do corpo e provocam mudanças no potencial de outras partes do organismo. Essas mudanças dão origem aos picos que compõem os potenciais evocados. Esses picos também podem ser causados por alterações na condutividade do meio que circunda a via sensorial ou por mudanças de direção da própria via (como, por exemplo, no plexo braquial). Além disso, os picos de menor amplitude e de freqüência 


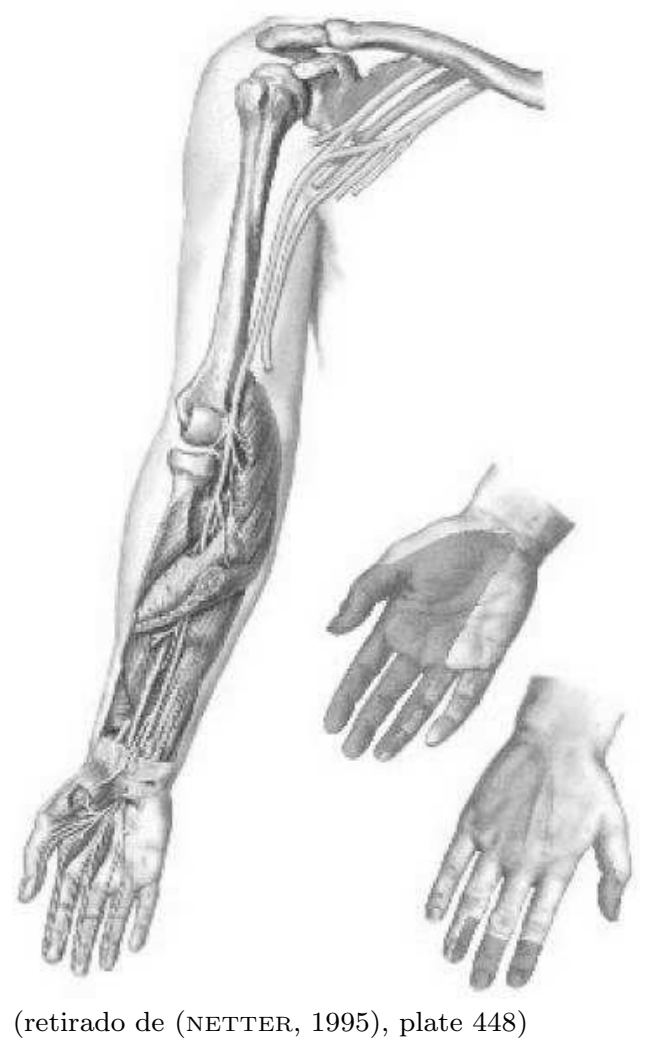

Figura 2.5: Localização do nervo mediano e as correspondentes regiões invervadas na mão.

de cerca de $600 \mathrm{~Hz}$ podem ser gerados pela atividade síncrona de neurônios do encéfalo (CURIO, 2000; VALENCIA et al., 2006).

A seguir, apresenta-se o potencial evocado e alguns aspectos do modo como ele é obtido. Espera-se que esta introdução auxilie na compreensão desse sinais, principalmente quanto à sua utilidade clínica.

\subsection{Considerações gerais}

Quando um indivíduo toca um objeto, essa informação é enviada para o encéfalo pelas vias somato-sensitivas. De forma semelhante, as informações sobre qualquer estímulo a um dos sentidos são transportadas até o encéfalo pelas respectivas vias sensoriais. A resposta do sistema nervoso à estimulação sensorial, que é denominado potencial evocado (PE), pode ser medida como um sinal, ao longo das vias sensoriais e sobre o escalpo. 
Em clínica, são utilizados PEs visuais, auditivos e somato-sensitivos que são respostas a estímulos visuais, auditivos e elétricos, respectivamente.

O sinal de potencial evocado captado no escalpo tem amplitude entre $0,1 \mu \mathrm{V}$ e $20 \mu \mathrm{V}$ (CHIAPPA, 1983). Sua análise é dificultada pela atividade de eletroencefalografia (EEG) de fundo e por outros sinais de origem biológica, que chegam a centenas de micro-volts de amplitude e nos quais o PE está imerso. Desse modo, o potencial evocado não é perceptível na resposta a um único estímulo. Para contornar esse problema, recorre-se à promediação ou média síncrona, que consiste no cálculo da média de várias respostas sincronizadas no instante de estimulação. A média síncrona faz com que a amplitude do sinal de EEG (não correlacionado ao estímulo) seja reduzida enquanto a resposta evocada pelo estímulo seja ressaltada (SPEHLMANN, 1985). Para PEs somato-sensitivos, a promediação é realizada com cerca de 1000 respostas individuais, sendo necessário validar a estimativa do PE com pelo menos mais uma média síncrona (DELISA; MACKENZIE; BARAN, 1987; SPEHLMANN, 1985). No restante do texto, a resposta a um único estímulo será denominada "resposta individual" e o resultado da promediação de 1000 ou mais respostas será denominado "potencial evocado padrão".

Os potenciais evocados são utilizados para testar a condução nas vias sensoriais (SPEHLMANN, 1985; AMINOFF, 1986). Eles podem auxiliar na localização de lesões e no diagnóstico de doenças (CHIAPPA, 1983; KRAFT et al., 1998; AMINOFF; EISEN, 1998). Além disso, podem ser utilizados para acompanhar a evolução e o tratamento de doenças (CHIAPPA, 1983). PEs somato-sensitivos são monitorados durante cirurgias que possam ocasionar lesões nas vias sensoriais (WALSH; KANE; BUTLER, 2005). Eles podem indicar alterações nos sistemas nervosos central e periférico, identificando distúrbios imperceptíveis a outros exames e lesões com sintomas inespecíficos (CHIAPPA, 1983; KRAFT et al., 1998; AMINOFF; EISEN, 1998).

O potencial evocado é caracterizado pelos picos que o compõem. Dependendo do posicionamento dos eletrodos de captação, eles podem refletir a mudança na direção da via, a alteração da resistência elétrica do tecido em torno da via ou a atividade dos 
neurônios nas estruturas em decorrência da passagem do sinal (CRACCO; BODIS-WOLLNER, 1986). A Figura 2.6 ilustra um sinal obtido a partir da estimulação do nervo mediano. Nessa figura, os picos são identificados por duas de suas características. A primeira é a polaridade, positiva $(\mathrm{P})$ ou negativa $(\mathrm{N})$, conforme sua deflexão. A outra característica é a sua latência típica, em mili-segundos, que é o tempo decorrido entre o estímulo e a ocorrência do pico. As figuras deste texto seguem a convenção utilizada pela maioria dos livros de potenciais evocados, com picos negativos para cima e picos positivos para baixo.

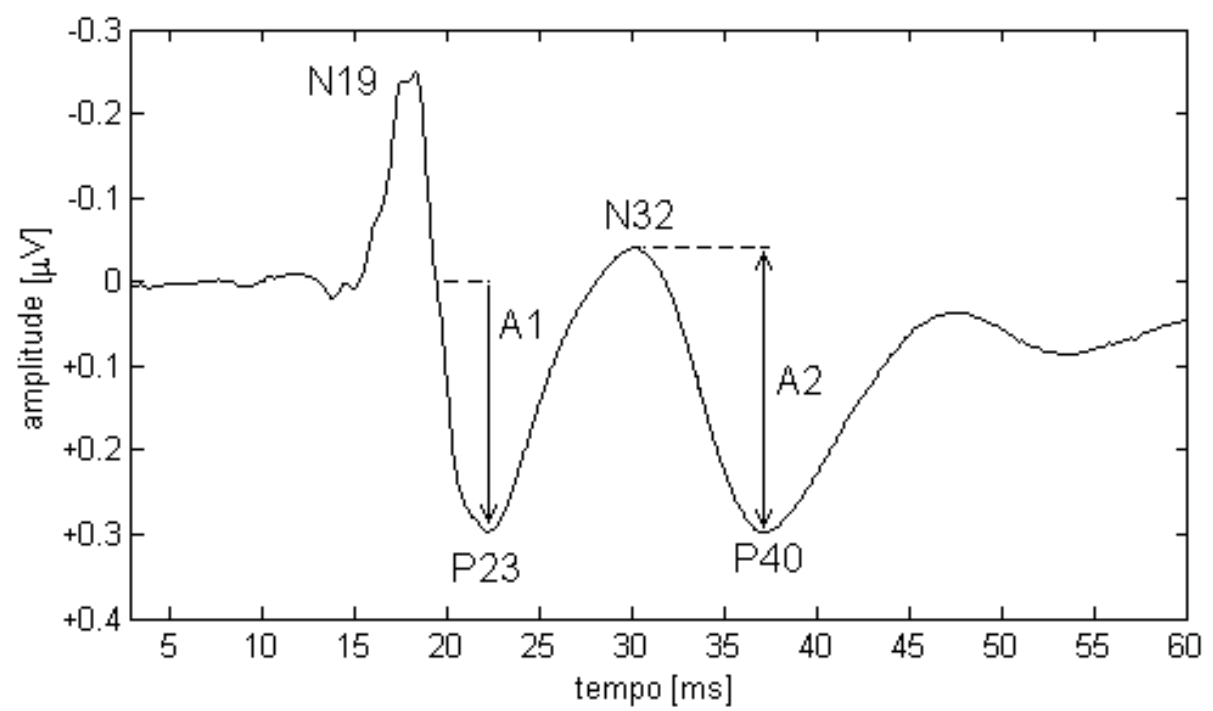

Figura 2.6: Potencial evocado somato-sensitivo cortical em resposta à estimulação do nervo mediano, média de 2000 respostas individuais. A1: amplitude a partir da linha de base; A2: amplitude pico-a-pico.

A análise do potencial evocado se baseia na presença dos picos relevantes, suas latências e amplitudes (SPEHLMANN, 1985). A amplitude de um pico pode ser medida a partir da linha de base ou em relação a um dos picos adjacentes (neste caso, a amplitude é denominada pico-a-pico) (CHIAPPA, 1983; SPEHLMANN, 1985). Na Figura 2.6, essas medidas estão representadas por A1 e A2, respectivamente. Os valores considerados normais de latência e amplitude são tabelados na literatura (CHIAPPA, 1983; DELISA; MACKENZIE; BARAN, 1987; CRACCO; BODIS-WOLLNER, 1986; REGAN, 1989), e servem de referência para a análise comparativa dos sinais captados. 


\subsection{PEs somato-sensitivos}

Os potenciais evocados somato-sensitivos são obtidos com a estimulação elétrica de nervos, principalmente dos membros superiores e inferiores (SPEHLMANN, 1985). Os PEs somatosensitivos são denominados de acordo com o nervo estimulado, por exemplo, PE de nervo mediano e PE de nervo ulnar (DELISA; MACKENZIE; BARAN, 1987). Além do nervo estimulado, também são importantes a duração e a amplitude dos estímulos, o local dos eletrodos de captação e a freqüência de amostragem, entre outros parâmetros utilizados nos exames. A seguir, são apresentados alguns aspectos sobre a estimulação, a captação, a aquisição e a análise de potenciais evocados somato-sensitivos. No texto, apresentam-se os parâmetros utilizados no exame de PE somato-sensitivo de nervo mediano captado no escalpo, que foi usado neste trabalho.

\subsubsection{Estimulação}

Os estímulos podem ser aplicados por eletrodos de superfície, de barra ou de anel (ver Figura 2.7) dependendo do nervo e da região a ser estimulada. Os eletrodos de estimulação são posicionados ao longo do nervo a ser excitado, com o catodo (pólo negativo) proximal e o anodo (pólo positivo) distal ${ }^{1}$ (SPEHLMANN, 1985; DELISA; MACKENZIE; BARAN, 1987; CRACCO; BODIS-WOLLNER, 1986). O local de colocação dos eletrodos deve ser preparado por meio de uma limpeza com álcool e de uma leve abrasão para melhorar o contato elétrico. Os eletrodos são então preenchidos com um gel condutor e fixados ao corpo com fitas adesivas, tomando-se o cuidado de não haver curto-circuito entre os eletrodos nem pelo contato direto, nem pelo gel. Além disso, pode-se posicionar um eletrodo de terra entre os eletrodos de estimulação e captação para reduzir artefatos de estímulo (SPEHLMANN, 1985; DELISA; MACKENZIE; BARAN, 1987).

Os estímulos aplicados são pulsos de corrente de pequena intensidade (de até $100 \mathrm{~mA}$ )

\footnotetext{
${ }^{1}$ Proximal e distal são termos utilizados em anatomia para comparar a posição de duas estruturas em relação a um ponto de referência. Nesse caso, a referência é a extremidade do nervo que se une com o sistema nervoso central (MOORE, 1992), denominado origem do nervo (DORLAND, 1999). Assim, o catodo é colocado mais perto da origem do nervo que o anodo.
} 


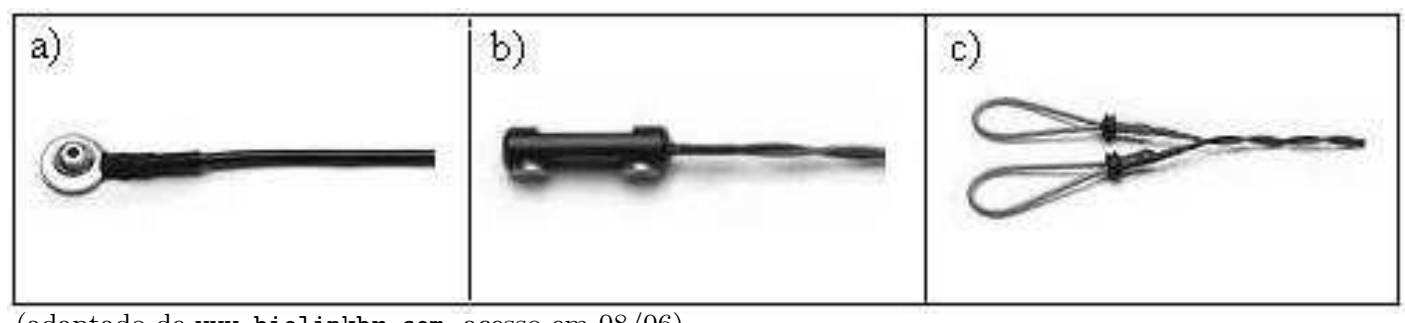

(adaptado de www.biolinkbr.com, acesso em 08/06)

Figura 2.7: Tipos de eletrodo de estimulação: a) eletrodo de superfície; b) eletrodo de barra; c) eletrodo de anel.

e de curta duração (de 200 $\mu$ s a 1ms) (SPEHLMANN, 1985; DELISA; MACKENZIE; BARAN, 1987). Pulsos de tensão também poderiam ser usados, mas nesse caso, o efeito da estimulação elétrica dependeria da impedância entre os eletrodos. Essa dependência representaria uma desvantagem pois a impedância poderia variar durante o exame (CHIAPPA, 1983; SPEHLMANN, 1985).

A intensidade da corrente escolhida para estimulação depende do tipo de nervo estimulado (sensorial, motor ou misto). No caso de nervos mistos, que são compostos por neurônios motores e sensitivos, ela é função do limiar motor, que é o valor mínimo de corrente que produz uma contração visível do(s) músculo(s) inervado(s). Para o nervo mediano, que é um nervo misto, o limiar é determinado aumentando-se gradativamente o valor da corrente aplicada pelos eletrodos no pulso, até que seja perceptível o movimento do dedo polegar, devido à contração do músculo abdutor curto do polegar. A estimulação pode ser repetida até dez vezes por segundo, mas freqüências altas podem ser incômodas para os pacientes (SPEHLMANN, 1985). A Figura 2.8 ilustra um exemplo de seqüência de estímulos. Em casos patológicos, há a possibilidade de esses padrões de estimulação não provocarem contrações visíveis, ou serem incômodos para o paciente. Nessas situações, pode-se aumentar a duração dos pulsos de corrente e diminuir a freqüência de estimulação (DELISA; MACKENZIE; BARAN, 1987). Quando nenhuma contração é gerada, deve-se utilizar uma corrente que provocaria os movimentos em sujeitos normais (SPEHLMANN, 1985). 


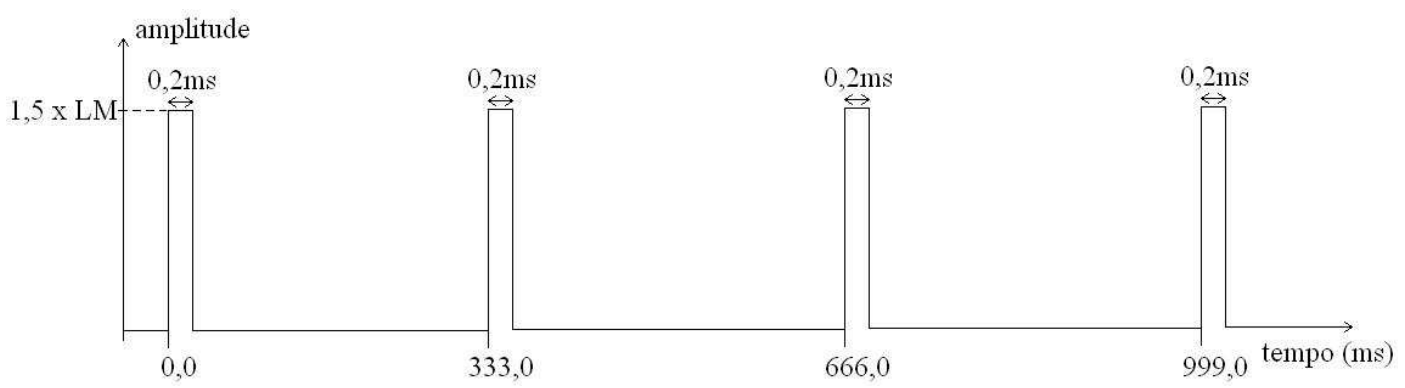

Figura 2.8: Exemplo de estimulação de nervo misto. O limiar motor foi de $6,4 \mathrm{~mA}$, portanto o estímulo aplicado tinha intensidade de $9,6 \mathrm{~mA}$.

\subsubsection{Captação}

A captação dos PEs é realizada ao longo da via estimulada (SPEHLMANN, 1985). O sinal analisado é a diferença entre os potenciais elétricos captados por dois eletrodos. Procura-se posicionar um deles o mais próximo possível das estruturas geradoras dos picos do potencial evocado (CHIAPPA, 1983; SPEHLMANN, 1985). No caso da estimulação do nervo mediano, os eletrodos podem ser posicionados na altura do cotovelo, do ombro, da vértebra CII e no escalpo (SPEHLMANN, 1985; DELISA; MACKENZIE; BARAN, 1987). O sistema internacional 10-20 de posicionamento de eletrodos, ilustrado na Figura 2.9, padroniza os locais de captação no escalpo. Nota-se que as distâncias não são fixas, mas sim relativas a medidas da cabeça do paciente.

Semelhantemente à colocação dos eletrodos de estimulação, a pele deve ser previamente limpa e esfoliada antes da colocação dos eletrodos de captação. Para captação no escalpo, podem ser usados eletrodos de disco empregados em eletroencefalografia. O eletrodo é preenchido por uma pasta eletrolítica, que além de facilitar a condução também fixa o eletrodo no escalpo. A captação é contralateral ao membro estimulado, isto é, se um nervo da mão esquerda é estimulado, o PE é captado no lado direito do escalpo, e vice-versa. Prefere-se estimular um membro de cada vez, pois a atividade simultânea pode obscurecer anomalias unilaterais (SPEHLMANN, 1985). Antes de aplicar os estímulos, deve-se verificar a impedância dos eletrodos de captação, que deve ficar abaixo de $10 \mathrm{k} \Omega$, para reduzir artefatos de estímulo (SPEHLMANN, 1985). 

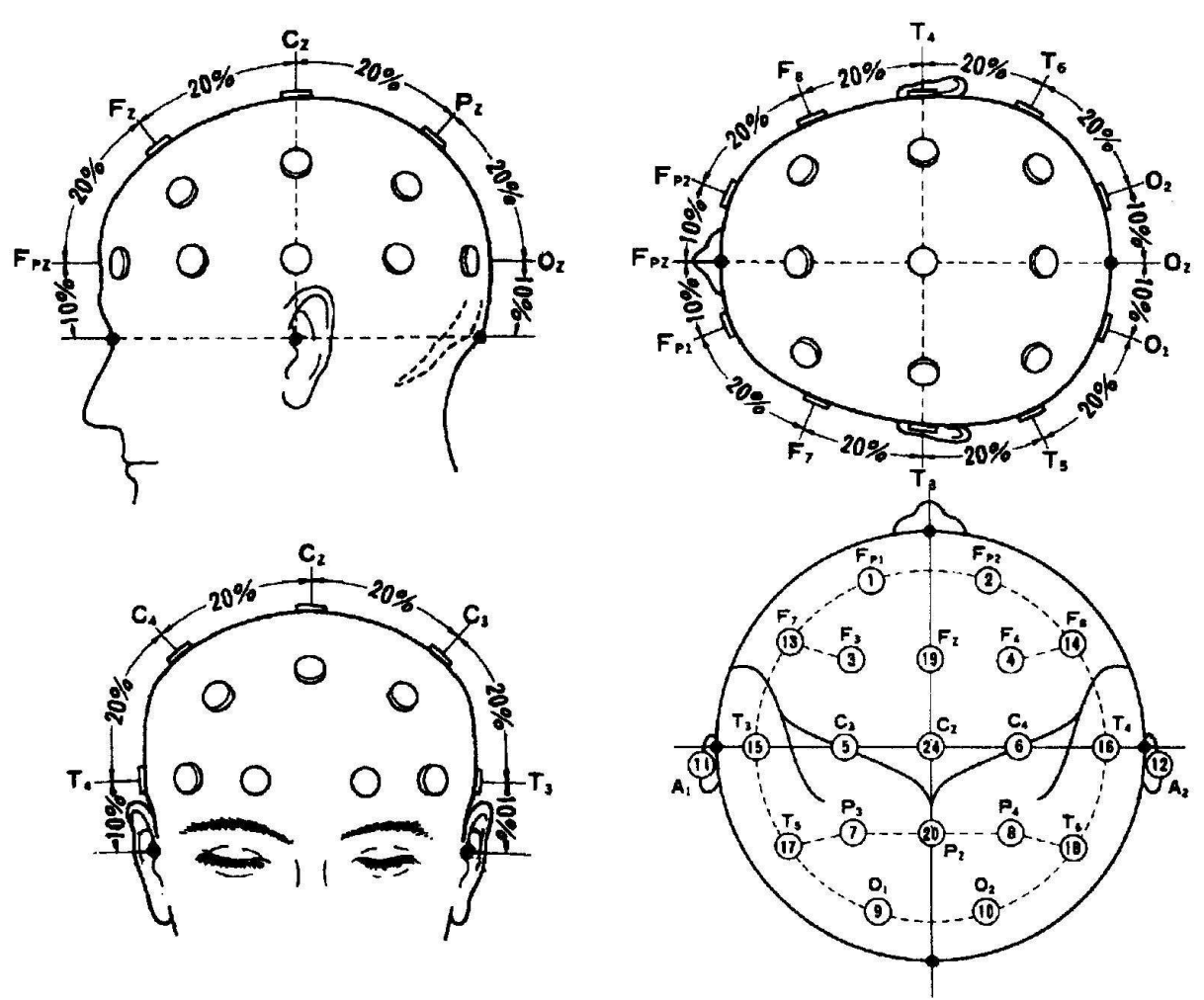

(adaptado de (NIHON KOHDEN, 1996b), pp.1.5-1.6.)

Figura 2.9: Sistema internacional 10-20 de posicionamento de eletrodos.

\subsubsection{Aquisição}

Uma forma de eliminar alguns dos sinais que dificultam a obtenção do PE é utilizando filtros analógicos. Com eles, é possível retirar componentes de freqüência fora da banda do potencial evocado, como ruídos de alta freqüência. Além disso, a filtragem também é importante para limitar as freqüências altas presentes no sinal, evitando erros quando o sinal captado é amostrado (filtro anti-aliasing) (SPEHLMANN, 1985). O erro seria causado pelo rebatimento das freqüências maiores que o dobro da freqüência de amostragem. Esse rebatimento gera componentes nas freqüências baixas. Os filtros utilizados para PEs somato-sensitivos têm freqüência de corte inferior da ordem de alguns hertz e freqüência de corte superior da ordem de quilo-hertz, variando de acordo com os locais de captação e o tipo de PE (SPEHLMANN, 1985; DELISA; MACKENZIE; BARAN, 1987). As transições entre as faixas de passagem e de rejeição não devem exceder 12dB/oitava no caso das freqüências baixas, e 24dB/oitava nas freqüências altas, para limitar a distorção em fase (SPEHLMANN, 1985). 
A conversão analógico-digital do sinal deve ser realizada a uma freqüência de amostragem maior que o dobro da freqüência máxima presente no sinal (teorema da amostragem). Essa taxa de amostragem é suficiente para prevenir erros na análise em freqüência devidos ao recobrimento do espectro (que é conseqüência da conversão do sinal). No entanto, a reconstrução no tempo, obtida a partir da interpolação linear (interligação de amostras consecutivas por segmentos de reta), não é muito boa visualmente. Por isso, na prática, usa-se uma freqüência de amostragem aproximadamente dez vezes maior que a freqüência máxima do sinal, o que permite uma melhor visualização dos picos dos PEs.

A amostragem está relacionada com o número de pontos utilizados para representar o potencial evocado. O número de amostras é limitado pela memória do equipamento de aquisição. Em clínica, geralmente as respostas individuais são promediadas e somente o potencial evocado é armazenado. Mas nesta dissertação, as amostras de cada resposta individual foram armazenadas.

\subsubsection{Análise}

A Tabela 2.1 apresenta os valores padrão para o PE da Figura 2.6. São considerados normais os valores que se afastam de até três desvios-padrão do valor médio (CHIAPPA, 1983; CRACCO; BODIS-WOLLNER, 1986).

Tabela 2.1: Latências e amplitudes dos picos de PE contralateral de nervo mediano, após estimulação unilateral (adaptado de (CRACCO; BODIS-WOLLNER, 1986) e (DELISA; MACKENZIE; BARAN, 1987)).

\begin{tabular}{|c|cc|cc|}
\hline Pico & $\begin{array}{c}\text { Latência } \\
\text { Média } \\
(\mathrm{ms})\end{array}$ & $\begin{array}{c}\text { Desvio-padrão } \\
(\mathrm{ms})\end{array}$ & $\begin{array}{c}\text { Amplitude } \\
\text { Média } \\
(\mu \mathrm{V})\end{array}$ & $\begin{array}{c}\text { Desvio-padrão } \\
(\mu \mathrm{V})\end{array}$ \\
\hline N19 & 19,1 & 1,4 & 0,6 & 0,2 \\
P23 & 23,4 & 1,7 & 2,1 & 0,9 \\
N32 & 31,6 & 1,8 & & \\
P40 & 43,9 & 3,1 & & \\
\hline
\end{tabular}

A amplitude do pico N19 é a partir da linha de base, e a amplitude do pico P23 é em relação ao pico N19.

Vários fatores podem afetar as latências e amplitudes dos picos do PE, incluindo a 
temperatura do membro estimulado, o sexo, a idade e a altura do sujeito (SPEHLMANN, 1985). Por isso, é preciso cautela na realização do exame e na interpretação dos resultados. 


\section{Metodologia}

Neste capítulo, são apresentados os materiais e métodos empregados neste trabalho. Inicialmente, é apresentada a metodologia de obtenção de dados experimentais. Em seguida, descreve-se o método de filtros seletivos no tempo. Logo após, é feita uma breve introdução às ondaletas. Finalmente, são mostradas as formas de análise dos resultados.

\subsection{Obtenção de sinais}

Os experimentos foram realizados no Laboratório de Engenharia Biomédica da Escola Politécnica da USP. Foi utilizado o sistema de medição de potenciais evocados Neuropack ${ }^{\circledR}$, modelo 8 MEB-4200K da Nihon Kohden ${ }^{\circledR}$ (Tóquio, Japão). Devido a um problema na placa de conversão analógico-digital desse sistema, ele foi usado em conjunto com o sistema de aquisição de dados Datawave ${ }^{\circledR}$, que funciona com um computador. A Figura 3.1 ilustra um esquema da montagem utilizada.

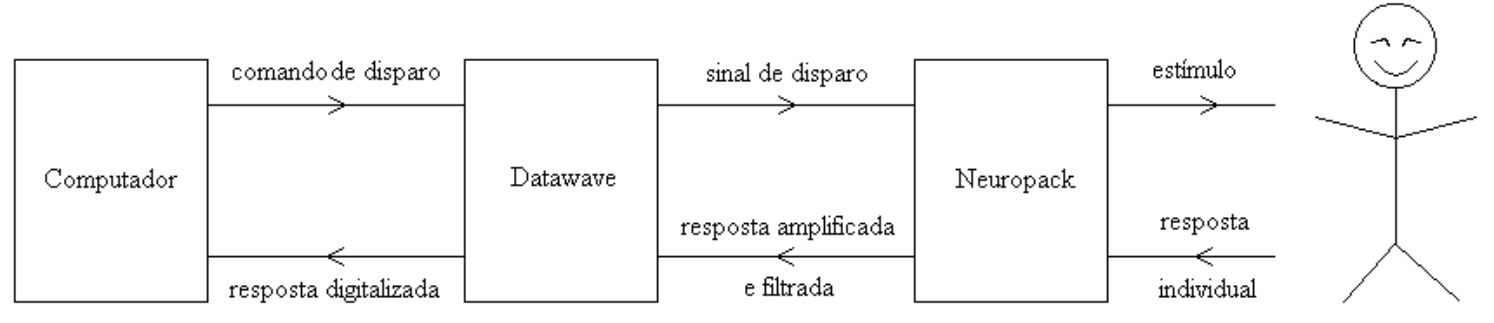

Figura 3.1: Esquema da montagem utilizada nos experimentos.

Para obter cada resposta individual, inicialmente o computador envia um comando para o Datawave ${ }^{\circledR}$, que, por sua vez, envia um sinal de disparo (trigger) para o Neuropack ${ }^{\circledR}$. O sinal de disparo é convertido em estímulo e aplicado ao sujeito. A resposta individual 
analógica é amplificada e filtrada pelo Neuropack ${ }^{\circledR}$, e é enviada para o Datawave ${ }^{\circledR}$, onde é digitalizada usando 12 bits. Finalmente, o sinal digital é salvo no computador em formato binário (.dat) e convertido ao formato texto (.txt), compatível com o Matlab ${ }^{\circledR}$.

A seguir, são apresentados maiores detalhes dos experimentos.

\subsubsection{Estimulação}

Os sinais utilizados neste trabalho foram obtidos pela estimulação por pulsos de corrente elétrica de $200 \mu$ s de duração e de intensidade equivalente a uma vez e meia o limiar motor (DELISA; MACKENZIE; BARAN, 1987). Os estímulos foram aplicados ao nervo mediano na altura do punho esquerdo. O intervalo entre estímulos era de 300ms. A Figura 3.2 ilustra a posição do nervo mediano no punho. Vê-se que ele se encontra entre os tendões dos músculos palmar longo e flexor radial do carpo, usados como referência na localização do nervo. A Figura 3.3 mostra esses tendões no membro de um sujeito. Os eletrodos de estimulação foram posicionados entre eles, ao longo do nervo, com o anodo sobre a dobra proximal do punho (DELISA; MACKENZIE; BARAN, 1987). O eletrodo apresentava separação de $2 \mathrm{~cm}$ borda-a-borda (3cm centro-a-centro) entre o anodo e o catodo.

\subsubsection{Captação}

A captação foi realizada por dois eletrodos de disco, no escalpo do lado contralateral (direito). Eles foram posicionados sobre os pontos $C_{4}^{\prime}$ e $F_{p z}^{\prime}$, que ficam $2 \mathrm{~cm}$ atrás, respectivamente, dos pontos $C_{4}$ e $F_{z}$ do sistema internacional 10-20 de posicionamento de eletrodos. A localização desses pontos pode ser vista na Figura 3.4. O eletrodo de terra foi posicionado a $20 \mathrm{~cm}$ proximais do catodo. A impedância dos eletrodos de captação ficou abaixo de $10 \mathrm{k} \Omega$. Aplicaram-se dois filtros analógicos aos sinais: um passa-altas de ordem 1 e freqüência de corte de $5 \mathrm{~Hz}$ e um passa-baixas de ordem 2 e freqüência de corte de 2kHz (DELISA; MACKENZIE; BARAN, 1987; NIHON KOHDEN, 1996a). 


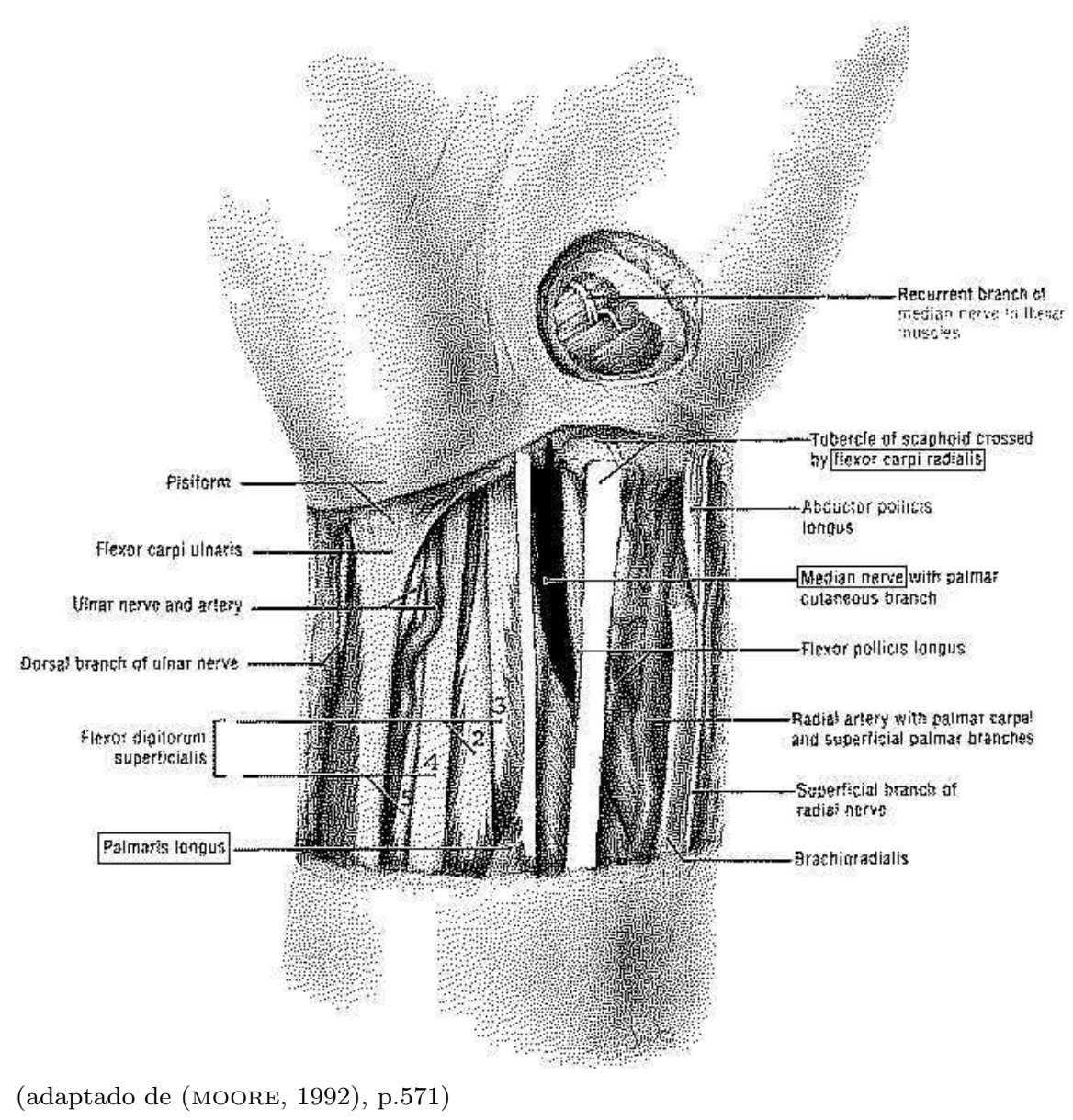

Figura 3.2: Estrutras do punho, mão direita. O nervo mediano está em preto e os tendões dos músculos palmar longo e flexor radial do carpo estão em branco.

\subsubsection{Aquisição}

Os sinais obtidos durante este mestrado são provenientes de três sujeitos do sexo feminino, com idade de $31,17 \pm 16,61$ anos (373,3 \pm 199, 6 meses) e 6 sujeitos do sexo masculino, de 23, $20 \pm 2,14$ anos $(278,2 \pm 25,9$ meses $)$ de idade, totalizando 9 sujeitos com 25, $86 \pm$ 9,37 anos (309, $9 \pm 112,4$ meses). Antes da realização dos experimentos, os voluntários assinaram um termo de consentimento, no qual permitiram o uso dos sinais captados. O exame foi dividido em blocos de 256 estímulos e cada conjunto de 256 respostas individuais foi salvo em um arquivo. Foram salvos pelo menos 8 blocos de 256 respostas individuais de cada sujeito. Cada resposta individual foi adquirida a $20 \mathrm{kHz}$.

\subsubsection{Análise}

Neste trabalho, foram utilizados os trechos de $3 \mathrm{~ms}$ a $60 \mathrm{~ms}$ dos sinais digitalizados. Antes de aplicar a metodologia, foi realizado um pré-processamento dos sinais. Inicialmente, os 


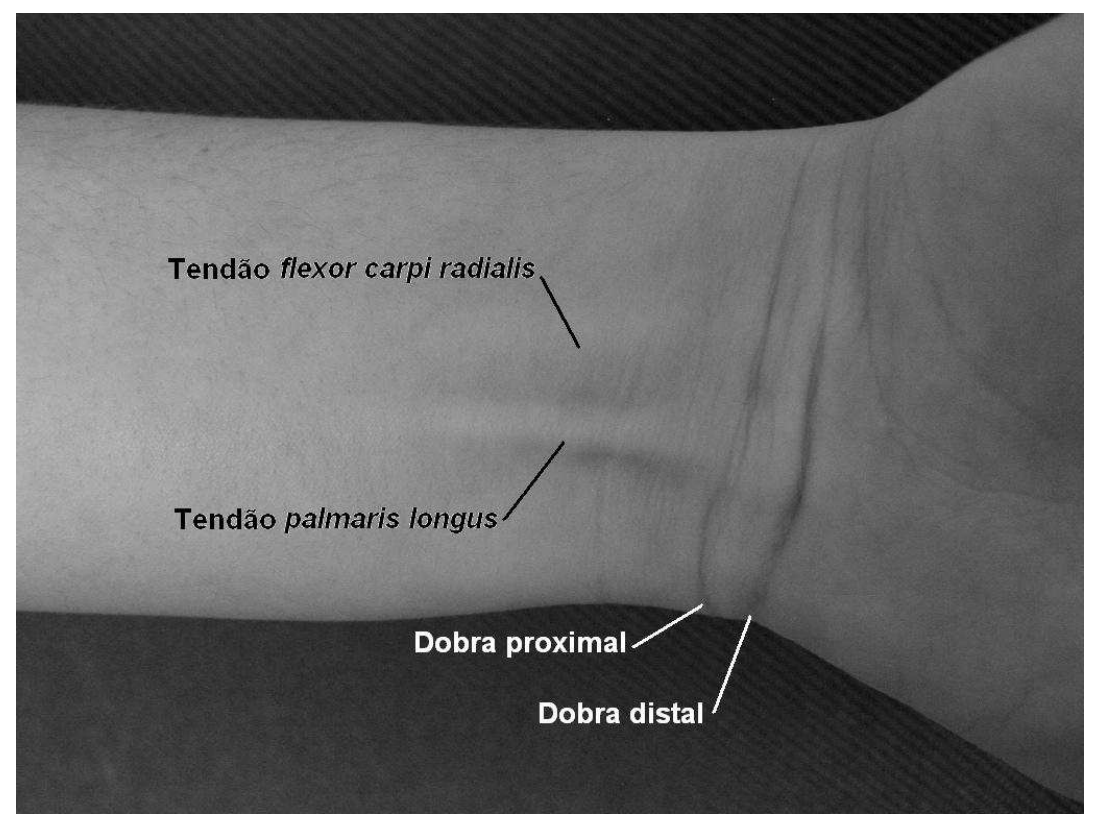

Figura 3.3: Marcas e estruturas, no membro esquerdo, utilizados no posicionamento do eletrodo de estimulação.

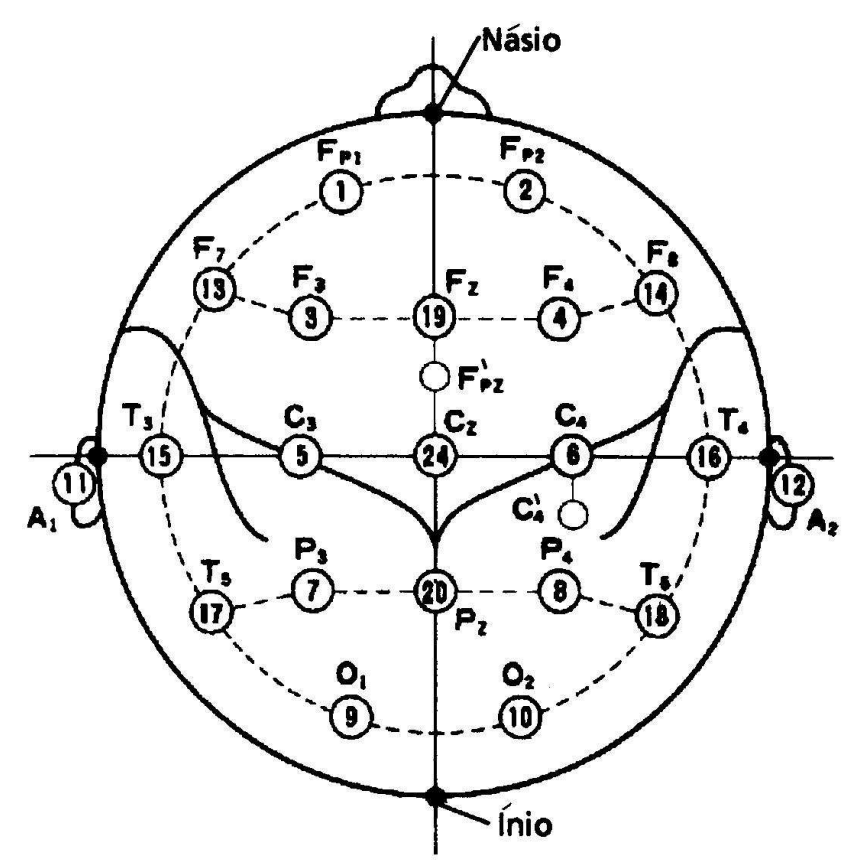

(adaptado de (NIHON KOHDEN, 1996b), p.1.5.)

Figura 3.4: Sistema internacional 10-20 de posicionamento de eletrodos. Os pontos $C_{4}^{\prime}$ e $F_{p z}^{\prime}$ ficam $2 \mathrm{~cm}$ atrás, respectivamente, dos pontos $C_{4}$ e $F_{z}$.

sinais que apresentavam saturações foram retirados. Em seguida, foram escolhidas 2000 respostas individuais consecutivas. Para padronizar o processamento desses sinais com o banco de dados do laboratório, essas respostas foram filtradas por um filtro digital passaaltas de Butterworth de ordem 1 e freqüência de corte de $5 \mathrm{~Hz}$, utilizando a função filtfilt 
do Matlab ${ }^{\circledR}$, o que corresponderia a um filtro de ordem 2. Essa filtragem garantiu que o atraso fosse igual a zero e as medidas de latência não fossem alteradas. Depois, a média do trecho até $14 \mathrm{~ms}$ foi retirada de cada resposta individual, para que as linhas de base dos potenciais evocados ficassem em torno de zero. Finalmente, os sinais foram multiplicados pelo ganho do canal utilizado na captação, e salvos em formato .mat.

Das 2000 respostas individuais de cada sujeito, as 1000 primeiras foram utilizadas para obter o potencial evocado padrão. As 1000 respostas restantes foram divididas em conjuntos de 100. Para cada conjunto de respostas, foram calculadas estimativas dos potenciais evocados pela média síncrona das 100 respostas, pelo método de filtros seletivos no tempo e pela DWT. A metodologia da obtenção das estimativas é explicada a seguir.

\subsection{Método de filtros seletivos no tempo}

Filtros digitais constituem-se de equações matemáticas que transformam o sinal de entrada em um sinal de saída. Em geral, os filtros atenuam uma faixa de freqüências ao mesmo tempo em que ressaltam outra. Dependendo da transformação entrada-saída, ou seja, das faixas atenuadas e ressaltadas, os filtros são usualmente classificados em passa-baixas, passa-altas, passa-faixa e rejeita-faixa. A Figura 3.5 ilustra os ganhos de filtros ideais e o efeito desses filtros nos sinais.

No caso de filtros recursivos, a saída é função de amostras da entrada e da própria saída:

$$
y(n)=-a_{1} y(n-1)-a_{2} y(n-2)-\ldots-a_{p} y(n-p)+b_{0} x(n)+b_{1} x(n-1)+\ldots+b_{q} x(n-q),
$$

em que $x(n)$ é o sinal de entrada e $y(n)$, o sinal de saída do filtro. A função de transferência correspondente a esse filtro é dada pela expressão

$$
H(z)=\frac{b_{0}+b_{1} z^{-1}+b_{2} z^{-2}+\ldots+b_{q} z^{-q}}{1+a_{1} z^{-1}+a_{2} z^{-2}+\ldots+a_{p} z^{-p}}
$$

em que $z$ representa uma variável complexa associada à transformada $z$. A ordem $n$ do 

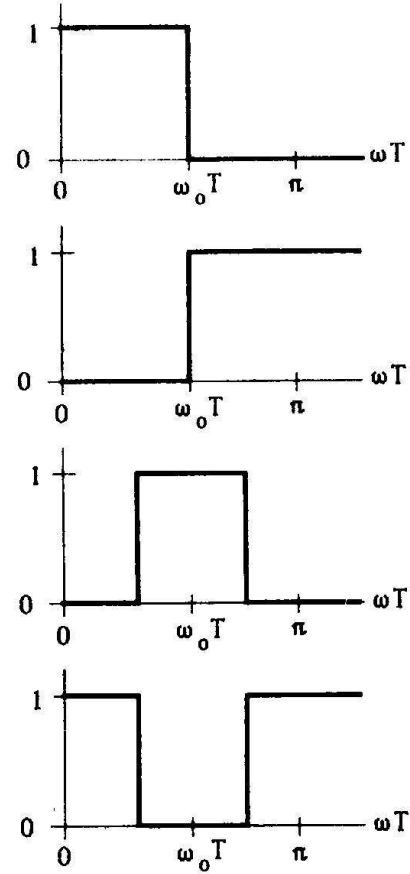

(adaptado de (LINDQUIST, 1989), p.435.)

(a)

(b)

(c)
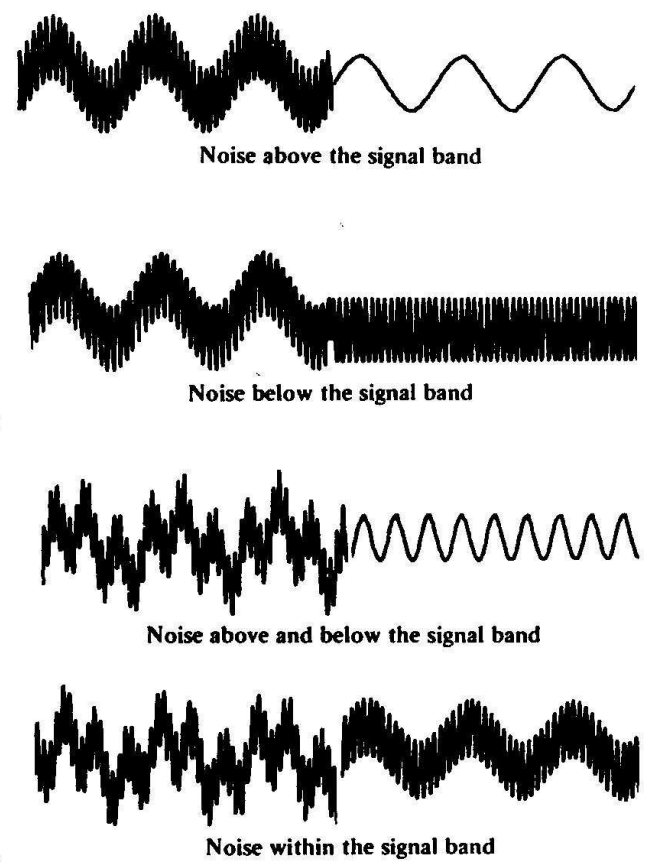

Figura 3.5: Exemplos de entrada e saída (coluna da direita) e ganho (coluna da esquerda) de filtros ideais a) passa-baixas, b) passa-altas, c) passa-faixa e d) rejeita-faixa.

filtro é definido como o maior valor dentre $p$ e $q$ (LINDQUIST, 1989).

Há várias aproximações de filtros recursivos, como por exemplo, de Butterworth, Chebyshev, Chebyshev invertido e elíptico. As suas respostas em freqüência se diferenciam pela transição entre as faixas de passagem e de rejeição e pela ondulação (ripple) do ganho nessas faixas. Para filtros passa-altas ou passa-baixas de ordem $n$, a aproximação de Butterworth apresenta taxa de atenuação de $20 n \mathrm{~dB}$ por década entre as bandas de passagem e de rejeição. Para filtros passa-faixa e rejeita-faixa de ordem $n$, a taxa de atenuação é de $10 n \mathrm{~dB}$ por década. Comparada às demais aproximações, a de Butterworth é a que apresenta menor taxa de atenuação. No entanto, os patamares nas bandas de passagem e de rejeição são mais planos (flat). Por isso, essa aproximação foi utilizada por Nishida, Nakamura e Shibasaki (1993), e também neste trabalho. Além disso, Nishida, Nakamura e Shibasaki (1993) adotaram filtros de ordem 4 para todos os filtros. A forma como os filtros foram utilizados é exposta a seguir. 


\subsubsection{Método de Nishida, Nakamura e Shibasaki (1993)}

A técnica proposta por Nishida, Nakamura e Shibasaki (1993) consiste em filtrar a resposta individual por meio de filtros digitais (OPPENHEIM; SCHAFER, 1989; LIM; OPPENHEIM, 1988) e eliminar a onda alfa (ou beta) correspondente ao EEG de fundo. Para essa eliminação, Nishida, Nakamura e Shibasaki (1993) modelaram o EEG, que foi retirado da saída de um dos filtros. Um esquema desse método para a determinação das estimativas individuais está na Figura 3.6.

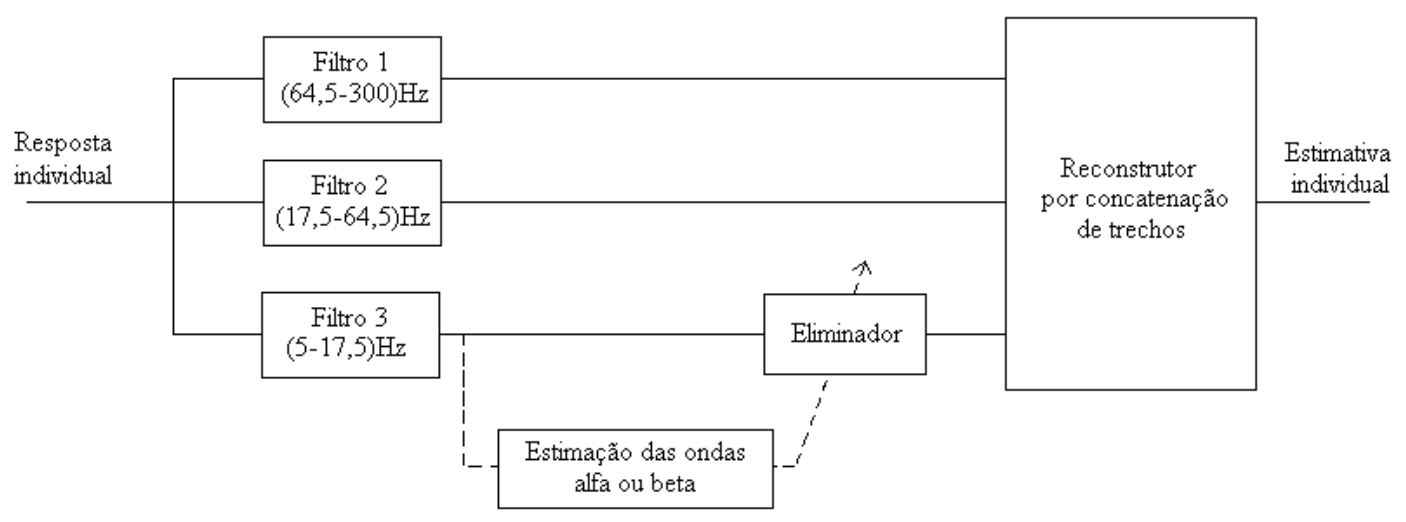

Figura 3.6: Método de reconstrução a partir de respostas individuais.

A reconstrução da estimativa individual é feita pela concatenação de trechos específicos das saídas dos filtros e do eliminador. A Figura 3.7 mostra um exemplo de entrada e saídas dos filtros. As curvas da Figura 3.7.b são resultantes do processamento do sinal da Figura 3.7.a. O componente de freqüências altas é a saída do filtro 1, o de freqüências médias é a saída do filtro 2 e o de freqüências baixas é a saída do filtro 3. Da saída do filtro 3 são eliminadas as estimativas das ondas alfa e beta do EEG de fundo, modeladas por uma senóide com amplitude descrita por um processo de Markov (NISHIDA; NAKAMURA; SHIBASAKI, 1993). Devido às características do potencial evocado, as freqüências mais altas estão relacionadas com os trechos iniciais, e as freqüências mais baixas correspondem aos trechos finais. A saída do filtro 1 é utilizada até 35ms, a saída do filtro 2 é usada de $25 \mathrm{~ms}$ a $90 \mathrm{~ms}$ e o sinal resultante do eliminador é utilizado a partir de 80ms. Os trechos de transição entre $25 \mathrm{~ms}$ e $35 \mathrm{~ms}$ (e entre $80 \mathrm{~ms}$ e $90 \mathrm{~ms}$ ) são ponderações dos dois sinais que se sobrepõem no tempo. 
a)
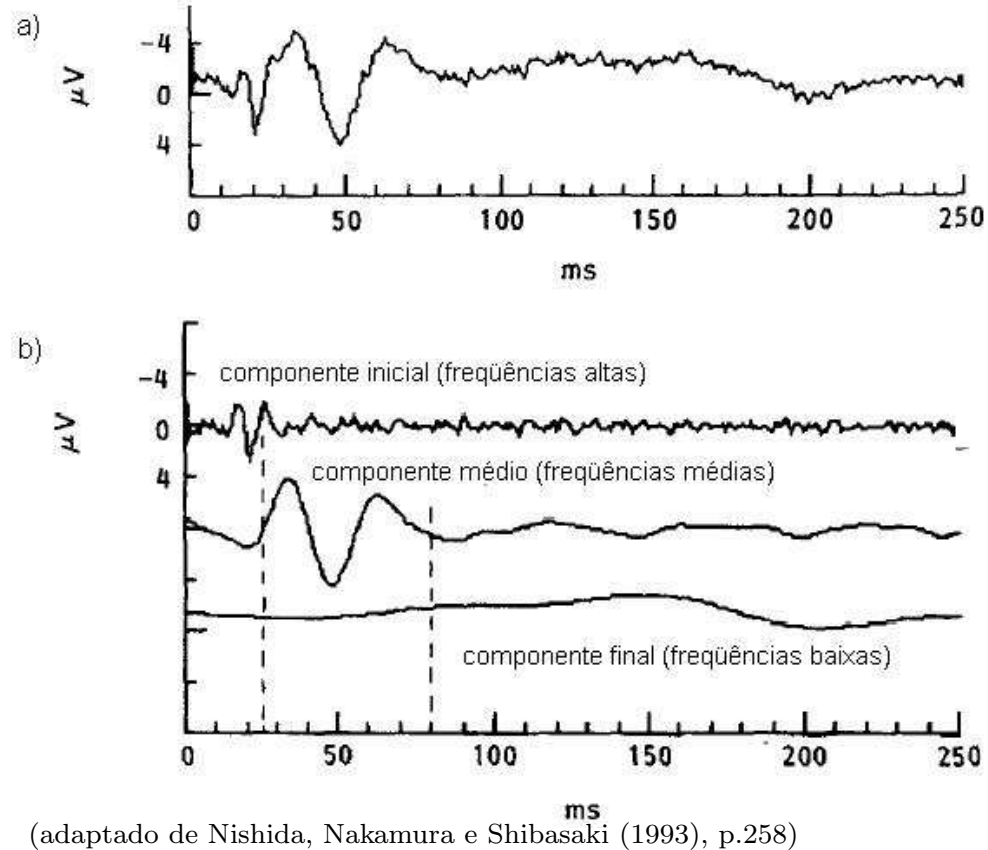

Figura 3.7: Exemplo de aplicação dos filtros de Nishida, Nakamura e Shibasaki (1993): a) sinal original e b) saídas dos filtros 1 (componente inicial), 2 (componente médio) e 3 (componente final).

Nota-se que, no trabalho de Nishida, Nakamura e Shibasaki (1993), a saída do eliminador só é utilizada a partir de $80 \mathrm{~ms}$. Essa faixa está fora do intervalo de interesse desta dissertação (até 60ms). Portanto, não foi necessário implementar o eliminador de EEG nem usar o filtro 3. Para implementar os outros filtros, foram utilizadas aproximações de Butterworth de ordem 4, como no trabalho de Nishida, Nakamura e Shibasaki (1993). A Figura 3.8 ilustra as respostas em freqüência dos filtros 1 (linha escura) e 2 (linha clara).

Na Figura 3.8.a, vê-se que as duas curvas se cruzam em $64,5 \mathrm{~Hz}$, que é uma das freqüências de corte ${ }^{1}$ dos filtros 1 e 2 . Além disso, como esperado, o ganho nessa freqüência é de -3dB. Ainda nessa figura, vê-se que a fase dos filtros é diferente de zero. Na Figura 3.8.b, nota-se que a taxa de atenuação de ambos os filtros é de -40dB por década. Isso corresponde a um filtro de ordem 2 para cada lado, totalizando ordem 4 para cada um dos filtros, como esperado.

\footnotetext{
${ }^{1}$ Freqüência de corte é a freqüência, entre as bandas de passagem e de rejeição, na qual a potência é reduzida pela metade. Isso equivale a um ganho de $-3 \mathrm{~dB}$.
} 

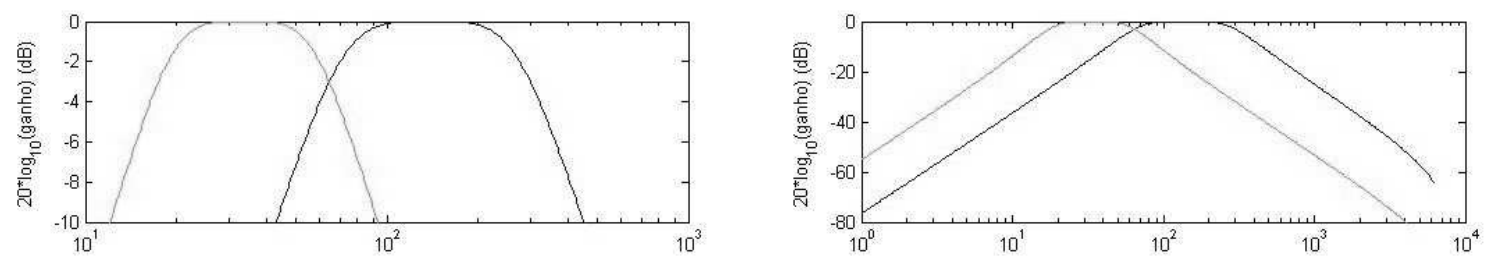

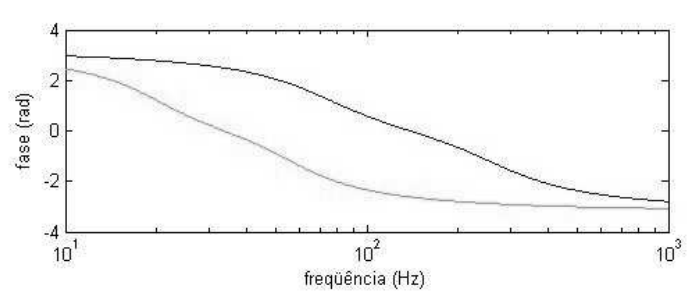

(a)

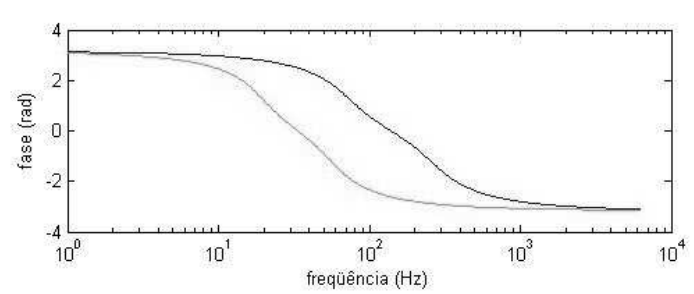

(b)

Figura 3.8: Resposta em freqüência dos filtros 1 (linha escura) e 2 (linha clara) a) até centenas de hertz e b) até milhares de hertz.

\subsubsection{Método alternativo 1}

Na Figura 3.8, vê-se que as fases dos filtros utilizados por Nishida, Nakamura e Shibasaki (1993) não são iguais a zero. No processamento de potenciais evocados, essa mudança de fase dos componentes é bastante prejudicial, pois afeta a latência dos picos, que é um dos parâmetros da análise em clínica. Dessa forma, seria interessante não inserir distorções de fase no sinal.

Por isso, a filtragem foi aplicada pela função filtfltt do Matlab ${ }^{\circledR}$, que garante atraso nulo e que dobra a ordem do filtro projetado. A implementação dos filtros foi baseada naqueles utilizados por Nishida, Nakamura e Shibasaki (1993), que empregaram filtros de Butterworth de ordem 4. Neste trabalho, foram projetados filtros passa-faixa de Butterworth de ordem 2. Os coeficientes dos filtros projetados foram aplicados pela função filtfilt, o que corresponderia a filtros de ordem 4. O ganho resultante é o quadrado do valor do ganho do filtro original.

A Figura 3.9 apresenta as respostas em freqüência dos filtros. Na Figura 3.9.a, nota-se que as duas curvas de ganho se cruzam em $64,5 \mathrm{~Hz}$, que é uma das freqüências de corte dos filtros 1 e 2 de Nishida, Nakamura e Shibasaki (1993), conforme o esquema da Figura 3.6. Também pode-se ver que o ganho nas freqüências de corte é de -6dB, o que corresponde 
ao quadrado do ganho esperado, de -3dB, devido ao uso da função filtfilt, como descrito anteriormente. Além disso, vê-se que as curvas de fase estão sobrepostas e são iguais a zero, o que confirma que a filtragem é realizada sem introdução de atrasos. Na Figura 3.9.b, observa-se que a taxa de atenuação das curvas de ganho é de 40dB/década, o que equivale a um filtro de ordem 2 , de cada lado, resultando em um filtro de ordem 4.
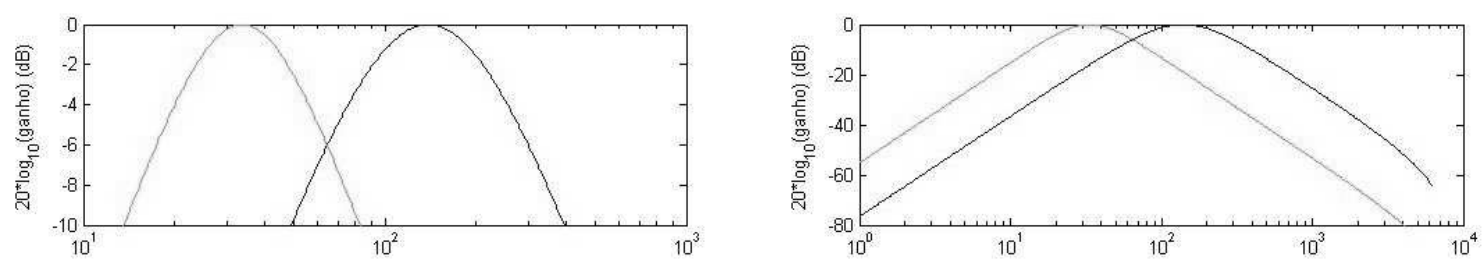

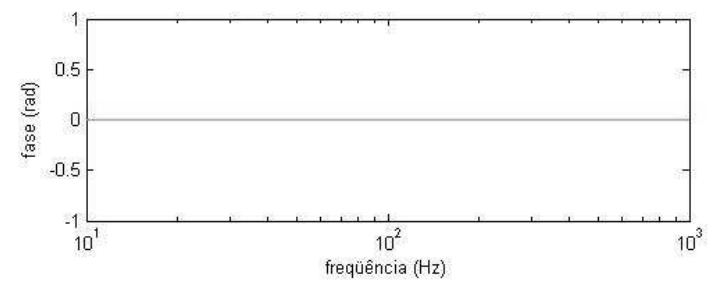

(a)

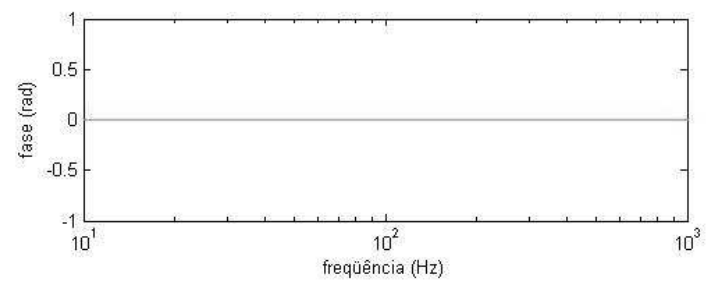

(b)

Figura 3.9: Resposta em freqüência dos filtros 1 (linha escura) e 2 (linha clara) a) até centenas de hertz e b) até milhares de hertz.

A Figura 3.10 ilustra os resultados obtidos para uma resposta individual. Os trechos escuros foram os utilizados na reconstrução do sinal.

\subsubsection{Método alternativo 2}

Neste método alternativo, os filtros passa-faixa foram trocados por passa-baixas, e as freqüências de corte também foram mudadas. Lembrando que os componentes de freqüências mais altas estão no trechos iniciais do $\mathrm{PE}$ e os de freqüência mais baixas estão nos trechos finais, uma possibilidade está ilustrada na Figura 3.11.

Os filtros foram implementados usando a função filtfilt do Matlab ${ }^{\circledR}$. Além disso, para obter a mesma taxa de atenuação, foram usados filtros passa-baixas de Butterworth de ordem 1. A Figura 3.12 mostra a resposta em freqüência dos novos filtros.

Vê-se, na Figura 3.12.a, que o ganho nas freqüências de corte é de -6dB/década, devido ao emprego da função filtfilt. Ainda nessa figura, nota-se que a fase do filtro é 

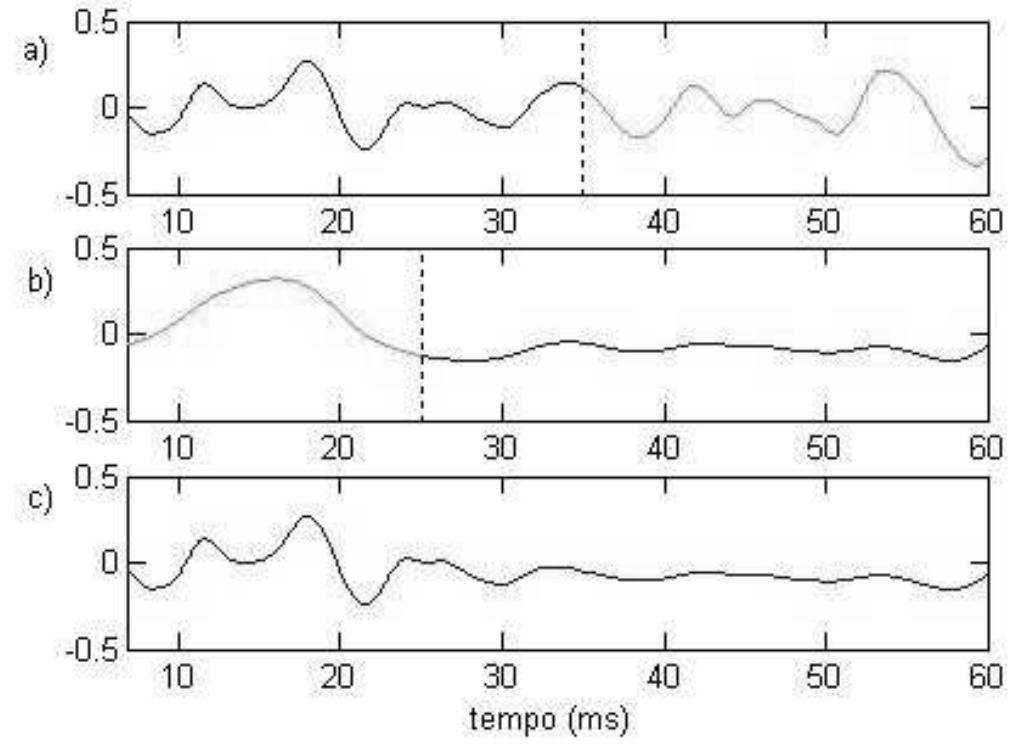

Figura 3.10: Sinais obtidos aplicando os filtros passa-faixas com a função filtfilt ao sinal 13 do sujeito 3: a) saída do filtro 1 ; b) saída do filtro 2; c) estimativa individual.

As linhas verticais indicam os intervalos em que os trechos foram utilizados na reconstrução do sinal. A amplitude está em micro-volts.

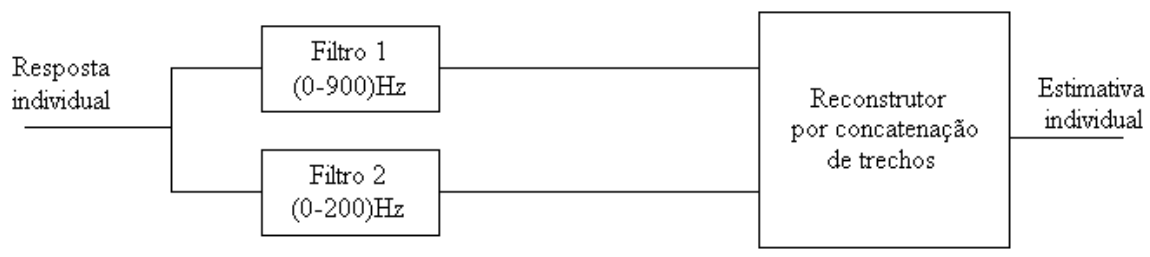

Figura 3.11: Método alternativo de reconstrução a partir de respostas individuais.

zero, como esperado. Na Figura 3.12.b, observa-se que a taxa de atenuação é a mesma dos filtros do método de Nishida, Nakamura e Shibasaki (1993), ou seja, 40dB/década, como desejado.

\subsection{Ondaletas}

A associação realizada por Nishida, Nakamura e Shibasaki (1993) entre trechos da resposta individual e determinadas bandas de freqüência é semelhante à análise de tempofreqüência. Nesse tipo de análise, o sinal a ser estudado ${ }^{2}$ é dividido em vários trechos temporais, que são obtidos a partir da multiplicação do sinal original por uma função, denominada janela. Cada um dos trechos é decomposto em diversas bandas de freqüência.

\footnotetext{
${ }^{2}$ Neste texto, assume-se que as funções pertencem ao espaço $\mathbb{L}^{2}(\mathbb{R})$ para que as transformadas existam $\left(f(t) \in \mathbb{L}^{2}(\mathbb{R}) \Leftrightarrow \int_{-\infty}^{+\infty}|f(t)|^{2} d t<\infty\right.$, com produto interno $\left.\langle f, g\rangle=\int_{-\infty}^{+\infty} f(t) g(t) d t\right)$.
} 

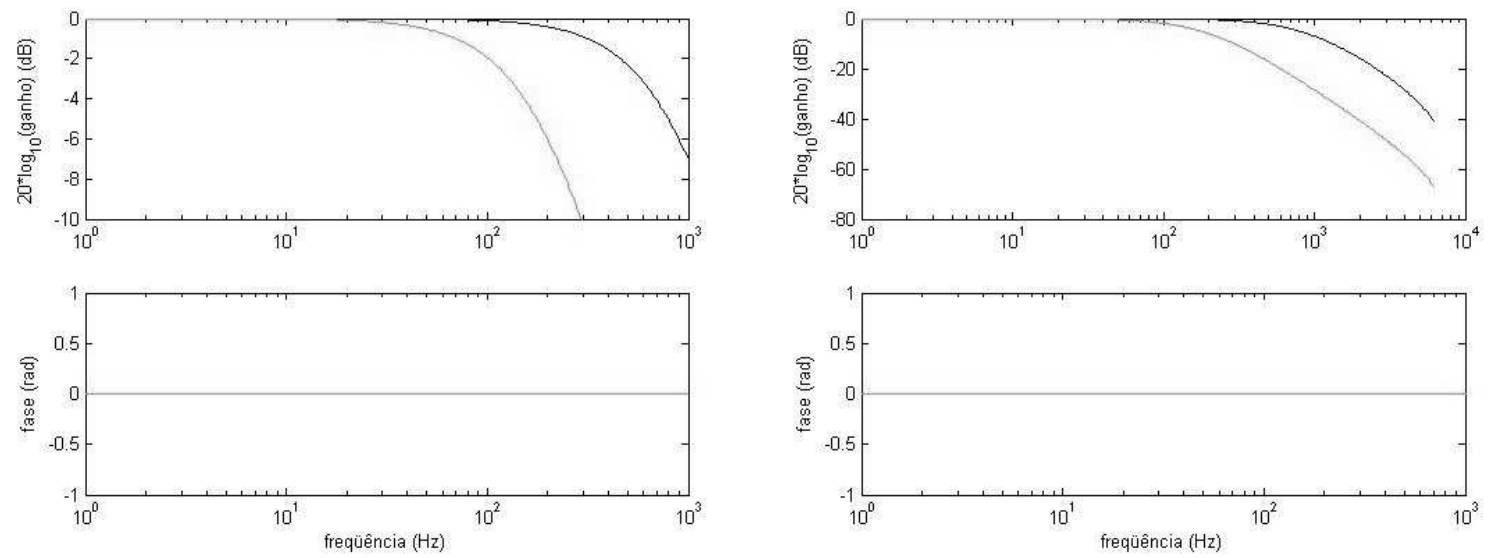

(a)

(b)

Figura 3.12: Resposta em freqüência dos filtros 1 (linha escura) e 2 (linha clara) a) até centenas de hertz e b) até milhares de hertz.

Dessa forma, tem-se uma representação bidimensional do sinal original, associando os trechos no tempo a bandas em freqüência. Uma técnica clássica de análise de tempofreqüência é a STFT (do inglês Short Time Fourier Transform), cuja representação no plano tempo-freqüência é o espectrograma.

A STFT se diferencia das outras transformadas de Fourier pois ela permite que se saiba a localização temporal dos componentes de freqüência do sinal. No entanto, não é possível relacionar uma única freqüência a um instante exato de tempo. Por exemplo, a função seno possui uma única freqüência, mas a sua duração é infinita. Por outro lado, um impulso (delta de Dirac) é diferente de zero somente no instante $t=0$, e a sua energia se distribui ao longo de todo o eixo das freqüências.

A relação entre as resoluções no tempo e na freqüência (das transformadas de tempofreqüência) é limitada pelo Princípio da Incerteza, que indica que deve haver um meiotermo entre essas resoluções (MALLAT, 2000; CHAN, 1995). Quanto mais precisa for a localização de um componente no tempo, menos se pode saber sobre sua freqüência, e vice-versa. Seja uma função $g(t)$ e sua Transformada de Fourier $G(\Omega)$, centrados, respectivamente, no instante

$$
t_{0}=\frac{\int_{-\infty}^{+\infty} t|g(t)|^{2} d t}{\int_{-\infty}^{+\infty}|g(t)|^{2} d t}
$$


e na freqüência

$$
\Omega_{0}=\frac{1}{2 \pi} \frac{\int_{-\infty}^{+\infty} \Omega|G(\Omega)|^{2} d \Omega}{\int_{-\infty}^{+\infty}|G(\Omega)|^{2} d \Omega} .
$$

As variâncias em torno desses valores médios são dadas por:

$$
\sigma_{t}^{2}=\frac{\int_{-\infty}^{+\infty}\left(t-t_{0}\right)^{2}|g(t)|^{2} d t}{\int_{-\infty}^{+\infty}|g(t)|^{2} d t}
$$

e

$$
\sigma_{\Omega}^{2}=\frac{1}{2 \pi} \frac{\int_{-\infty}^{+\infty}\left(\Omega-\Omega_{0}\right)^{2}|G(\Omega)|^{2} d \Omega}{\int_{-\infty}^{+\infty}|G(\Omega)|^{2} d \Omega} .
$$

Elas devem obedecer, pelo Princípio da Incerteza, à relação

$$
\sigma_{t}^{2} \sigma_{\Omega}^{2} \geq \frac{1}{4}
$$

Se $g(t)$ é a janela da STFT, ela divide o plano tempo-freqüência em retângulos de duração $\sigma_{t}$ e largura de banda $\sigma_{\Omega}$. A Figura 3.13.a ilustra essa divisão. Nota-se que ela é uniforme por todo o plano. Seria interessante analisar freqüências mais baixas com trechos mais longos e freqüências mais altas com trechos mais curtos, para que a resolução fosse proporcional às freqüências analisadas. Uma divisão possível está ilustrada na Figura 3.13.b. Essa divisão do plano tempo-freqüência é obtida utilizando as ondaletas.

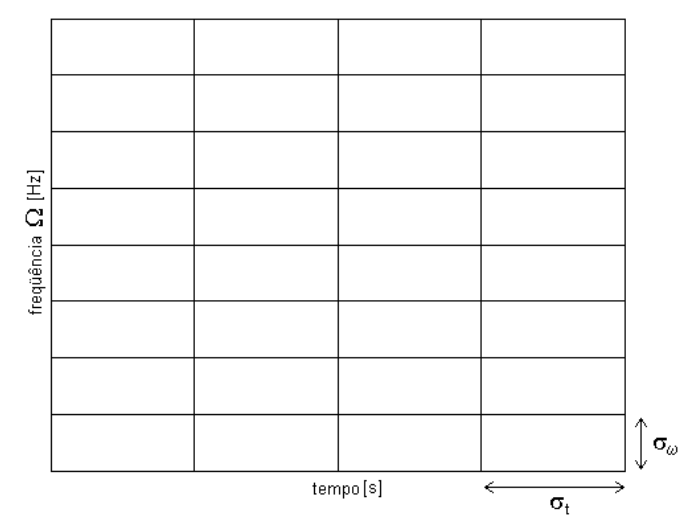

(a)

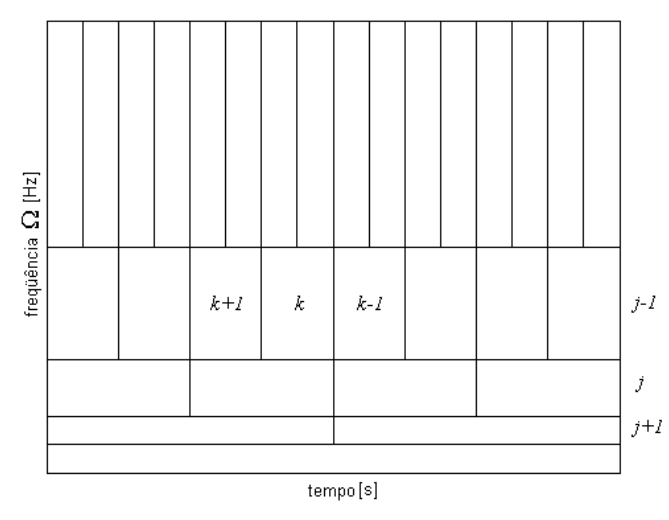

(b)

Figura 3.13: Divisão do plano tempo-freqüência por a) STFT e b) ondaletas.

De forma semelhante às transformadas de Fourier, as ondaletas se aplicam a sinais de tempo contínuo e discreto. Também podem ser representadas por coeficientes discretos ou por funções contínuas. Neste trabalho, serão aplicadas ondaletas com parâmetros 
discretos a seqüências (sinais de tempo discreto). A decomposição e a reconstrução dos sinais por essas ondaletas são descritas nas seções a seguir.

\subsubsection{Decomposição}

A representação de uma seqüência por ondaletas possibilita localizar os componentes dessa seqüência no plano de tempo-freqüência (BURRUS; GOPINATH; GUO, 1998). A base de funções utilizadas na decomposição é originada a partir de uma função denominada ondaleta-mãe. Existem vários tipos de ondaletas-mãe como, por exemplo, as ondaletas de Haar, de Daubechies, Biortogonal e Symlet, que estão ilustradas na Figura 3.14.
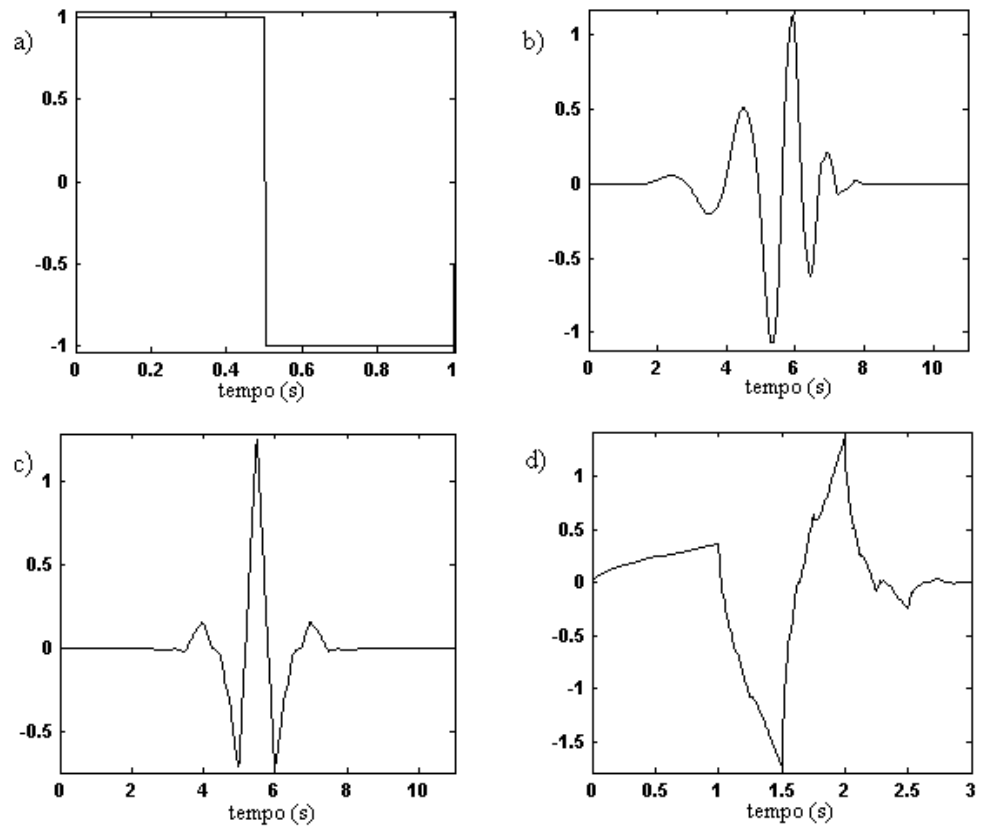

Figura 3.14: Exemplos de ondaletas-mãe usadas na decomposição: a) Haar; b) Daubechies 6; c) Biortogonal 5.5 e d) Symlet 2 .

Algumas características desejáveis das ondaletas são a banda limitada, a média igual a zero e o rápido decaimento para zero, no domínio do tempo (MALLAT, 2000; CHAN, 1995). Cada ondaleta-mãe, transladada e dilatada, dá origem a uma base do espaço das funções. Matematicamente, se $\psi(t)$ é a ondaleta-mãe, a base é composta por funções da forma

$$
\psi_{a, b}(t)=\frac{1}{\sqrt{a}} \psi\left(\frac{t-b}{a}\right),
$$

em que $a \in \mathbb{R}, a>0$ e $b \in \mathbb{R}$. Nota-se que a dilação por $a$ permite a variação das 
freqüências presentes na ondaleta e a translação por $b$ possibilita o estudo do comportamento local da função analisada em diferentes instantes de tempo. Dessa forma, pode-se estudar a variação dos componentes em freqüência ao longo do tempo. Na transformada wavelet discreta (DWT, do inglês Discrete Wavelet Transform), os parâmetros $a$ e $b$ são da forma $a=2^{j}$ e $b=k . a$, para $j \in \mathbb{Z}$ e $k \in \mathbb{Z}$. O parâmetro $j$ é denominado escala (COHEN; KOVACEVIC, 1996). As funções são então denotadas $\psi_{j, k}(t)$. As Figuras 3.15.a e 3.15.b ilustram as ondaletas obtidas pela variação de $k$ e $j$, respectivamente. A partir das figuras, é fácil compreender o efeito da alteração desses parâmetros no formato e no posicionamento das ondaletas.
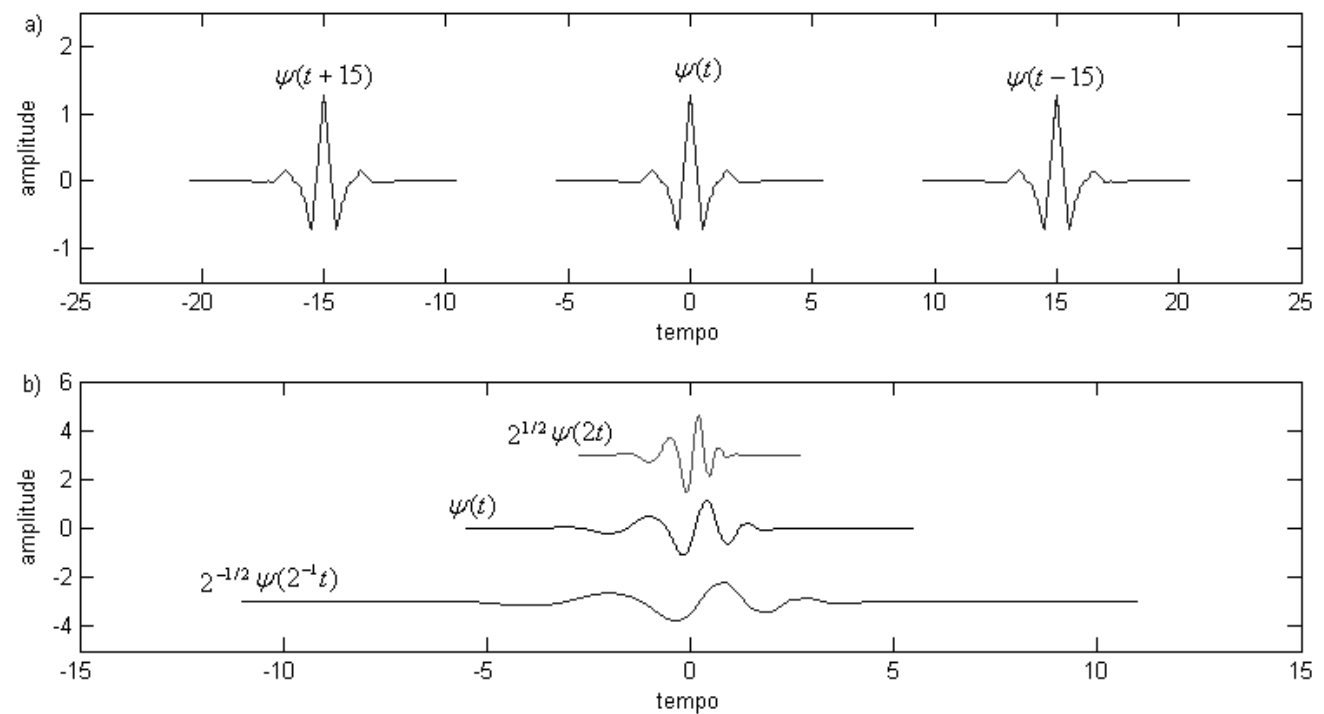

Figura 3.15: Variação dos parâmetros das ondaletas: a) $k$, ondaleta biortogonal 5.5 e b) $j$, ondaleta daubechies 6 .

A divisão do plano tempo-freqüência pela DWT está ilustrada na Figura 3.13.b, em que cada retângulo representa uma ondaleta. Vê-se que o aumento da escala $j$ para a escala $j+1$, isto é, a diminuição das freqüências analisadas, é acompanhado pelo aumento da duração das ondaletas por um fator 2 e pela diminuição da largura de banda pela metade $^{3}$. Essa característica da DWT de analisar freqüências mais altas com janelas de duração mais curta e analisar freqüências mais baixas com janelas de duração mais longa faz com que, numa determinada escala, a distância mínima entre dois componentes de freqüência seja proporcional ao valor das freqüências analisadas. Assim, se é possível

\footnotetext{
${ }^{3}$ Pela propriedade da transformada de Fourier: $\psi\left(\frac{t}{2}\right) \longleftrightarrow 2 \Psi(2 \Omega)$.
} 
distinguir entre $10.000 \mathrm{~Hz}$ e $11.000 \mathrm{~Hz}$, em outra escala pode-se separar o componente de $100 \mathrm{~Hz}$ daquele de 110Hz (CHAN, 1995). A Figura 3.13.b mostra ainda que as translações $b$ são proporcionais à duração das ondaletas de uma certa escala, percorrendo todo o eixo de tempo sem redundância.

A DWT é calculada em ordem de escalas crescentes, ou seja, de freqüências cada vez menores. A decomposição em uma determinada escala resulta em um sinal correspondente às freqüências mais altas, denominado detalhe, e um sinal com as freqüências mais baixas, denominado aproximação. O detalhe é resultado da projeção nas ondaletas de escala $j$, com sua característica de banda passa-faixa. Da mesma forma, a aproximação pode ser associada à decomposição sobre uma base de funções com característica passabaixas. Essas novas funções são denominadas funções de escala. Assim como no caso das ondaletas, os elementos da base formada pelas funções de escala também são translações e dilações de uma função-mãe $\phi(t)$. No caso da TWD, a função de escala é descrita por

$$
\phi_{j, m}(t)=2^{-j / 2} \phi\left(2^{-j} t-m\right)
$$

em que $j$ é a escala e $m \in \mathbb{Z}$.

Na prática, não são usadas as fórmulas de decomposição em bases de ondaletas e funções de escala para realizar a DWT. Os coeficientes da transformada podem ser obtidos a partir da filtragem digital. A ondaleta está associada a um filtro passa-banda enquanto que a função de escala corresponde a um filtro passa-baixas. A Figura 3.16 ilustra um exemplo de decomposição em 3 escalas partindo de $j=0$. Em cada escala $j$, o sinal de entrada é decomposto em duas partes. A saída do filtro passa-faixa é subamostrado e dá origem aos coeficientes de detalhe $d_{j}$. A saída do filtro passa-baixas também é subamostrado, gerando os coeficientes de aproximação $a_{j}$, que formam o sinal de entrada para a escala $j+1$. No final da decomposição, o sinal original é representado pelo conjunto de coeficientes da aproximação de maior escala e dos coeficientes de detalhe de todas as escalas. No exemplo da Figura 3.16, o sinal original A0 é representado pelo conjunto $\left\{a_{3}, d_{3}, d_{2}, d_{1}\right\}$ de coeficientes. 


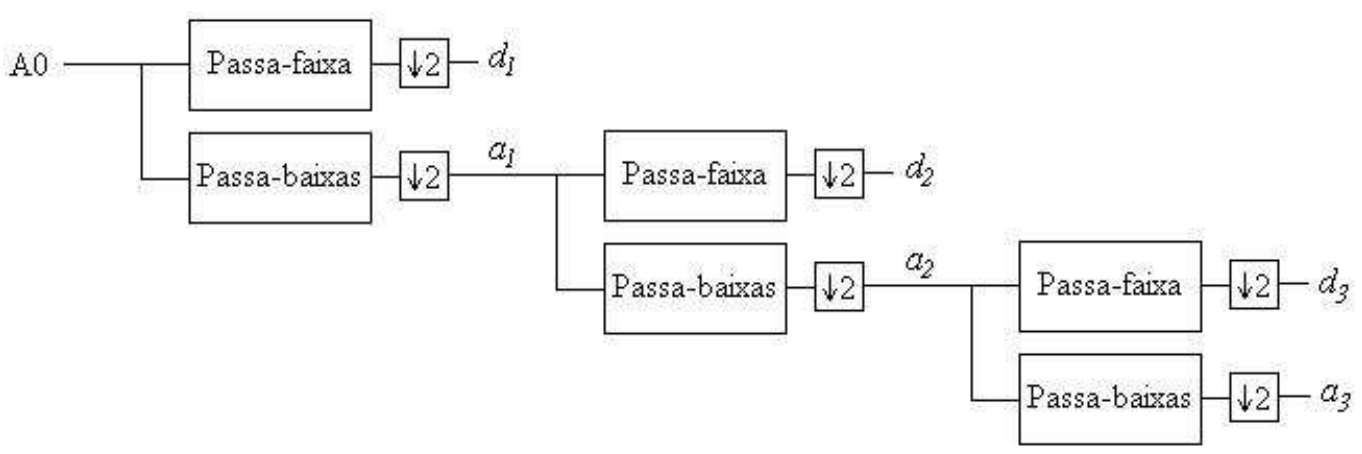

Figura 3.16: Decomposição em 3 escalas.

Cada um desses subconjuntos de coeficientes pode ser utilizado para representar uma parte do sinal original, bastando, para isso, zerar todos os outros coeficientes. Dessa forma, obtém-se o sinal de detalhe $D_{j}$ a partir dos coeficientes $d_{j}$ e o sinal de aproximação $A_{j}$ a partir dos coeficientes $a_{j}$. Assim, no final da decomposição, o sinal original é representado pela soma da aproximação de maior escala com os detalhes de todas as escalas. No exemplo da Figura 3.16, $A_{0}=A_{3}+D_{3}+D_{2}+D_{1}$.

A subamostragem realizada após a filtragem é feita retirando-se uma amostra em cada duas dos sinais de saída dos filtros. Esse é o significado do bloco “ $\downarrow 2$ ". Não há perda de informação pois as saídas dos filtros possuem metade da banda do sinal de entrada, e sabe-se que a mínima taxa de amostragem necessária para que um sinal de banda limitada possa ser reconstruído depende somente da largura da banda (BandPass Sampling Theorem) (BURRUs; GOPInATH; GUO, 1998; KOHLEnBERG, 1953). Com essa subamostragem, o número de pontos é mantido aproximadamente constante e a complexidade da TWD pode ser reduzida a $O(N)$, em que $N$ é o número de amostras do sinal original. Em comparação à transformada discreta de Fourier, esse valor é inferior à complexidade dos algoritmos rápidos de FFT (do inglês Fast Fourier Transform), que necessitam de $O\left(N \log _{2} N\right)$ operações.

\subsubsection{Relação entre as ondaletas e os filtros}

As ilustrações do algoritmo de decomposição na Figura 3.16 evidenciam que as funções de escala e as ondaletas de escala $j+1$ geram o mesmo espaço que o conjunto $\left\{\phi_{j, m}(t)\right\}_{m \in \mathbb{Z}}$. 
Isso significa que elas podem ser escritas como equações de escalas gêmeas (twin-scale equations) (MALLAT, 2000; MISITI et al., 2005):

$$
\begin{aligned}
\phi_{j+1}(t) & =\sum_{k=-\infty}^{+\infty} h[k] \phi_{j, m}(t) \\
\psi_{j+1}(t) & =\sum_{k=-\infty}^{+\infty} g[k] \phi_{j, m}(t) .
\end{aligned}
$$

O conjunto de coeficientes $h[k]$ corresponde a um filtro passa-baixas, associado à aproximação. O conjunto de coeficientes $g[k]$ corresponde a um filtro passa-faixa, associado ao detalhe. Caso se quisesse criar uma nova ondaleta, o processo seria iniciado pela escolha adequada desses coeficientes, buscando-se as características desejáveis da ondaleta e da função de escala, de forma que fosse possível obter a transformada inversa. Por exemplo, duas condições necessárias para a existência da função de escala são:

$$
\begin{aligned}
\sum_{k=-\infty}^{+\infty} h[k] & =\sqrt{2} \\
\sum_{k \text { par }} h[k] & =\sum_{k \text { impar }} h[k] .
\end{aligned}
$$

Uma vez determinados os coeficientes dos filtros, é possível estabelecer o formato da ondaleta e da função de escala. Uma forma de obter essas funções é aplicando as equações 3.10 e 3.11, iterativamente, a partir das condições iniciais (CHAN, 1995):

$$
\phi_{0,0}(t)= \begin{cases}1, & 0<t<1 \\ 0, & \text { caso contrário. }\end{cases}
$$

\subsubsection{Reconstrução}

A reconstrução consiste no processo oposto da decomposição: a partir dos coeficientes da transformada, recompõe-se o sinal no tempo. Quando uma base ortonormal de ondaletas é usada na decomposição, esse mesmo conjunto de ondaletas é utilizado para reconstruir os sinais. No entanto, as bases compostas pelas ondaletas não são necessariamente ortonormais. Um exemplo são as ondaletas biortogonais. Nesse caso, precisa-se de um outro 
conjunto de ondaletas para representar o sinal de tempo contínuo:

$$
f(t)=\sum_{j=-\infty}^{+\infty} \sum_{k=-\infty}^{+\infty}\left(\int_{-\infty}^{+\infty} f(\tau) \psi_{j, k}(\tau) d \tau\right) \tilde{\psi}_{j, k}(t)
$$

em que $\left\{\tilde{\psi}_{j, k}(t)\right\}_{(j, k) \in \mathbb{Z}^{2}}$ é a base dual de $\left\{\psi_{j, k}(t)\right\}_{(j, k) \in \mathbb{Z}^{2}}$, ou seja,

$$
\left\langle\psi_{j, k}, \tilde{\psi}_{j^{\prime}, k^{\prime}}\right\rangle=\delta\left(j-j^{\prime}\right) \delta\left(k-k^{\prime}\right)
$$

em que $\delta(n)$ é o delta de Kronecker ${ }^{4}$. De forma semelhante, existe uma base dual $\left\{\tilde{\phi}_{j, m}(t)\right\}_{(j, m) \in \mathbb{Z}^{2}}$ das funções de escala $\left\{\phi_{j, m}(t)\right\}_{(j, m) \in \mathbb{Z}^{2}}$, que obedecem a

$$
\left\langle\phi_{j, m}, \tilde{\phi}_{j, m^{\prime}}\right\rangle=\delta\left(m-m^{\prime}\right)
$$

Analogamente à expressão 3.15 , um sinal de tempo discreto $f(n)$ pode ser descrito como (BURRUS; GOPINATH; GUO, 1998; CHAN, 1995)

$$
f(n)=\sum_{j=-\infty}^{+\infty} \sum_{k=-\infty}^{+\infty} d_{j}(k) 2^{-j / 2} \tilde{\psi}\left(2^{-j} n-k\right),
$$

em que $d_{j}(k)$ são os coeficientes da DWT, que podem ser calculados a partir do sinal de tempo discreto

$$
d_{j}(k)=\sum_{n} f(n) \psi\left(2^{-j} n-k\right)
$$

Assim como na decomposição, são utilizados filtros digitais para realizar a reconstrução do sinal. Da mesma forma que as ondaletas e as funções de escala correspondem a filtros, os elementos das bases duais também podem ser expressos como:

$$
\begin{aligned}
\tilde{\phi}_{j+1}(t) & =\sum_{k=-\infty}^{+\infty} \tilde{h}[k] \tilde{\phi}_{j, m}(t), \\
\tilde{\psi}_{j+1}(t) & =\sum_{k=-\infty}^{+\infty} \tilde{g}[k] \tilde{\phi}_{j, m}(t),
\end{aligned}
$$

em que o conjunto de coeficientes $\tilde{h}[k]$ corresponde a um filtro passa-baixas, e o conjunto $\tilde{g}[k]$ corresponde a um filtro passa-faixa. Assim, para realizar a DWT e a antitransformada correspondente, são necessários quatro filtros: dois de decomposição $(h[k]$ e

\footnotetext{
${ }^{4}$ Nota-se que uma base ortonormal é o caso particular em que $\tilde{\psi}_{j, k}(t)=\psi_{j, k}(t)$.
} 
$g[k])$ e dois de reconstrução $(\tilde{h}[k]$ e $\tilde{g}[k])$. Para que a reconstrução seja perfeita, os filtros devem se relacionar por (MALLAT, 2000; DAUBECHIES, 1992)

$$
\begin{aligned}
& g[k]=(-1)^{1-k} \tilde{h}(1-k), \\
& \tilde{g}[k]=(-1)^{1-k} h(1-k) .
\end{aligned}
$$

Dessa forma, é possível obter um sinal decomposto em uma base de ondaletas, a partir dos coeficientes $d_{j}(k)$ calculados. Inversamente à subamostragem realizada na decomposição, na anti-DWT há inserção de zeros entre os coeficientes antes de passarem pelos filtros de reconstrução. Esse procedimento é representado pelos blocos " $\uparrow 2$ ". A Figura 3.17 ilustra os passos da anti-transformação correspondente à Figura 3.16.

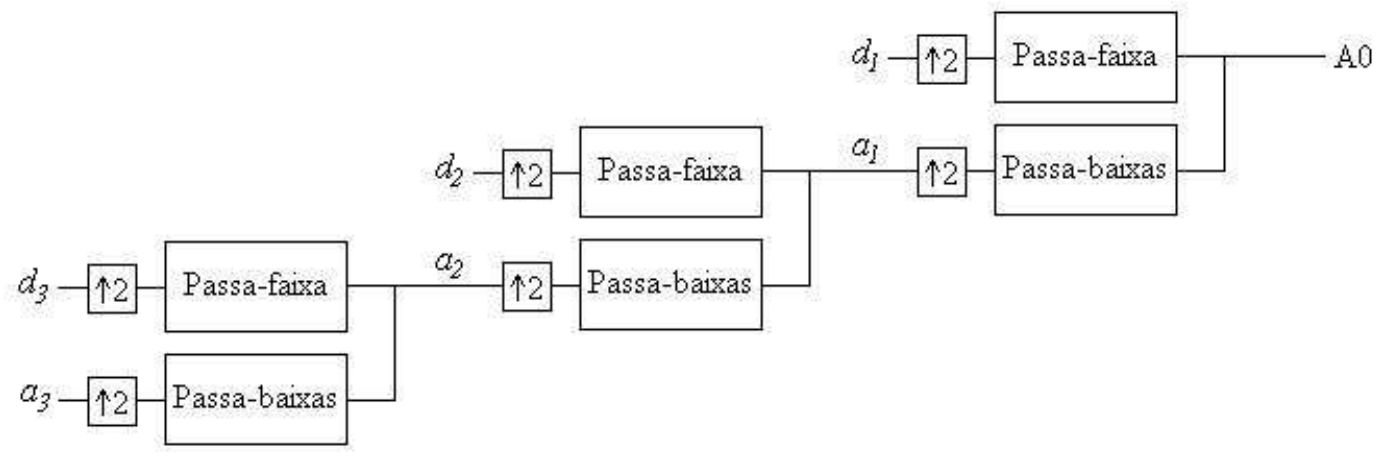

Figura 3.17: Reconstrução em 3 escalas.

Se nem todos os coeficientes forem utilizados na reconstrução, ou seja, se os valores de alguns coeficientes forem trocados por zero, o sinal obtido passa a ser uma estimativa do sinal original. Esse procedimento pode ser vantajoso em aplicações como na compressão de sinais (MALLAT, 2000) e na melhoria da relação sinal-ruído (EFFERN et al., 2000; QUIROGA; GARCIA, 2003). Nesses casos, é necessário escolher os coeficientes a serem utilizados na reconstrução. Podem-se escolher os maiores coeficientes (HOPPE et al., 2002) ou aqueles que ultrapassam certa amplitude (ZHANG et al., 2004). Em potenciais evocados, essas técnicas não são vantajosas quando aplicadas a respostas individuais, pois os maiores coeficientes são associados ao EEG de fundo que se quer eliminar, uma vez que o PE é muito menor. Uma técnica que tem sido utilizada é a seleção de determinadas bandas de freqüência em diferentes instantes de tempo, dado o comportamento típico do sinal 
(BERTRAND; BOHORQUEZ; PERNIER, 1994; QUIROGA; GARCIA, 2003). Em outras palavras, definem-se os intervalos de tempo em que se localizam os picos do PE e escolhem-se os coeficientes relacionados à faixa de freqüências esperada. Com esse método, pode-se melhorar a relação sinal-ruído do PE (EFFERN et al., 2000; QUIROGA; GARCIA, 2003).

Um outro problema no uso da DWT é a escolha da ondaleta-mãe. Existem autores que defendem a escolha da ondaleta-mãe cujo formato mais se aproxime daquele do sinal analisado (WILSON, 2004; QUIROGA, 2000). Outros dizem que o mais importante são as propriedades da ondaleta-mãe (BRADLEY; WILSON, 2004) como, por exemplo, a simetria e os tamanhos dos suportes (região fora da qual a função vale zero) no tempo e na freqüência. No entanto, grande parte dos trabalhos nem sequer discute a seleção da ondaleta-mãe utilizada (HOPPE et al., 2002).

Neste trabalho, a ondaleta-mãe biortogonal 5.5 foi escolhida em função de sua fase linear (ZHANG et al., 2004) e dos resultados da Seção 4.2. A Tabela 3.1 apresenta os filtros passa-baixas utilizados na DWT e na sua anti-transformada, quando se opta por essa ondaleta. Os coeficientes dos filtros passa-faixa podem ser obtidos utilizando as relações 3.22 e 3.23. Os filtros são simétricos, ou seja, $h[k]=h[-k]$ e $\tilde{h}[k]=\tilde{h}[-k]$, o que explica a linearidade da fase. Além disso, pode-se verificar que as condições 3.12 e 3.13 são obedecidas.

Tabela 3.1: Coeficientes dos filtros $h[k]$ e $\tilde{h}[k]$ para a TWD e anti-transformada usando a ondaleta biortogonal 5.5. Os filtros têm simetria par, ou seja, $h[k]=h[-k] \mathrm{e}$ $\tilde{h}[k]=\tilde{h}[-k]$.

\begin{tabular}{ccc}
\hline$k$ & $h[k]$ & $\tilde{h}[k]$ \\
\hline 0 & 0,73666018142821 & 0,89950610974865 \\
1 & 0,34560528195603 & 0,47680326579848 \\
2 & $-0,05446378846824$ & $-0,09350469740094$ \\
3 & 0,00794810863724 & $-0,13670658466433$ \\
4 & 0,03968708834741 & $-0,00269496688011$ \\
5 & 0 & 0,01345670945912 \\
\hline
\end{tabular}

A Figura 3.18 ilustra os ganhos das respostas em freqüência desses filtros. A linha clara indica a resposta em freqüência do passa-baixas. A linha escura mostra uma resposta 
típica de passa-altas, correspondente ao filtro passa-faixa da ondaleta. Com a inserção de zeros realizada na reconstrução, representada pelo bloco " $\uparrow 2$ ", a freqüência de Nyquist dobra e o filtro passa-altas associado à ondaleta passa a ter uma resposta típica de um passa-faixa.

Vê-se, nas Figuras a) e b), que a taxa de atenuação dos filtros passa-baixas é mais acentuada que a dos filtros passa-altas.

A Figura 3.19 mostra as fases das respostas em freqüência. Observa-se novamente que a fase é linear.

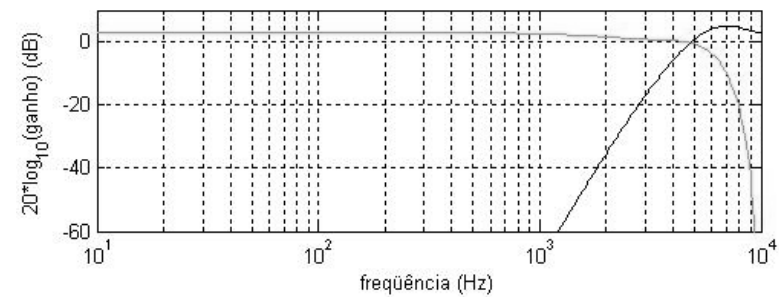

(a)

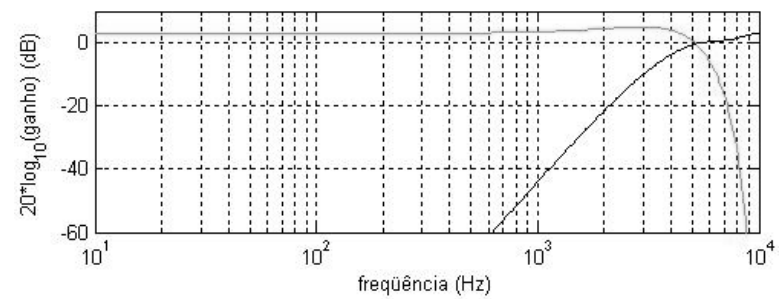

(b)

Figura 3.18: Ganho das respostas em freqüência dos filtros passa-faixa (linha escura) e passa-baixas (linha clara) relacionados à ondaleta biortogonal 5.5: a) filtros de decomposição e b) filtros de reconstrução.

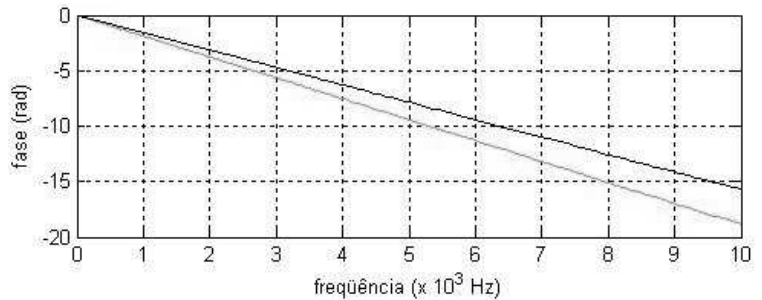

(a)

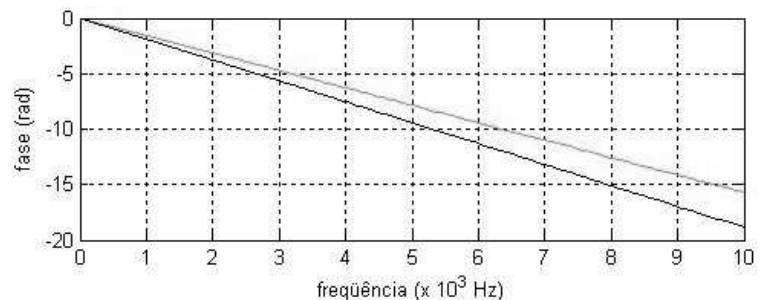

(b)

Figura 3.19: Fase das respostas em freqüência dos filtros passa-faixa (linha escura) e passa-baixas (linha clara) relacionados à ondaleta biortogonal 5.5: a) filtros de decomposição e b) filtros de reconstrução.

Adotou-se a decomposição em 6 escalas, pois é o maior número de escalas possível para o tipo de ondaleta e o número de amostras utilizadas: 1141 (MISITI et al., 2005). A estimativa do PE foi obtida após a seleção dos coeficientes resultantes da decomposição. Essa seleção foi baseada em faixas de coeficientes considerados relevantes em cada escala. A determinação das faixas é mostrada no item 4.1.2. 


\subsection{Forma de análise dos resultados}

A média síncrona de 100 respostas e as estimativas obtidas pela aplicação das técnicas apresentadas acima foram comparadas com os potenciais evocados padrão obtidos pela média síncrona de 1000 respostas individuais. A seguir, são descritos os métodos utilizados na análise das estimativas obtidas.

\subsubsection{Análise visual}

A análise visual é a forma classicamente utilizada em clínica para avaliar os sinais de potencial evocado (ver seção 2.3). Por isso, ela foi uma das maneiras usadas neste trabalho para comparar as diversas estimativas obtidas. Foi observado principalmente o formato do PE.

No entanto, esse método fornece apenas uma análise qualitativa das estimativas obtidas. Outras técnicas, quantitativas, mostraram-se necessárias, e são apresentadas a seguir.

\subsubsection{Erro quadrático}

Foi analisado o erro quadrático normalizado, dado por

$$
E Q=\frac{\sum_{n=1}^{N}(s(n)-\hat{s}(n))^{2}}{\sum_{n=1}^{N} s^{2}(n)},
$$

em que $s(n)$ é o potencial evocado resultante da média síncrona de 1000 respostas individuais, $\hat{s}(n)$ é a estimativa calculada a partir da reconstrução da média síncrona de 100 respostas e $N=1141$ é o número de amostras por resposta individual.

\subsubsection{Análise estatística para duas técnicas}

As medidas de erro obtidas usando diferentes técnicas de processamento podem ser comparadas por meio de testes estatísticos. O teste do sinal (sign test) é não-paramétrico e aplicável em casos em que se pretende testar o efeito de dois "tratamentos" realizados 
entre as coletas pareadas (dependentes) (HOLLANDER; WOLFE, 1973). Para cada sujeito $i$, é feita uma coleta pré-tratamento $X_{i}$ e outra pós-tratamento $Y_{i}$, como ilustrado na Tabela 3.2. Neste trabalho, as técnicas (ou "tratamentos") eram as diferentes formas de obtenção das estimativas. Para cada sujeito $i$, o valor médio $X_{i}$ dos erros das 10 estimativas obtidas pela média síncrona e o valor médio $Y_{i}$ dos erros das 10 estimativas por filtros (ou ondaletas) foram tabelados.

Tabela 3.2: Dados para o teste do sinal.

\begin{tabular}{clc} 
Sujeito $i$ & $X_{i}$ & $Y_{i}$ \\
\hline 1 & $X_{1}$ & $Y_{1}$ \\
2 & $X_{2}$ & $Y_{2}$ \\
$\vdots$ & $\vdots$ & $\vdots$ \\
$n$ & $X_{n}$ & $Y_{n}$
\end{tabular}

O efeito da técnica é analisado estudando a diferença $Z_{i}=Y_{i}-X_{i}$, que se assume ser da forma $Z_{i}=\theta+e_{i}$, em que $\theta$ é o efeito devido à técnica. Supõe-se que as variáveis aleatórias $e_{i}$ sejam não observáveis, independentes e que sua distribuição tenha mediana igual a zero ${ }^{5}$ (HOLLANDER; WOLFE, 1973). O teste é realizado atribuindo-se valores $\delta_{i}$ às diferenças $Z_{i}$. Se $Z_{i}$ for maior que zero, $\delta_{i}$ é igual a um; se $Z_{i}$ for menor que zero, $\delta_{i}$ é igual a zero e se $Z_{i}$ é igual a zero, o par de valores $\left(X_{i}, Y_{i}\right)$ é eliminado e $n$ é redefinido como o número de $Z_{i}$ diferentes de zero. Em seguida, é calculado

$$
B=\sum_{i=1}^{n} \delta_{i} .
$$

Se as hipóteses a serem testadas forem

$$
\begin{aligned}
& H_{0}: \theta=0 \\
& H_{1}: \theta>0
\end{aligned}
$$

então $H_{0}$ é rejeitada com nível de significância $\alpha$ se $B=b(\alpha, n, 1 / 2)$. A expressão $b(\alpha, n, 1 / 2)$ é proveniente de uma distribuição binomial com parâmetros $n$ e $p$, tal que $P[B=b(\alpha, n, 1 / 2)]=\alpha$. Os valores de $b(\alpha, n, 1 / 2)$ podem ser encontrados em tabelas

\footnotetext{
${ }^{5}$ ou seja, que as probabilidades sejam tais que $P\left(e_{i}<0\right)=P\left(e_{i}>0\right)=1 / 2$
} 
estatísticas (HOLLANDER; WOLFE, 1973).

\subsubsection{Análise estatística para mais de duas técnicas}

No caso de três ou mais técnicas ("tratamentos"), pode-se aplicar o teste de Friedman. Denotando os efeitos das técnicas por $\tau_{i}$, as hipóteses a serem testadas são

$$
\begin{aligned}
& H_{0}: \tau_{1}=\tau_{2}=\ldots=\tau_{k} \\
& H_{1}: \tau_{1} \neq \tau_{2} \neq \ldots \neq \tau_{k}
\end{aligned}
$$

em que $k$ é o número de técnicas. No entanto, caso se queira ordenar os efeitos das técnicas, aplica-se o teste não-paramétrico de Page (HOLLANDER; WOLFE, 1973). Nesse caso, deseja-se testar

$$
\begin{gathered}
H_{0}: \tau_{1}=\tau_{2}=\ldots=\tau_{k} \\
H_{1}: \tau_{1} \leq \tau_{2} \leq \ldots \leq \tau_{k},
\end{gathered}
$$

em que pelo menos uma desigualdade de $H_{1}$ é estrita. Inicialmente são atribuídos os postos de Friedman às médias pareadas de cada sujeito $i$. Para isso, monta-se uma tabela semelhante à Tabela 3.2, mas com mais colunas (uma coluna para cada técnica). Para cada sujeito, as médias dependentes são colocadas em ordem crescente. Na tabela, isso equivale a ordenar os elementos de cada linha. Em seguida, é atribuído o posto 1 à técnica de menor média, o valor 2 é associado à técnica de segunda menor média, e assim por diante. Caso uma linha possua elementos iguais, os postos devem ser corrigidos para o valor médio dos postos atribuídos inicialmente. Por exemplo, se há $k$ técnicas e as duas maiores médias são iguais, então é atribuído o posto $(k-0,5)$ às duas técnicas correspondentes. Em seguida, calcula-se a soma dos postos de cada técnica. Os valores obtidos são ponderados pela ordem da técnica na hipótese $H_{1}$, dada pelo índice, e somados novamente. Esse resultado é denominado $L$. A hipóteste $H_{0}$ é rejeitada com nível de significância $\alpha$ se $L \geq \ell(\alpha, k, n)$, em que $P[L \geq \ell(\alpha, k, n)]=\alpha$. Os valores de $\ell(\alpha, k, n)$ podem ser encontrados em tabelas estatísticas (HOLLANDER; WOLFE, 1973). A Tabela 3.3 apresenta uma parte dessa tabela 
estatística.

Tabela 3.3: Valores críticos para a distribuição nula da estatística do L de Page. São apresentados os valores de $\ell(\alpha, k, n)$ que satisfazem $P[L \geq \ell(\alpha, k, n)]=\alpha$, dados o número de técnicas $(k)$, o número de indivíduos $(n)$ e o nível de significância $(\alpha)$.

\begin{tabular}{|c|c|c|c|c|c|c|c|c|c|}
\hline & \multicolumn{9}{|c|}{$k$} \\
\hline & \multicolumn{3}{|c|}{3} & \multicolumn{3}{|c|}{4} & \multicolumn{3}{|c|}{5} \\
\hline & & $\alpha$ & & & $\alpha$ & & & $\alpha$ & \\
\hline$n$ & 0,001 & 0,01 & 0,05 & 0,001 & 0,01 & 0,05 & 0,001 & 0,01 & 0,05 \\
\hline 2 & & & 28 & & 60 & 58 & 109 & 106 & 103 \\
\hline 3 & & 42 & 41 & 89 & 87 & 84 & 160 & 155 & 150 \\
\hline 4 & 56 & 55 & 54 & 117 & 114 & 111 & 210 & 204 & 197 \\
\hline 5 & 70 & 68 & 66 & 145 & 141 & 137 & 259 & 251 & 244 \\
\hline 6 & 83 & 81 & 79 & 172 & 167 & 163 & 307 & 299 & 291 \\
\hline 7 & 96 & 93 & 91 & 198 & 193 & 189 & 355 & 346 & 338 \\
\hline 8 & 109 & 106 & 104 & 225 & 220 & 214 & 403 & 393 & 384 \\
\hline 9 & 121 & 119 & 116 & 252 & 246 & 240 & 451 & 441 & 431 \\
\hline 10 & 134 & 131 & 128 & 278 & 272 & 266 & 499 & 487 & 477 \\
\hline
\end{tabular}

Adaptado de (HOLLANDER; WOLFE, 1973), p.372. 


\section{Resultados}

Todo o processamento foi realizado no Matlab ${ }^{\circledR}$, v.6.5 R13, tanto a definição dos parâmetros da metodologia quanto a aplicação das técnicas definidas.

A metodologia foi definida para sinais de um banco de dados anterior do laboratório. Esses sinais eram provenientes de 4 sujeitos do sexo masculino, sadios e neurologicamente normais, com idade entre 20 e 25 anos. Esses sujeitos foram denominados sujeitos 1, 2, 3 e 4 .

Em seguida, as técnicas de estimação de potenciais evocados foram aplicadas a sinais obtidos durante este mestrado, de 9 sujeitos sadios e neurologicamente normais, sendo 3 do sexo feminino e 6 do sexo masculino, com idades entre 18 e 49 anos. Esses sujeitos foram denominados sujeitos 5 a 13. As seções a seguir apresentam os resultados obtidos em cada etapa.

\subsection{Escolha dos coeficientes}

Para aplicar a técnica de estimação que utiliza as ondaletas, é necessário determinar de que forma os coeficientes da transformada são escolhidos para representar o potencial evocado. Neste trabalho, seguiu-se um procedimento semelhante ao utilizado por Zhang et al. (2004). Esses autores escolheram, em cada escala de decomposição, uma porcentagem dos maiores coeficientes. Aqueles que se encontravam dentro de uma faixa de tempo considerada relevante para a representação do potencial evocado foram usados na estimação. Nesta seção, mostra-se a escolha das faixas de coeficientes relevantes para o 
PE somato-sensitivo e as porcentagens desses coeficientes a serem utilizados, para cada escala.

\subsubsection{Contribuição de cada escala}

Antes de se fazer a escolha dos coeficientes da DWT, é importante saber como um sinal é representado por eles. Como exemplo, foi utilizado o potencial evocado padrão do sujeito 3 (resultados semelhantes foram obtidos para todos os sujeitos). A Figura 4.1 ilustra o sinal analisado (Figura 4.1.a) e os respectivos coeficientes de aproximação de escala 6 (Figura 4.1.b) e detalhe da escala 6 (Figura 4.1.c) à escala 1 (Figura 4.1.h), em ordem decrescente.

Comparando a Figura 4.1.d (escala 5) com a Figura 4.1.c (escala 6), nota-se que o número de coeficientes de detalhe diminui com o aumento da escala. Essa redução pode ser observada entre os coeficientes de detalhe de quaisquer escalas consecutivas. O fator de redução é de aproximadamente 2, e está de acordo com a subamostragem citada no item 3.3. Além disso, vê-se que a ordem de grandeza dos coeficientes aumenta com a escala. Isso mostra que os componentes de freqüências mais altas, representados pelas menores escalas, têm amplitude baixa em relação aos componentes de freqüências mais baixas associados às maiores escalas. Também se pode notar, nas Figuras 4.1.c até 4.1.f, que parece haver uma concentração dos coeficientes de maior valor absoluto em certas faixas, que correspondem a intervalos de tempo. Esse fato reforça a idéia da associação de determinadas bandas de freqüência (ou escalas) a diferentes instantes de tempo (ou faixas). Por outro lado, analisando a Figura 4.1.h, não ocorre essa concentração na escala 1. Os valores dos coeficientes parecem ser aleatórios, como se fossem ruído de alta freqüência.

Os coeficientes da Figura 4.1, usados na anti-transformada, reconstroem o PE padrão. Conhecer a contribuição de cada escala na constituição do potencial evocado é importante para auxiliar na escolha dos coeficientes das escalas que serão utilizados na obtenção da estimativa usando ondaletas. Para mostrar o efeito de cada escala na reconstrução 

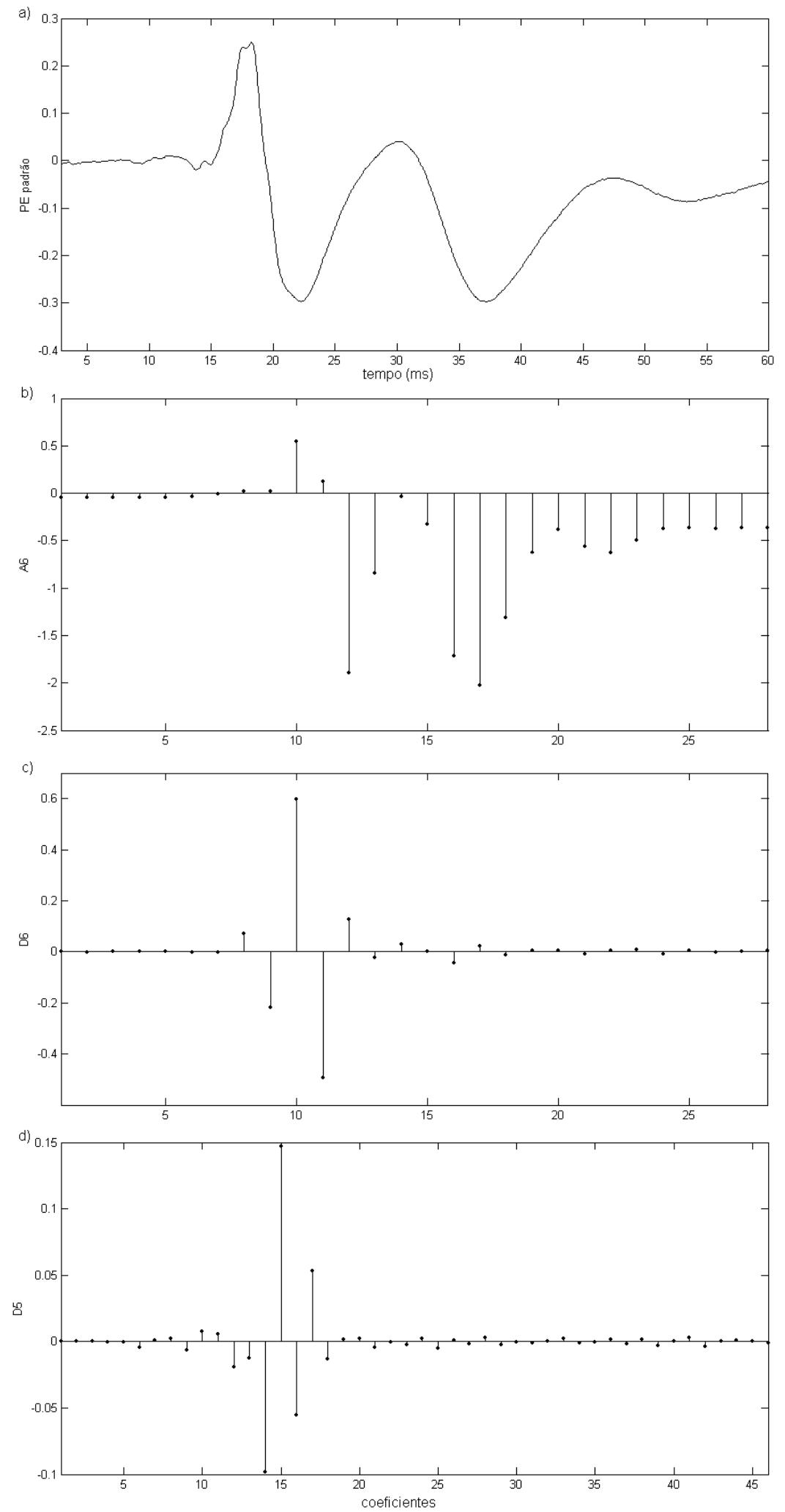

Figura 4.1: Valores dos coeficientes da DWT: a) PE padrão, b) aproximação de escala 6, c) detalhe de escala $6, \mathrm{~d}$ ) detalhe de escala 5 . (continua) 

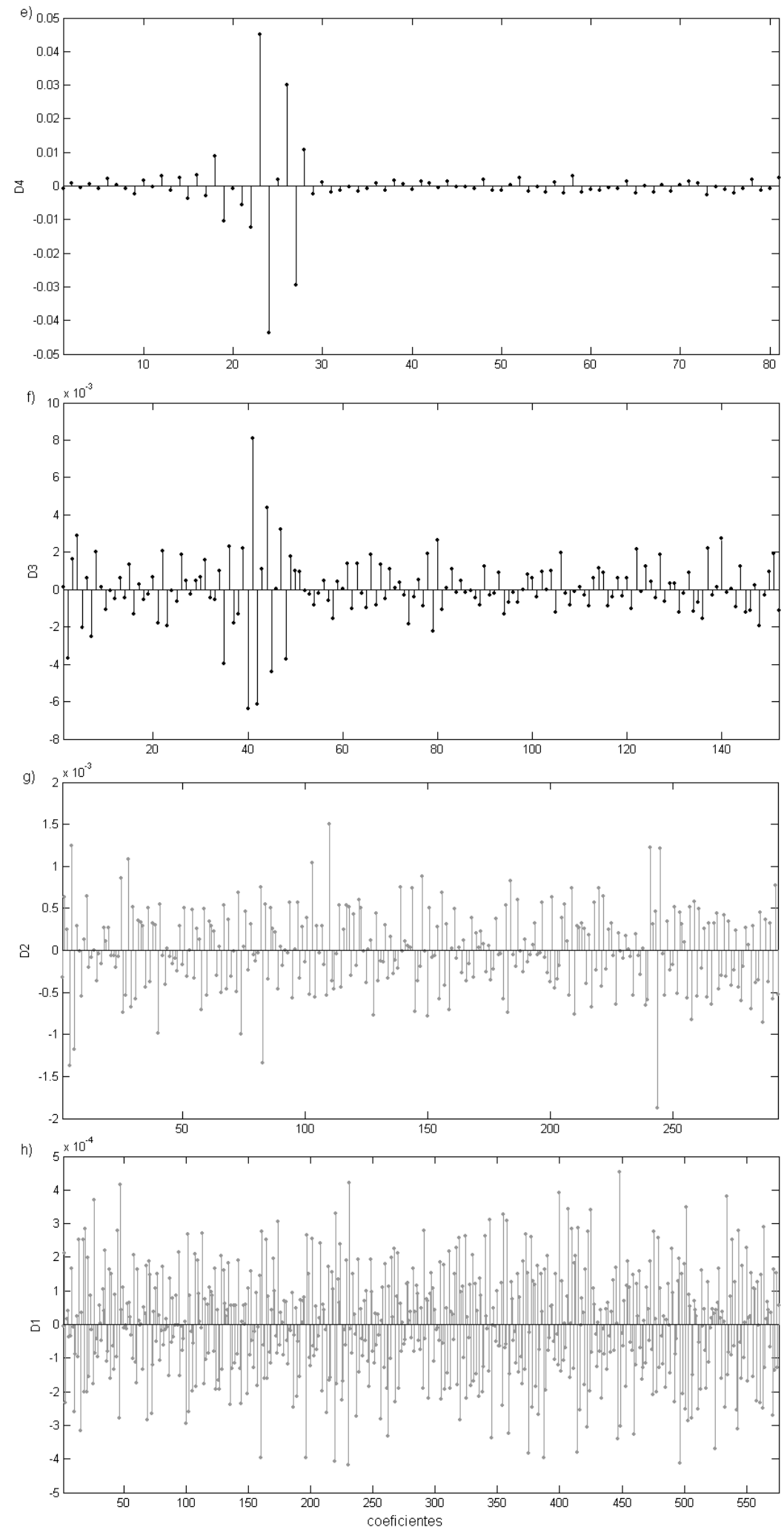

Figura 4.1: (continuação) e) detalhe de escala 4, f) detalhe de escala 3, g) detalhe de escala $2, \mathrm{~h}$ ) detalhe de escala 1. 
do PE padrão, a transformada inversa foi aplicada acrescentando-se as escalas uma de cada vez e em ordem decrescente. Dessa forma, pode-se atribuir a diferença entre duas reconstruções consecutivas aos coeficientes da escala inserida. As Figuras 4.2 a 4.8 ilustram essa reconstrução, com o PE padrão em linha pontilhada e o resultado da transformada inversa em linha pontilhada. Nessas figuras, também pode ser observado o erro quadrático, em função do tempo, de cada reconstrução.

Na Figura 4.2, vê-se que a aproximação de escala 6 representa as freqüências mais baixas. Nota-se que ela é a base do potencial evocado. Também pode-se ver que o sinal reconstruído se aproxima mais do PE a partir de 30ms, mostrando que esse trecho é quase completamente representado pelos coeficientes A6. Por outro lado, até 30ms, a diferença entre o PE padrão e a aproximação de escala 6 é bastante clara, indicando a necessidade das outras escalas para representar os picos nesse trecho. Essa diferença se reflete no erro quadrático, que é maior entre $10 \mathrm{~ms}$ e $25 \mathrm{~ms}$.
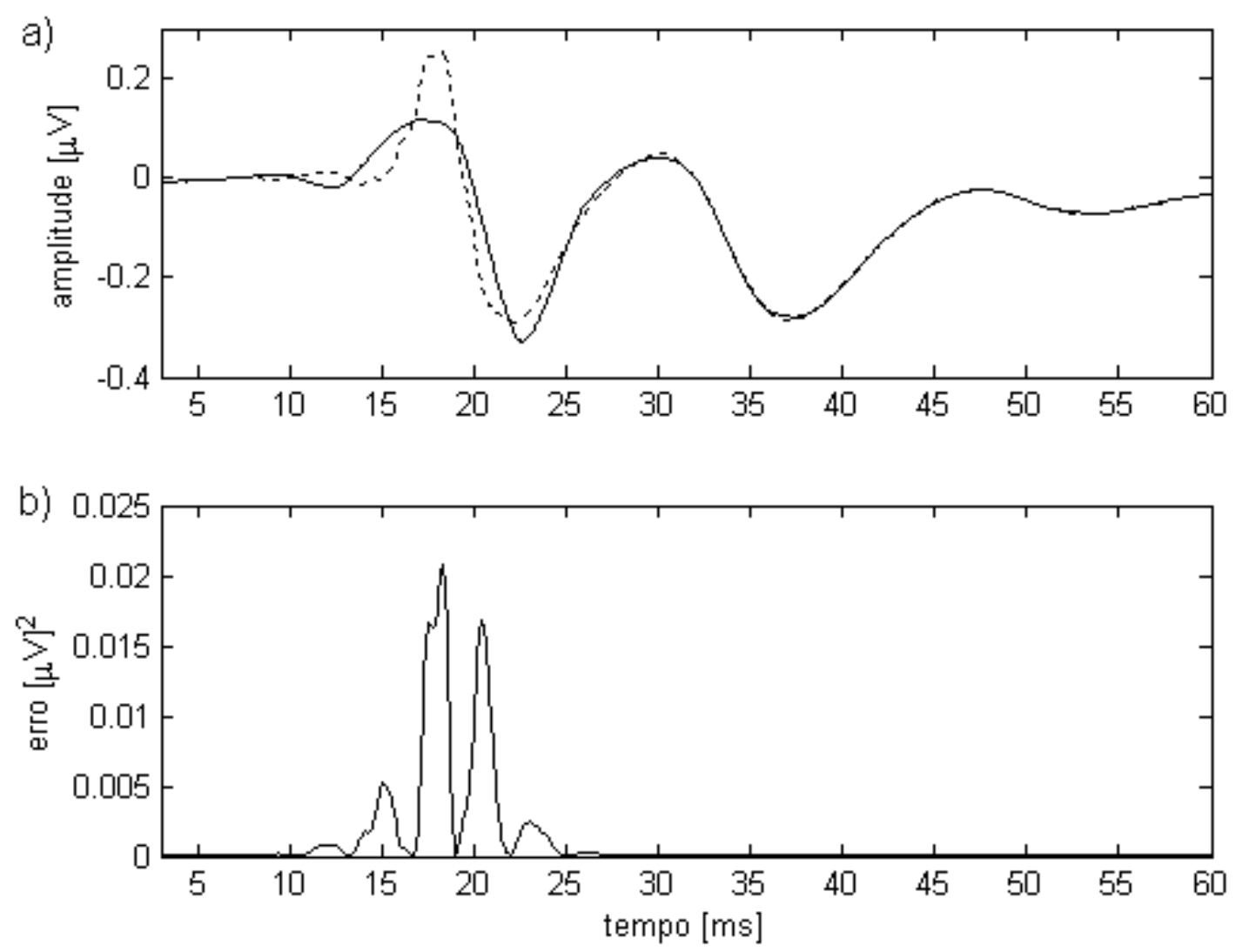

Figura 4.2: Contribuição de cada escala da DWT: a) PE padrão em linha pontilhada e reconstrução usando os coeficientes A6 e b) erro quadrático. 
Comparando as Figuras 4.2 e 4.3, nota-se que o detalhe de escala 6 melhorou bastante o sinal reconstruído até 30ms. Nota-se que os coeficientes D6 representam principalmente o pico N19, e que também alteram o pico P23. Além disso, esses coeficientes de detalhe contribuem, ainda que pouco, na representação dos extremos dos picos após 30ms. também modelam as regiões extremas dos picos após 30ms. Vê-se em ambas as figuras que o erro quadrático é maior em um intervalo ao redor de 20ms, mas a ordem de grandeza do erro quadrático diminuiu na Figura 4.3.b.
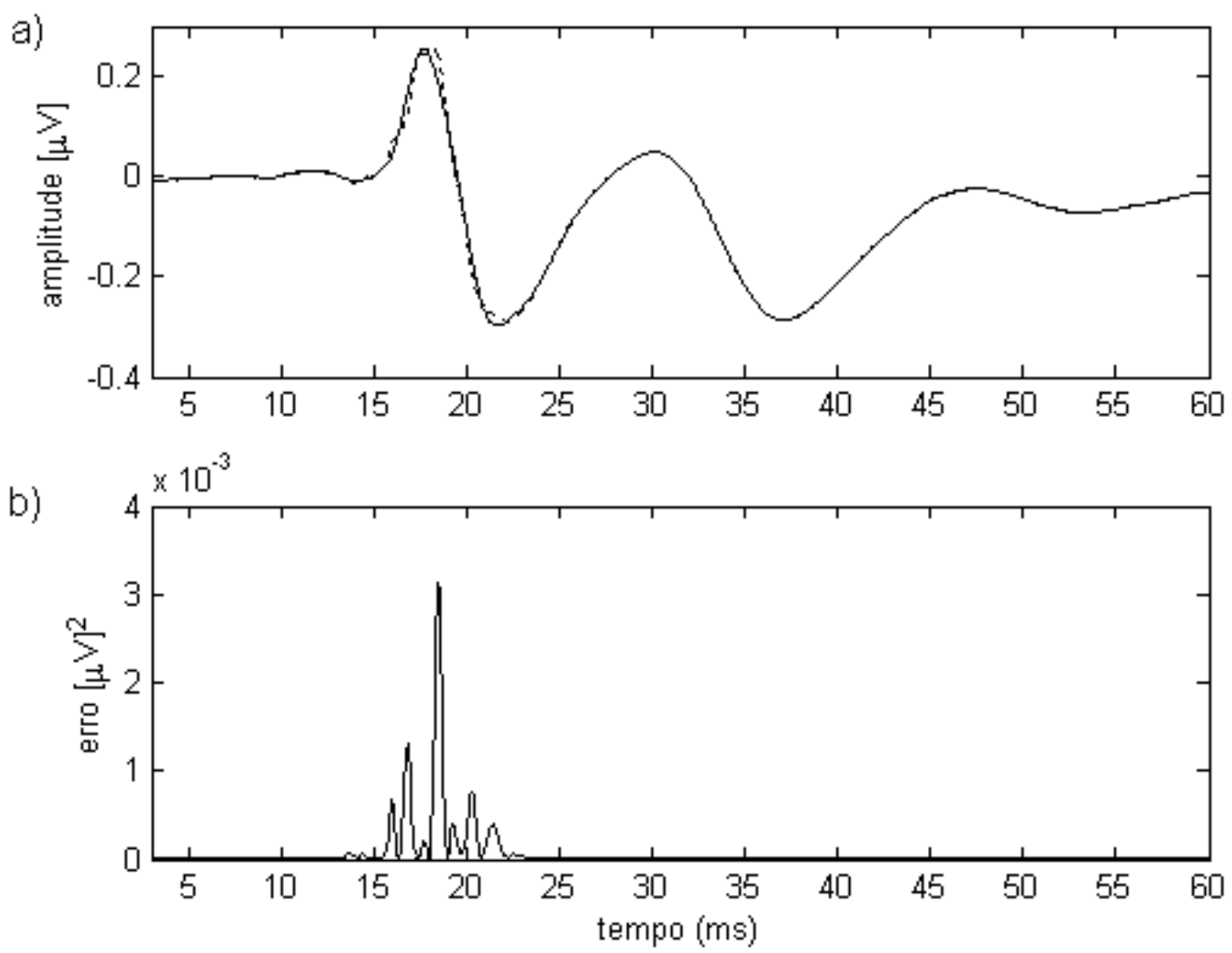

Figura 4.3: Contribuição de cada escala da DWT: a) PE padrão em linha pontilhada e reconstrução usando os coeficientes A6 e D6 e b) erro quadrático. 
Na Figura 4.4, continuam as mudanças nos picos N19 e P23. Vê-se que há alterações nas inclinações de subida e descida do pico N19 e de descida do pico P23. Além disso, ondulações mais rápidas, como na base do pico N19 ou no extremo do pico N23, são melhor modelados. Como no caso dos coeficientes D6, o erro continua maior em torno de 20ms e os erros diminuem de uma ordem de grandeza.
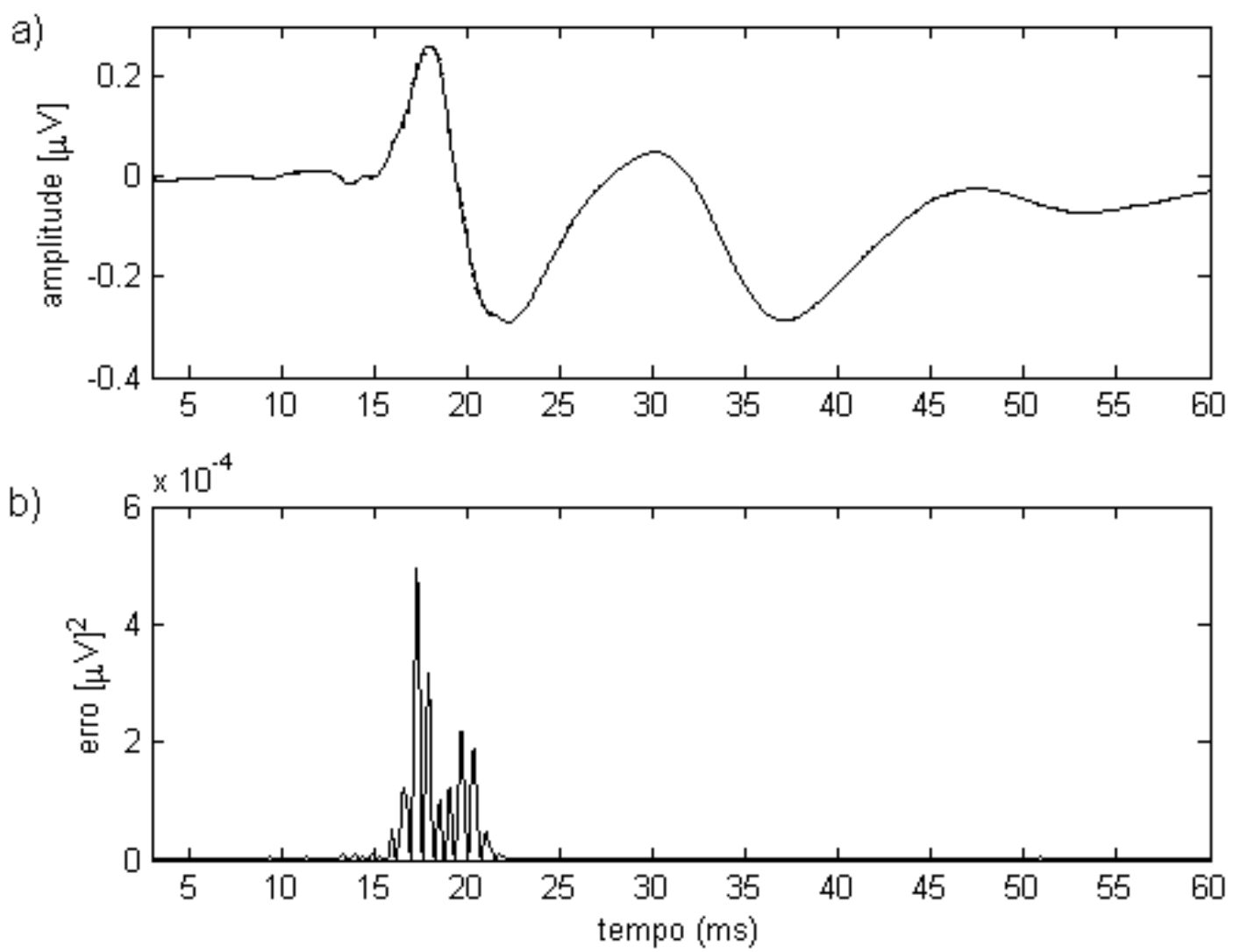

Figura 4.4: Contribuição de cada escala da DWT: a) PE padrão em linha pontilhada e reconstrução usando os coeficientes A6, D6 e D5 e b) erro quadrático. 
Os mesmos picos continuam sendo modificados com a inclusão dos coeficientes de detalhe de escala 4. A amplitude das contribuições vai diminuindo com cada nova escala considerada, e fica mais difícil notar a mudança no pico N19 da Figura 4.5. No entanto, a contribuição de cada escala pode ser observada pelas alterações nos erros, que continuam diminuindo.
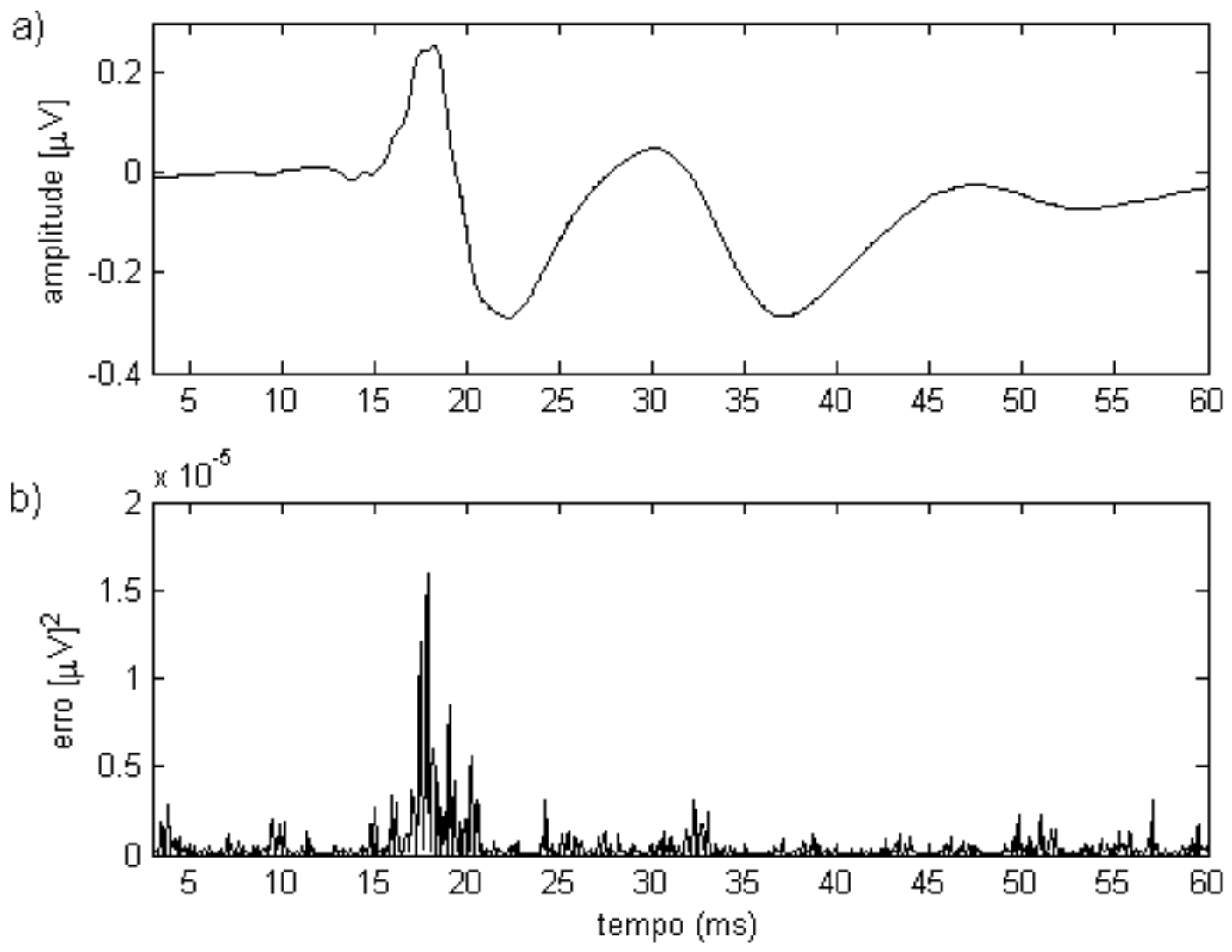

Figura 4.5: Contribuição de cada escala da DWT: a) PE padrão em linha pontilhada e reconstrução usando os coeficientes A6, D6, D5 e D4 e b) erro quadrático. 
Na Figura 4.6.b, vê-se que o erro quadrático diminuiu novamente de uma ordem de grandeza. Além disso, pela primeira vez, o erro quadrático não é muito maior no intervalo em torno de 20ms que nos demais instantes de tempo, o que indica que os coeficientes de aproximação de escala 6 e os de detalhe de escalas 3 a 6 são necessários para a representação dos picos nesse trecho, mas que os demais coeficientes não têm contribuição marcante neste intervalo de tempo. Também se nota o aspecto aleatório do erro quadrático, reforçando a idéia de que os coeficientes de detalhe das escalas restantes (1 e 2) representam ruído de alta freqüência.
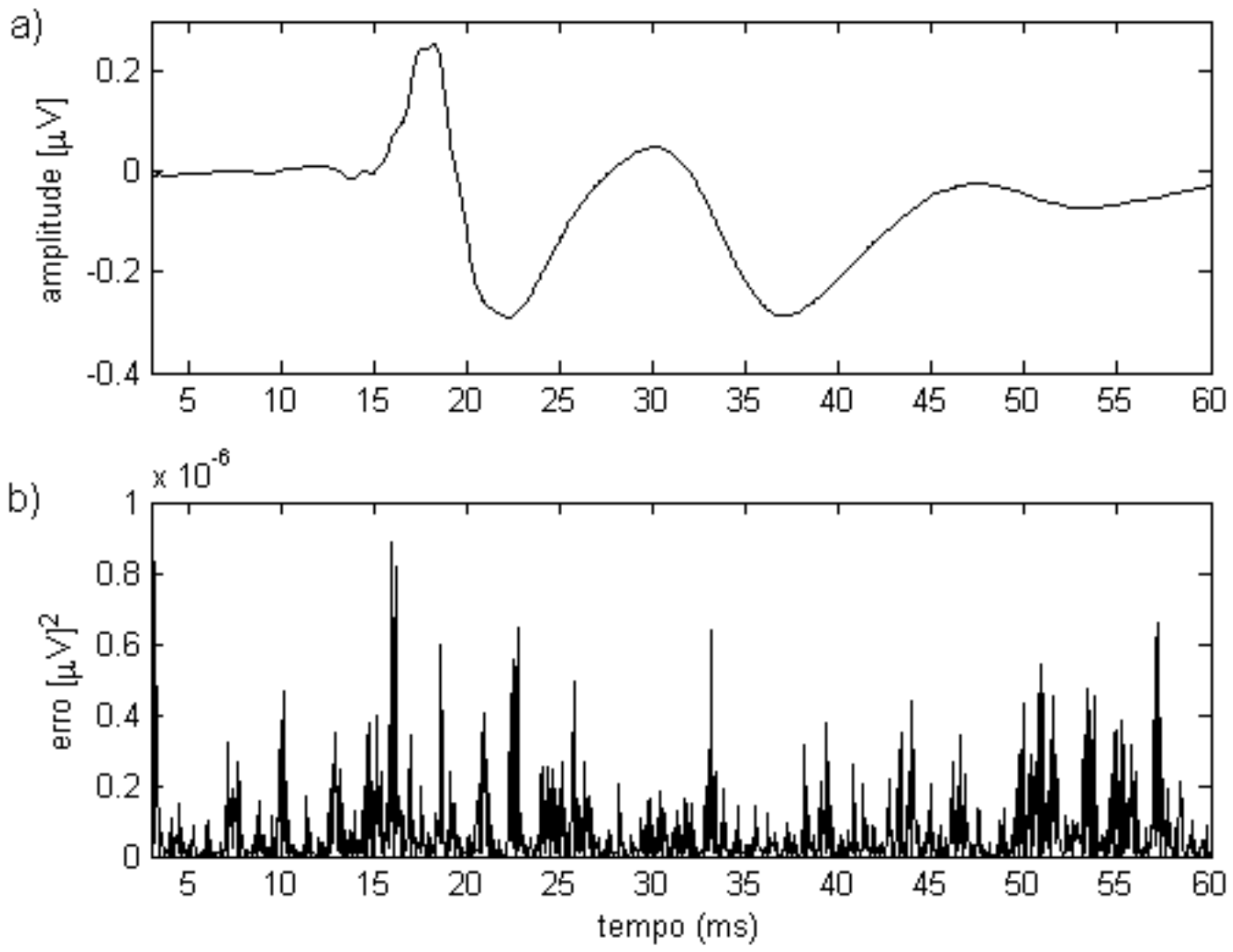

Figura 4.6: Contribuição de cada escala da DWT: a) PE padrão em linha pontilhada e reconstrução usando os coeficientes A6, D6, D5, D4 e D3 e b) erro quadrático. 
As mesmas características vistas na Figura 4.6 podem ser observadas no erro quadrático da Figura 4.7. O intervalo de tempo em torno de $20 \mathrm{~ms}$ não apresenta um erro maior que nos demais instantes. O aspecto aleatório do erro quadrático sugere que os coeficientes de detalhe da escala D1 não contêm informação relevante à reconstrução do potencial evocado.
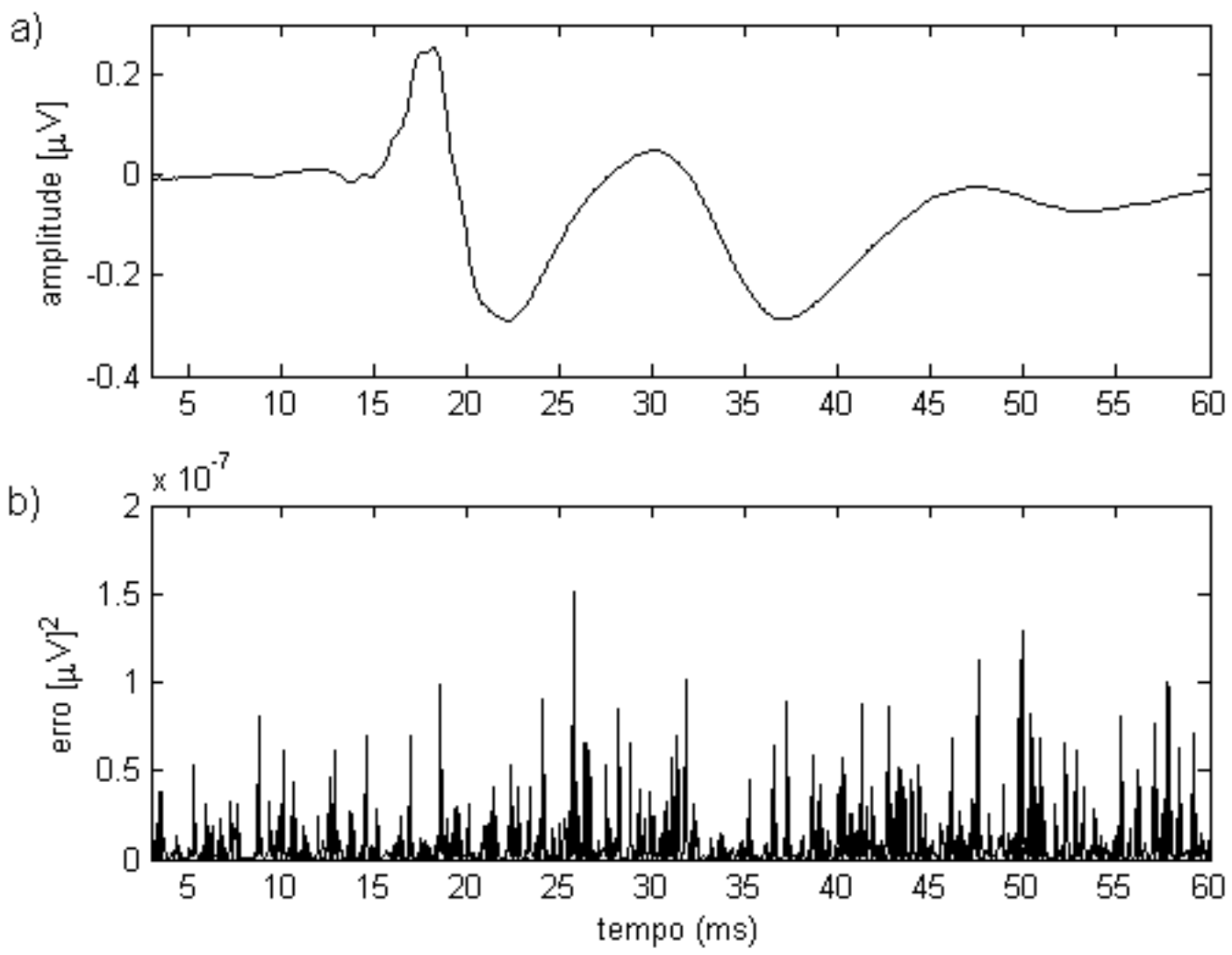

Figura 4.7: Contribuição de cada escala da DWT: a) PE padrão em linha pontilhada e reconstrução usando os coeficientes A6, D6, D5, D4, D3 e D2 e b) erro quadrático. 
Na Figura 4.8, o erro quadrático cai bruscamente em relação à Figura 4.7, indicando o final da reconstrução. Comparando os erros das duas figuras, vê-se que os coeficientes D1 modelam um sinal com características de ruído aleatório, assim como observado anteriormente nos coeficientes D2. Os erros quadráticos finais são muito pequenos e são causados por erros numéricos que se acumulam ao longo dos processos de decomposição e reconstrução. É importante lembrar que a precisão do Matlab ${ }^{\circledR}$ é de $2 \cdot 10^{-16}$, indicando que os valores de erro obtidos na Figura 4.8.b, da ordem de $10^{-24}$ equivalem a zero.
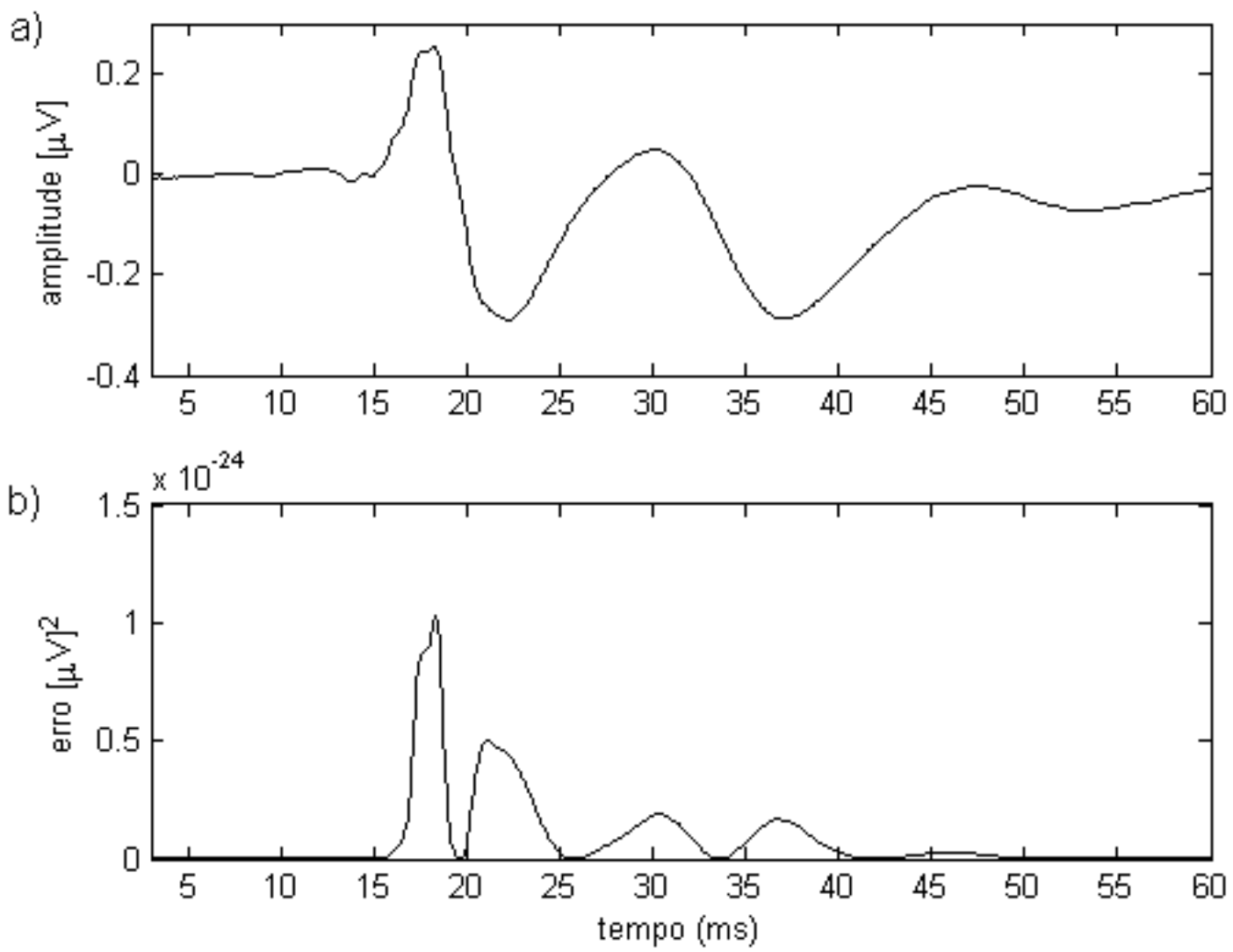

Figura 4.8: Contribuição de cada escala da DWT: a) PE padrão em linha pontilhada e reconstrução usando todos coeficientes e b) erro quadrático.

Nesta seção, viu-se como as diferentes escalas da DWT contribuem na representação do potencial evocado. Realizando a reconstrução a partir das freqüências baixas, observouse que os coeficientes de escalas menores alteravam o PE com contribuições de amplitude menor e de freqüência mais alta, representando as regiões de valores mais extremos dos picos. 


\subsubsection{Determinação das faixas de coeficientes relevantes}

Para determinar as faixas de coeficientes relevantes, os potenciais evocados padrão (média síncrona de 2000 respostas individuais) dos sujeitos 1 a 4 foram decompostos e calcularamse os valores quadráticos dos coeficientes da DWT. A média dos valores quadráticos dos quatro indivíduos foi utilizada na escolha de coeficientes da DWT para a reconstrução dos sinais. A Figura 4.9 ilustra a média dos valores quadráticos dos quatro indivíduos.

Semelhantemente à Figura 4.1, a ordem de grandeza aumenta com a escala. Além disso, nas escalas 4, 5 e 6, observa-se uma concentração dos maiores coeficientes de detalhe em faixas específicas. Essa concentração é menos acentuada na escala 3 e difícil de se delimitar nas escalas 1 e 2. A escolha dos coeficientes a serem usados foi baseada nos maiores valores quadráticos. Além disso, levou-se em consideração a contribuição de cada escala na reconstrução do potencial evocado, como foi visto no item 4.1.1. Os coeficientes foram escolhidos para fornecer boas estimativas dos potenciais evocados padrão. Dessa forma, todos coeficientes da aproximação de escala 6 foram utilizados na reconstrução, já que representam as freqüências mais baixas e constituem a base do sinal de potencial evocado. Para cada escala de detalhe foram considerados os $20 \%$ maiores valores quadráticos (ZHANG et al., 2004). Em seguida, uma faixa contígua de coeficientes foi escolhida com base nesses maiores valores quadráticos. A Figura 4.10 ilustra essas etapas. Os 20\% maiores valores quadráticos de cada escala foram representados por hastes e os demais valores foram zerados. As linhas pontilhadas verticais são os limites das faixas escolhidas em cada escala. No caso das escalas D3 e D6, foi escolhido um intervalo relativamente maior de coeficientes, que inclui coeficientes abaixo dos $20 \%$ maiores. Esses intervalos foram escolhidos heuristicamente e ajustados conforme os sinais recompostos.

Todos coeficientes de detalhe das escalas 1 e 2 foram descartados, pois as escalas não apresentavam concentrações dos maiores coeficientes em uma única faixa específica. Além disso, por representarem freqüências altas demais, nenhum dos coeficientes de detalhe das escalas 1 e 2 foi considerado na reconstrução das estimativas. 
a)

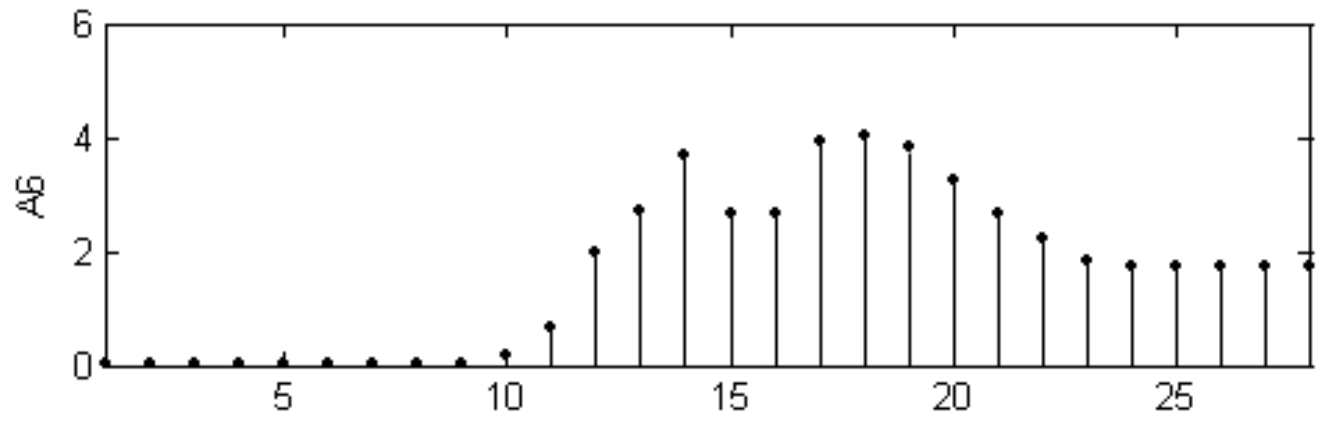

b)

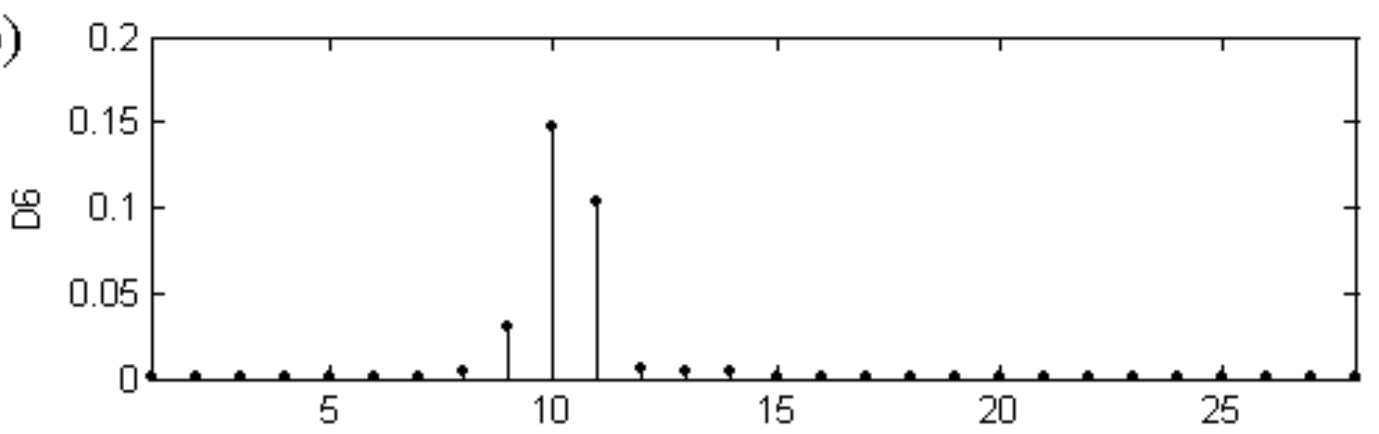

c) 0.0

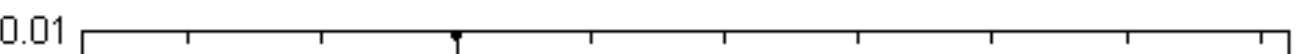

4

0.005

d)
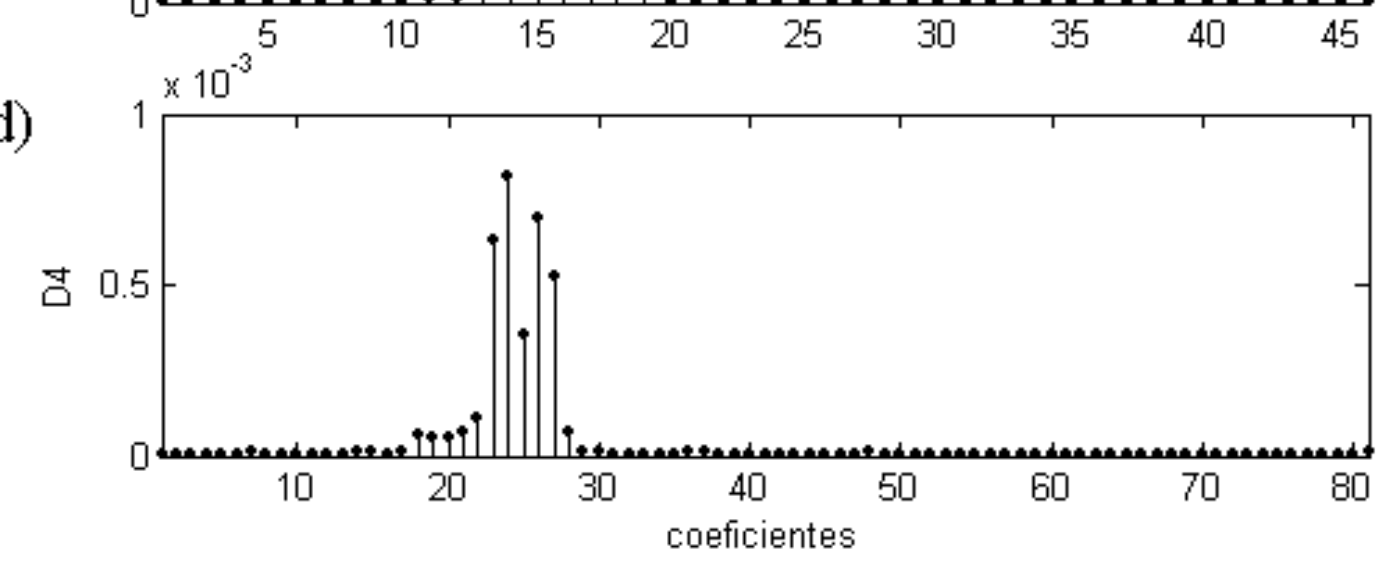

Figura 4.9: Média dos valores quadráticos dos coeficientes da TWD: a) aproximação de escala $6, \mathrm{~b}$ ) detalhe de escala $6, \mathrm{c}$ ) detalhe de escala $5, \mathrm{~d}$ ) detalhe de escala 4 . (continua) 

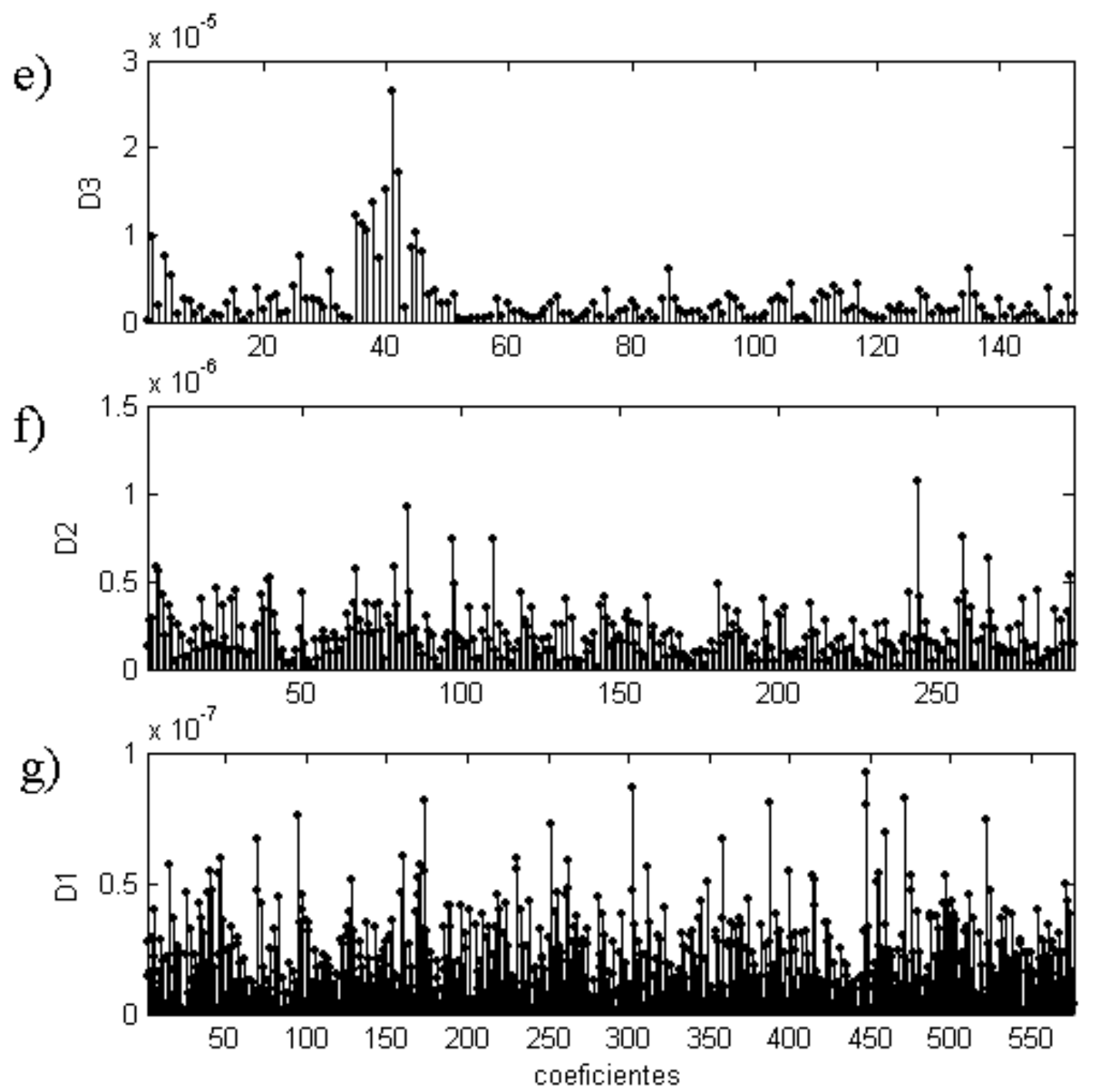

Figura 4.9: (continuação) e) detalhe de escala 3, f) detalhe de escala 2, g) detalhe de escala 1. 

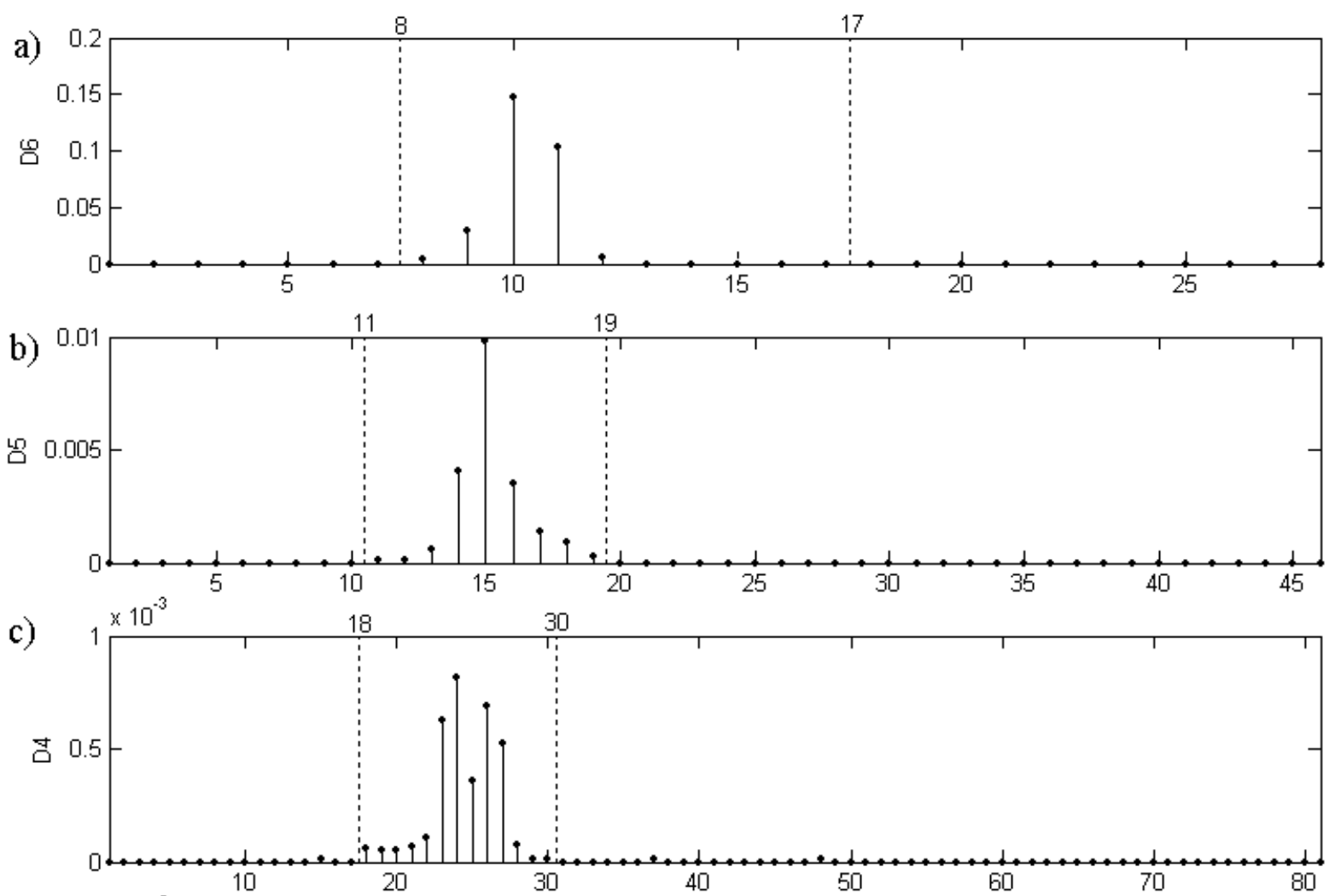

d)

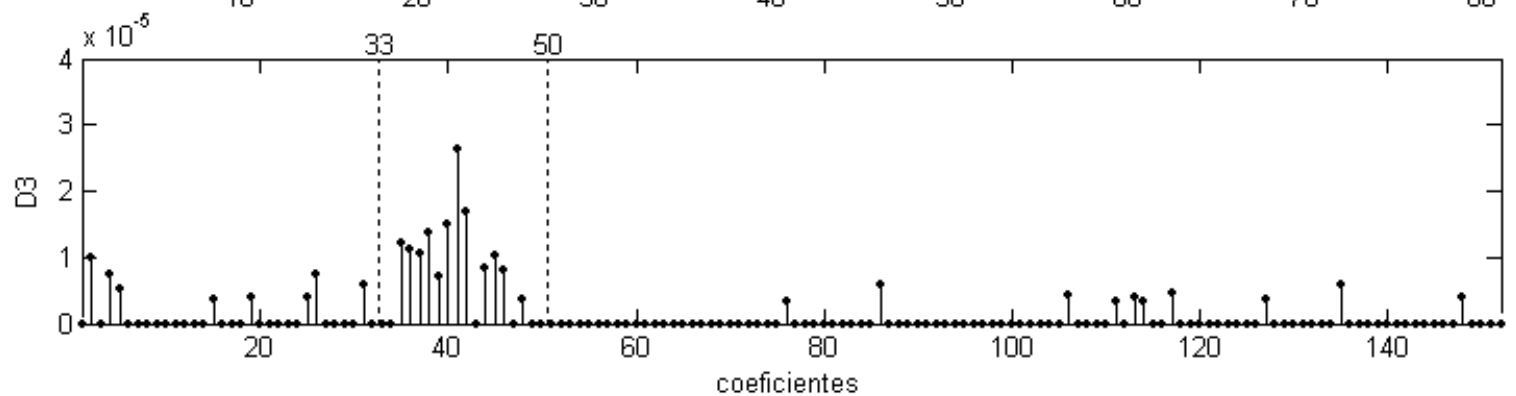

Figura 4.10: Média dos valores quadráticos dos coeficientes da TWD. Os $20 \%$ (ou $50 \%)$ maiores valores são representados por hastes. As faixas de coeficientes relevantes são delimitadas pelas linhas pontilhadas e os números dos coeficientes que limitam a faixa estão indicados na parte superior do gráfico. São representados os detalhes das escalas: a) 6, b) 5, c) 4 e d) 3 . 


\subsubsection{Determinação das porcentagens de coeficientes relevantes}

A estimativa usando ondaletas não utiliza todos os coeficientes dentro das faixas consideradas relevantes, mas somente aqueles que também estão dentre os de maior valor absoluto de sua escala. Zhang et al. (2004) estimaram potenciais evocados auditivos utilizando os $20 \%$ maiores coeficientes de cada escala que estivessem dentro das faixas escolhidas. No entanto, para os sinais usados neste trabalho, essa porcentagem não foi suficiente para fornecer boas estimativas. Por isso, partindo de $20 \%$, as porcentagens de cada escala foram alteradas procurando-se melhorar o sinal obtido. Essa busca resultou na manutenção de $20 \%$ para todas as escalas exceto a D6, que foi aumentada para 50\%. As Figuras 4.11.a a 4.14.a ilustram o potencial evocado padrão, em linha pontilhada, e a estimativa aplicando as faixas e as novas porcentagens, em linha contínua. Nas Figuras 4.11.b a 4.14.b, vê-se o erro quadrático, e nas Figuras 4.11.c a 4.14.c, está ilustrado o erro quadrático quando todos os coeficientes das faixas são usados (o que corresponde a 100\%).

Nas Figuras 4.11.c a 4.14.c, vê-se que os erros quadráticos são menores no trecho em torno de 20ms, que é onde se encontram os picos mais relevantes do potencial evocado. Além disso, comparando essas figuras com as Figuras 4.11.b a 4.14.b, nota-se que a diferença no erro é muito pequena, indicando que as porcentagens escolhidas para cada escala contêm os coeficientes relevantes para representar o potencial evocado. Isso também pode ser visto nas Figuras 4.11.a a 4.14.a, em que as diferenças visuais entre os sinais é muito pequena. 
a)

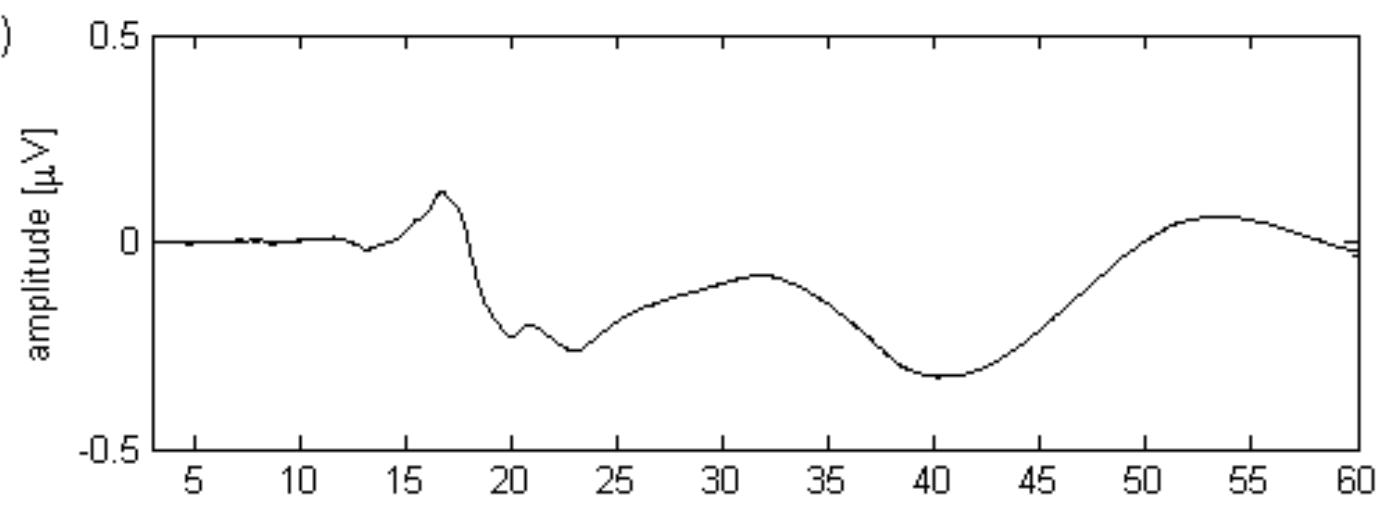

b)

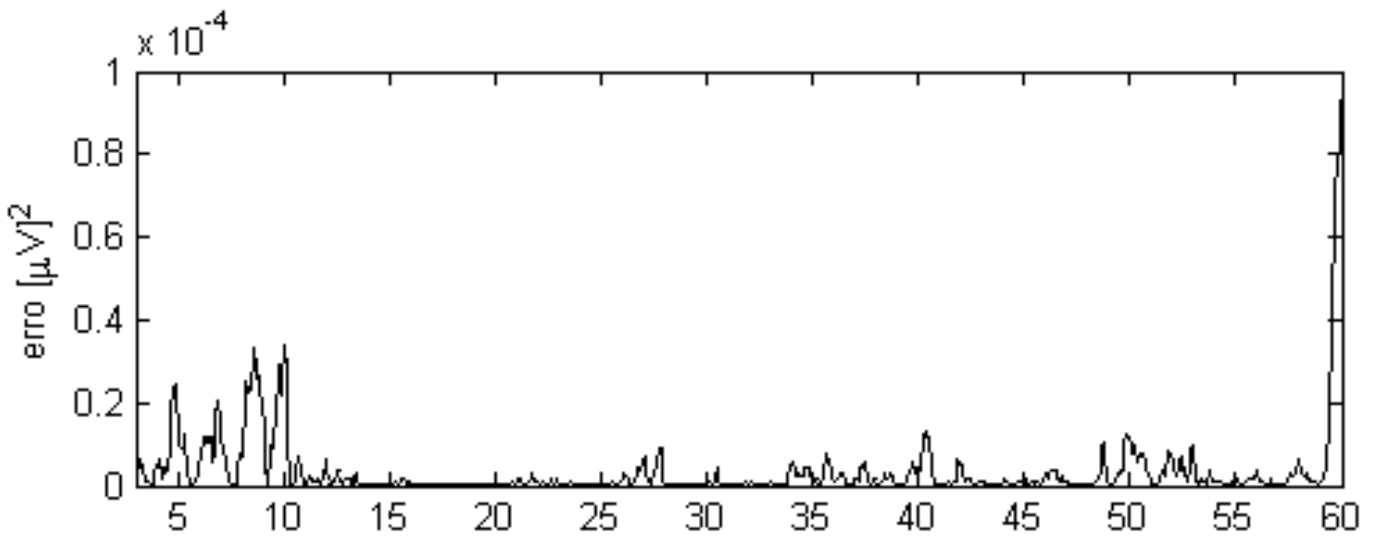

c)

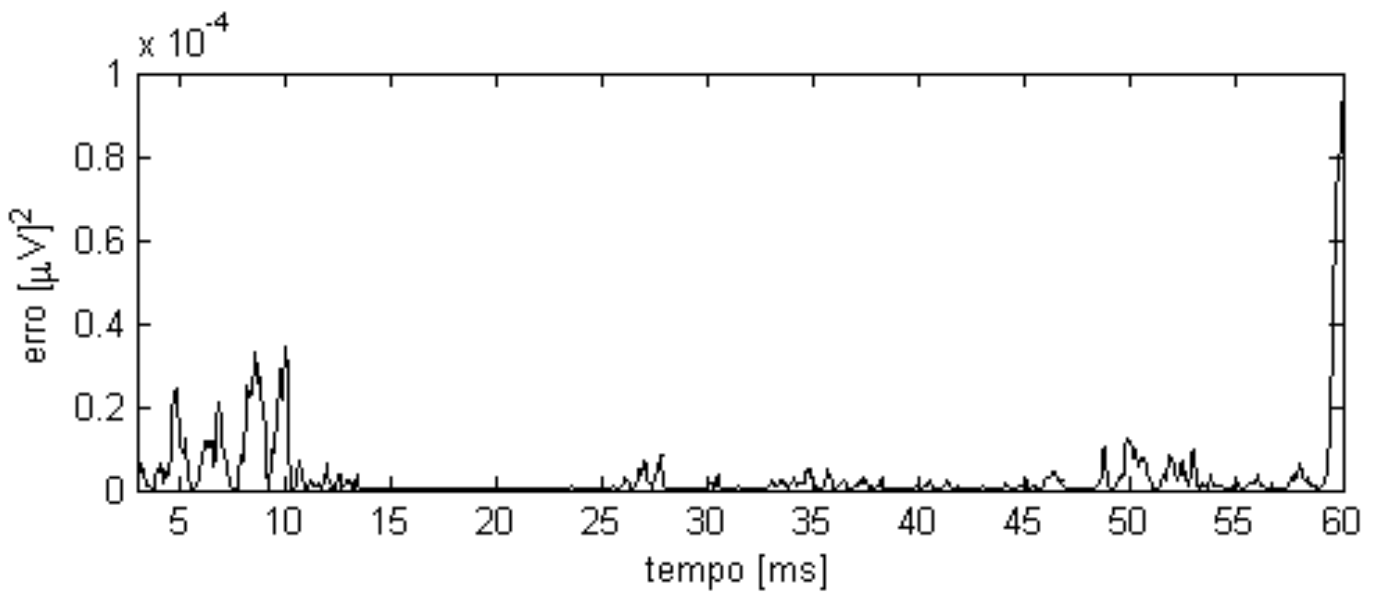

Figura 4.11: Estimativa do potencial evocado padrão do sujeito 1 usando ondaletas:

a) PE padrão (linha pontilhada) e estimativa (linha contínua), b) erro quadrático usando todos os coeficientes das faixas relevantes que também estejam entre os $20 \%$ maiores e c) erro quadrático usando todos os coeficientes das faixas relevantes. 
a)

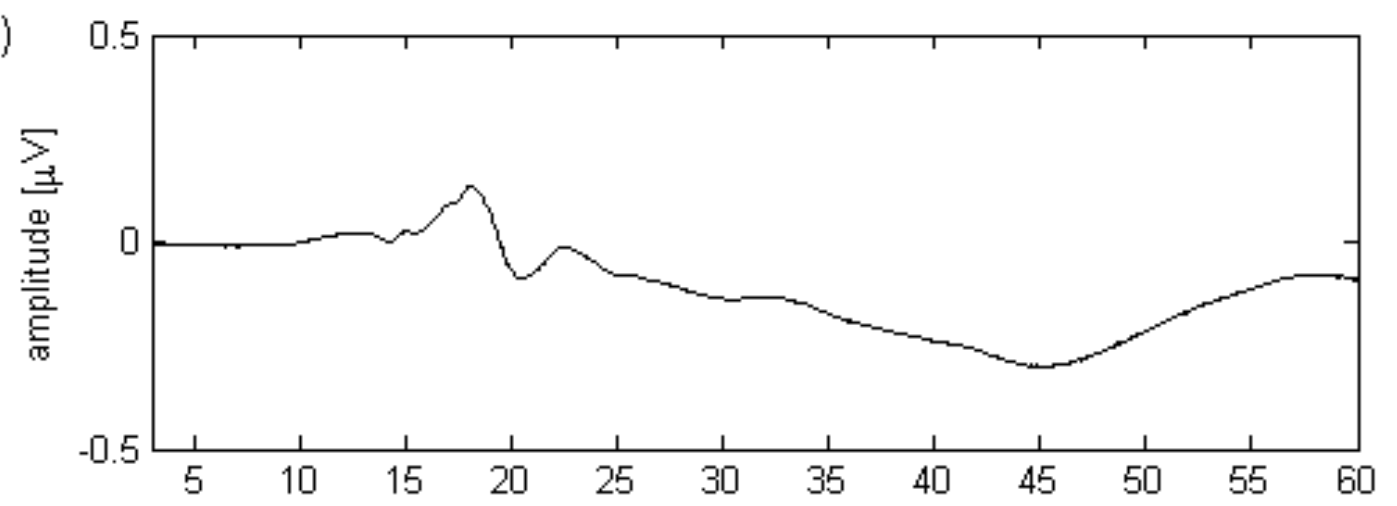

b)

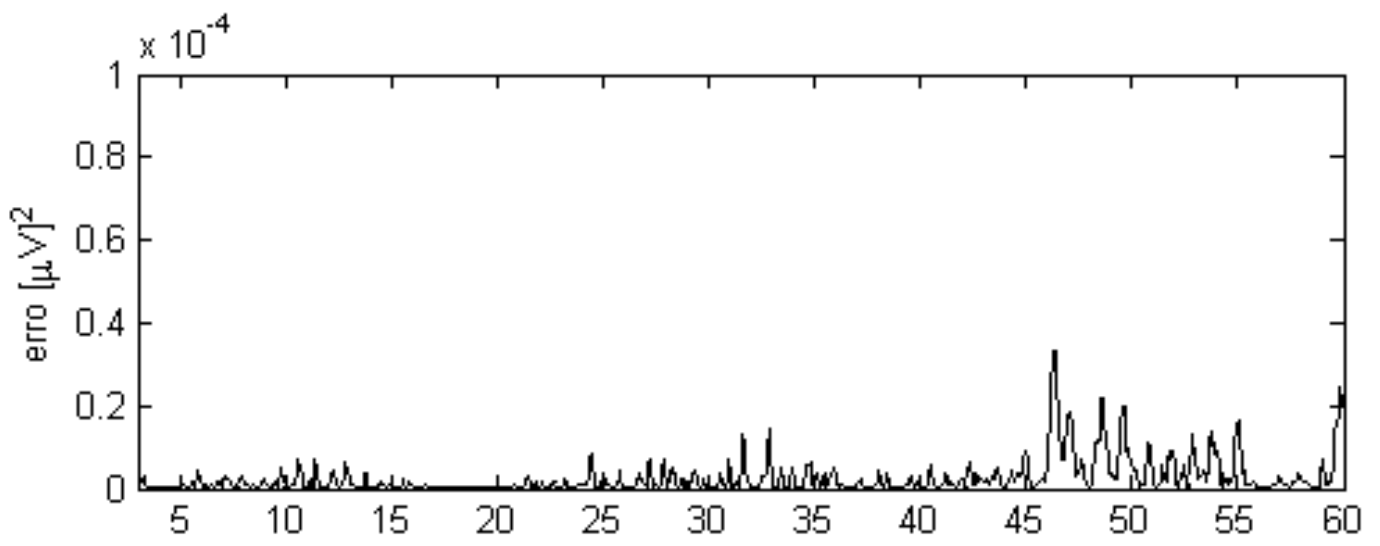

c)

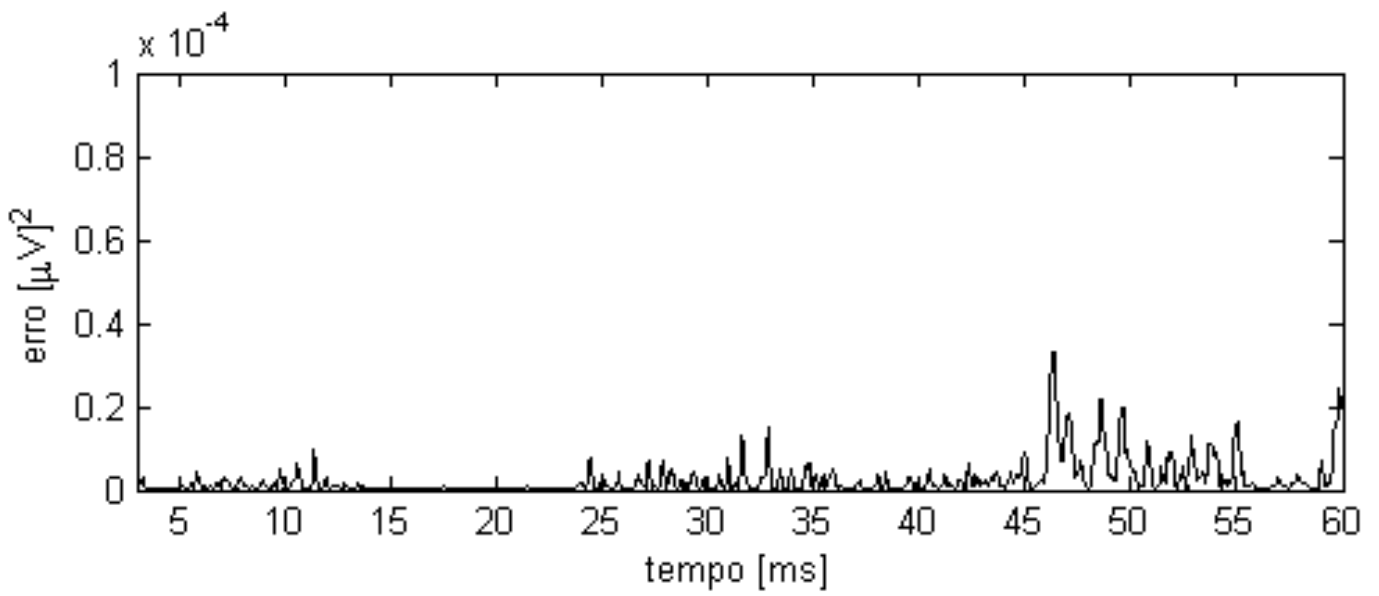

Figura 4.12: Estimativa do potencial evocado padrão do sujeito 2 usando ondaletas: a) PE padrão (linha tracejada) e estimativa (linha contínua), b) erro quadrático usando todos os coeficientes das faixas relevantes que também estejam entre os $20 \%$ (ou 50\%) maiores e c) erro quadrático usando todos os coeficientes das faixas relevantes. 
a)

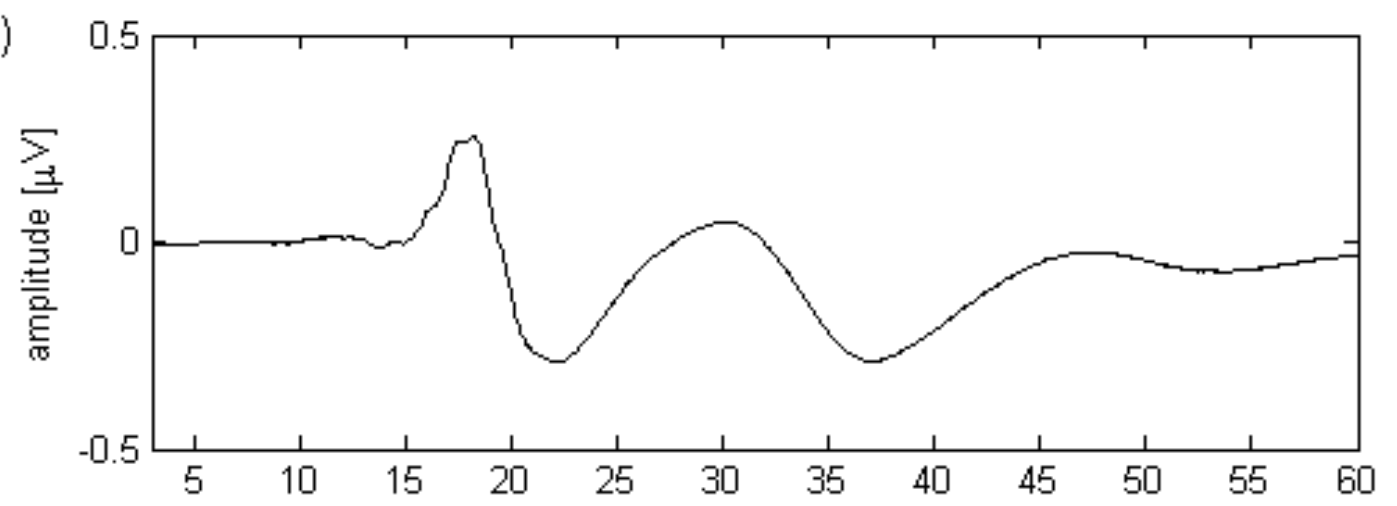

b)

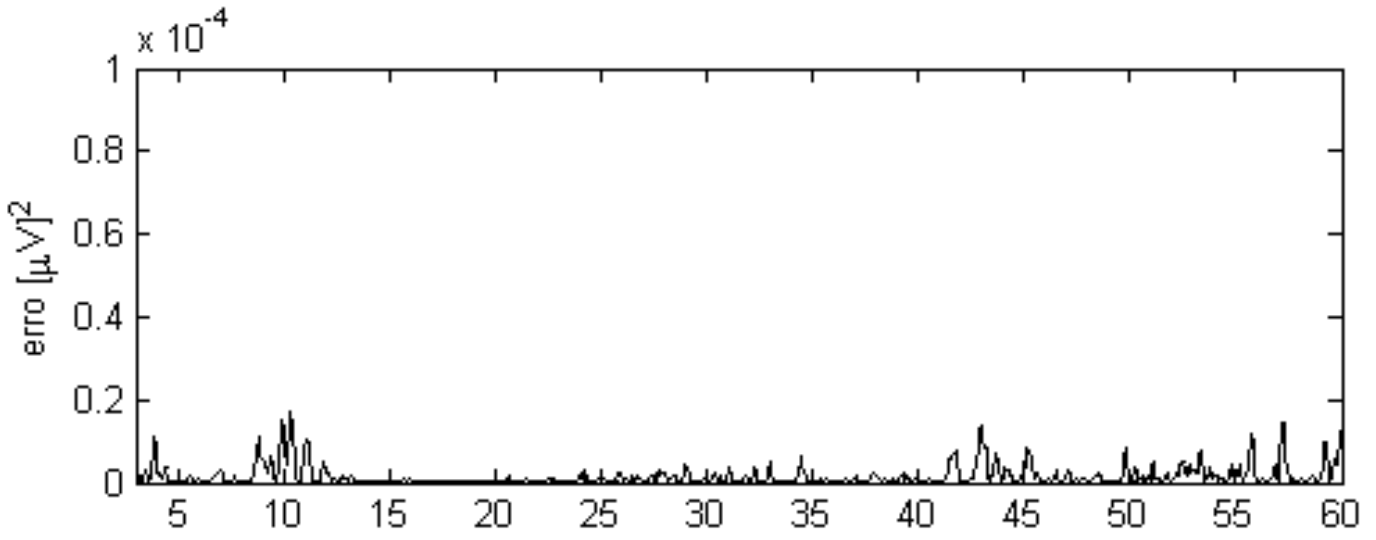

c)

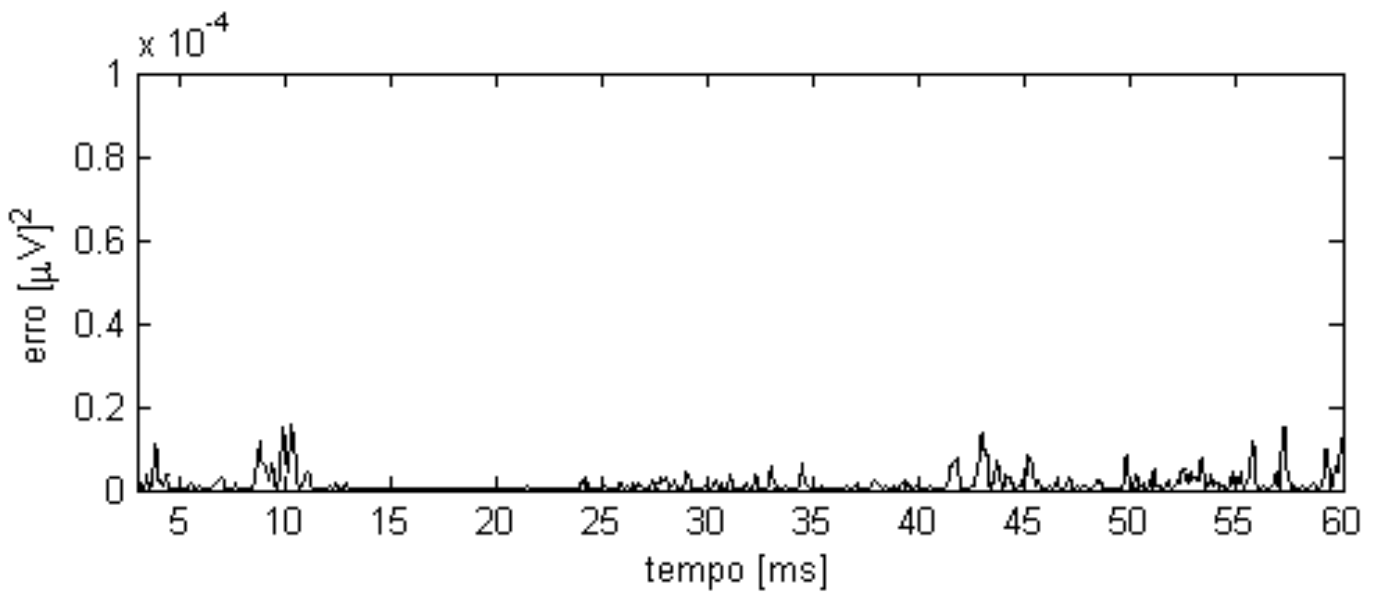

Figura 4.13: Estimativa do potencial evocado padrão do sujeito 3 usando ondaletas: a) PE padrão (linha tracejada) e estimativa (linha contínua), b) erro quadrático usando todos os coeficientes das faixas relevantes que também estejam entre os $20 \%$ (ou 50\%) maiores e c) erro quadrático usando todos os coeficientes das faixas relevantes. 
a)

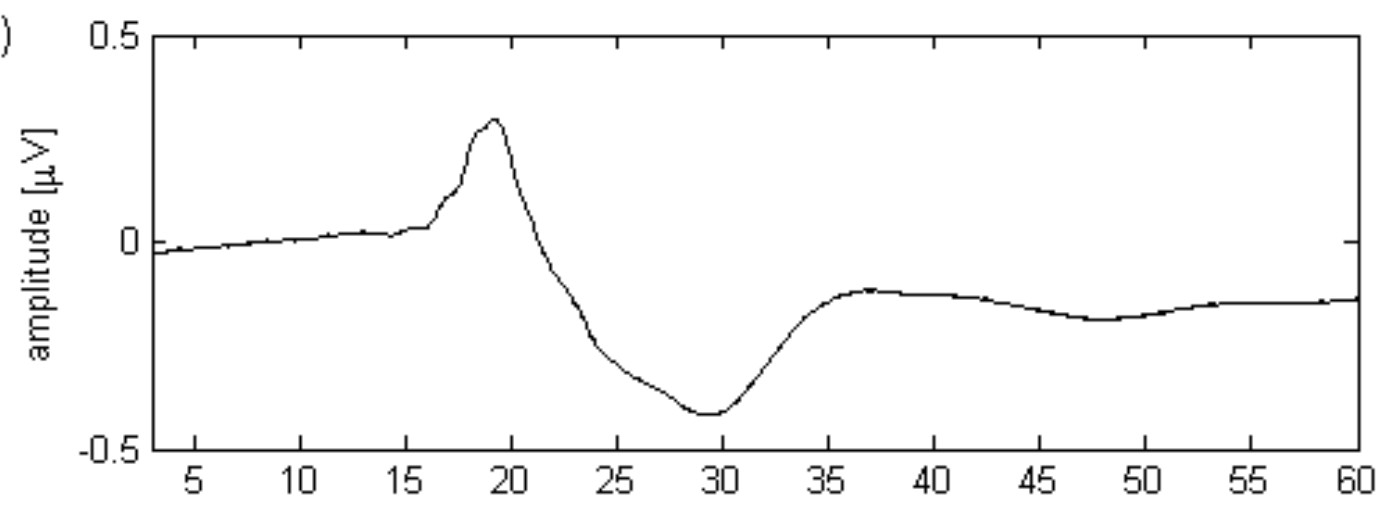

b)

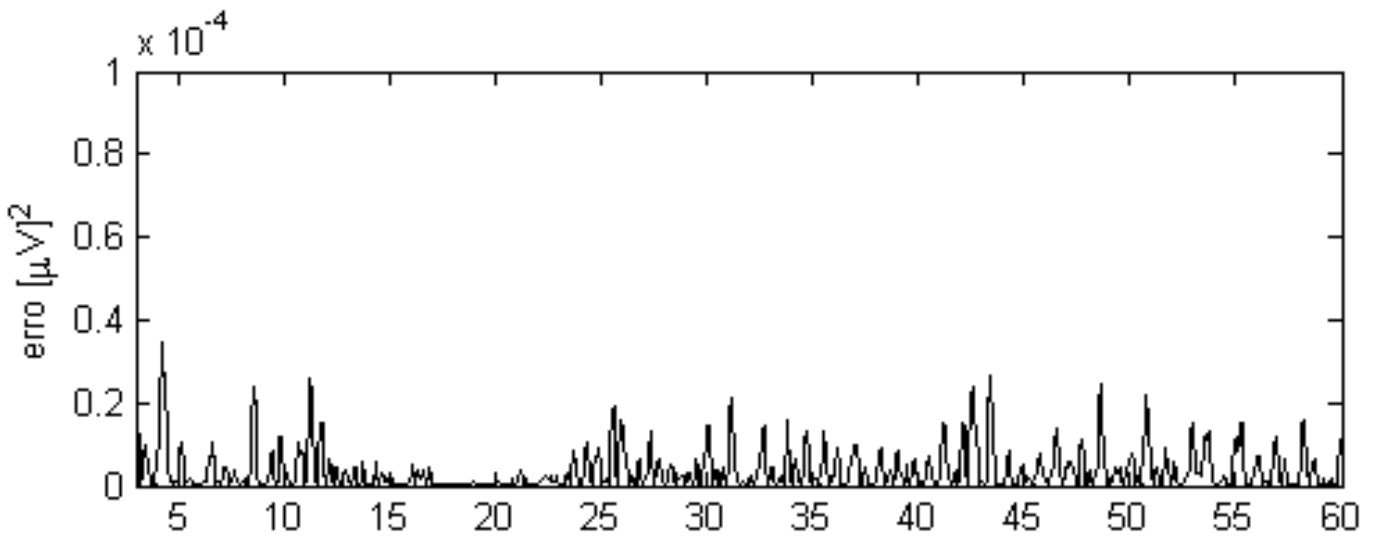

c)

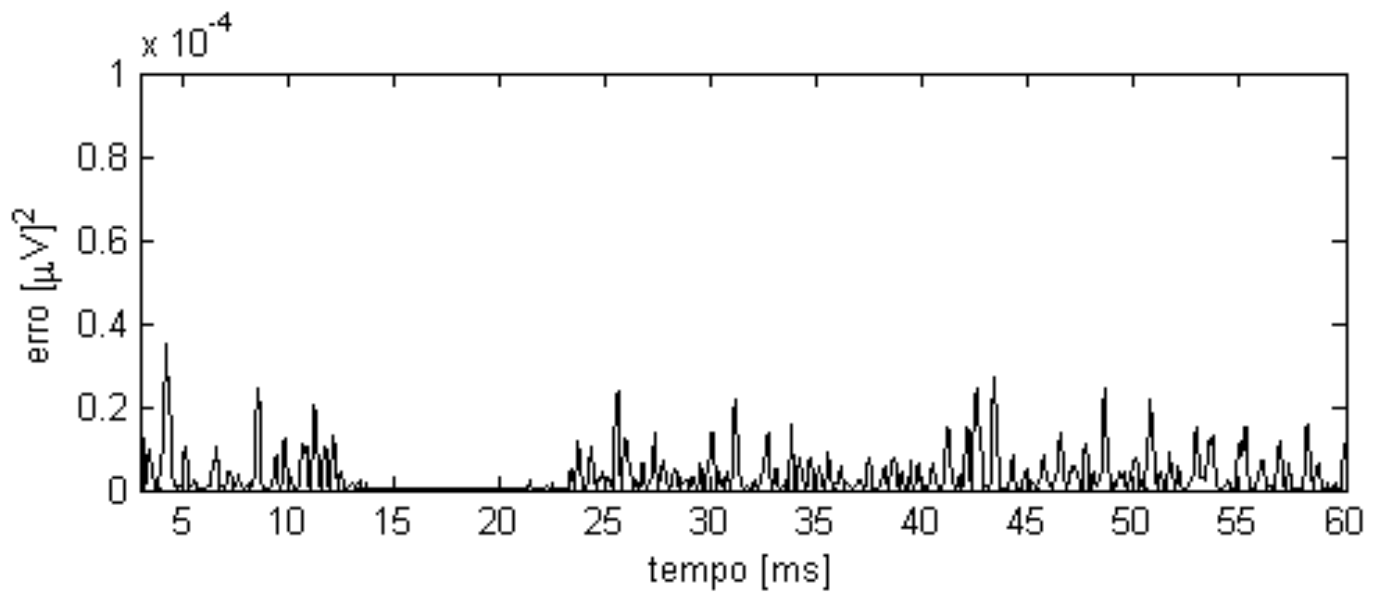

Figura 4.14: Estimativa do potencial evocado padrão do sujeito 4 uusando ondaletas: a) PE padrão (linha tracejada) e estimativa (linha contínua), b) erro quadrático usando todos os coeficientes das faixas relevantes que também estejam entre os $20 \%$ (ou 50\%) maiores e c) erro quadrático usando todos os coeficientes das faixas relevantes. 


\subsection{Outras ondaletas-mãe}

A técnica de estimativa usando a DWT foi testada com outras ondaletas-mãe. Foram testadas ondaletas das famílias mais utilizadas na literatura: daubechies, symlet e coiflet (WILSON, 2004; SCHELLER et al., 2006).

Dessas famílias, foram testadas as ondaletas daubechies 6 , symlet 6 e coiflet 2 pois elas correspondem a filtros de comprimento 12, igual à implementação da ondaleta biortogonal 5.5 no Matlab ${ }^{\circledR}$. Desse modo, obteve-se o mesmo número de coeficientes na decomposição em 6 escalas, e as faixas determinadas na seção 4.1.2 foram mantidas para todas as ondaletas.

Além disso, foi estudada a influência da ordem das ondaletas dessas famílias. Para isso, foram utilizadas as ondaletas daubechies 3 , symlet 3 e coiflet 1 , que correspondem a filtros de comprimento 6 . As faixas de coeficientes relevantes foram baseadas nas faixas determinadas anteriormente, para a ondaleta biortogonal 5.5. Essas faixas foram determinadas utilizando a proporção entre o número de coeficientes de uma dessas ondaletas numa certa escala e o número de coeficientes da biortogonal 5.5 nessa mesma escala.

Para excluir o efeito de determinado conjunto de respostas individuais no sinal de referência, o PE padrão foi considerado igual à média das 1000 primeiras respostas do sujeito. As outras 1000 respostas foram divididas em 10 conjuntos de 100 e processadas. A Tabela 4.1 apresenta os erros quadráticos normalizados, para o sujeito 3 (resultados semelhantes foram obtidos para todos os sujeitos). Nota-se que, em cada linha da Tabela 4.1, os erros obtidos com as diversas ondaletas são muito próximos. No entanto, esse valor pode variar consideravelmente de uma linha a outra, dependendo da média síncrona utilizada. Os erros médios das estimativas obtidas com as ondaletas de ordem menor (db3, sym3 e coif1) são maiores que os erros das ondaletas da mesma família de ordem maior (db6, sym6 e coif2). Além disso, vê-se que, na média, a ondaleta biortogonal 5.5 fornece um erro menor que a coiflet 2 , que é inferior ao erro da symlet 6 , que, por sua vez, é menor que o erro da daubechies 6 . Também se nota que os desvios-padrão são tais 
que todos os erros médios são equivalentes.

Tabela 4.1: Erros quadráticos normalizados das estimativas de médias de 100 respostas individuais do sujeito 3 obtidas pelas ondaletas biortogonal 5.5 (bior5.5), daubechies 6 (db6), symlet 6 (sym6), coiflet 2 (coif2), daubechies 3 (db3), symlet 3 (sym3) e coiflet 1 (coif1), em porcentagem.

\begin{tabular}{cccccccc} 
& \multicolumn{3}{c}{ Filtros de comprimento 12} & \multicolumn{3}{c}{ Filtros de comprimento 6} \\
\cline { 2 - 7 } Conjunto & bior5.5 & db6 & sym6 & coif2 & db3 & sym3 & coif1 \\
\hline 1 & 2,227 & 2,227 & 2,219 & 2,221 & 2,247 & 2,247 & 2,303 \\
2 & 8,922 & 8,945 & 8,926 & 8,922 & 8,939 & 8,939 & 8,977 \\
3 & 12,566 & 12,544 & 12,555 & 12,562 & 12,596 & 12,596 & 12,637 \\
4 & 4,930 & 4,908 & 4,935 & 4,935 & 4,964 & 4,964 & 5,041 \\
5 & 10,704 & 10,734 & 10,718 & 10,713 & 10,726 & 10,726 & 10,786 \\
6 & 4,831 & 4,841 & 4,837 & 4,844 & 4,851 & 4,851 & 4,902 \\
7 & 3,342 & 3,368 & 3,348 & 3,342 & 3,355 & 3,355 & 3,408 \\
8 & 2,523 & 2,536 & 2,526 & 2,532 & 2,528 & 2,528 & 2,577 \\
9 & 3,965 & 3,982 & 3,978 & 3,971 & 3,987 & 3,987 & 4,041 \\
10 & 0,929 & 0,946 & 0,938 & 0,945 & 0,954 & 0,954 & 1,002 \\
\hline média & 5,494 & 5,503 & 5,498 & 5,499 & 5,515 & 5,515 & 5,567 \\
desvio-padrão & 3,901 & 3,898 & 3,900 & 3,899 & 3,904 & 3,904 & 3,901 \\
\hline
\end{tabular}

Os resultados da tabela confirmam a escolha da ondaleta biortogonal 5.5, já que apresenta um erro médio menor. Além disso, ela é mais adequada à estimação de potenciais evocados devido à sua fase linear.

A Figura 4.15 apresenta um exemplo de resultado obtido, com o PE padrão e as estimativas para o primeiro conjunto de 100 respostas desse sujeito. Nessa figura, vê-se que as estimativas são parecidas com o PE padrão. Além disso, a média síncrona apresenta mais ruído de alta freqüência que as estimativas por ondaletas. Também se pode notar que as ondaletas de ordem menor, como a coiflet 1 , fornecem estimativas menos alisadas que as ondaletas de ordem maior. 


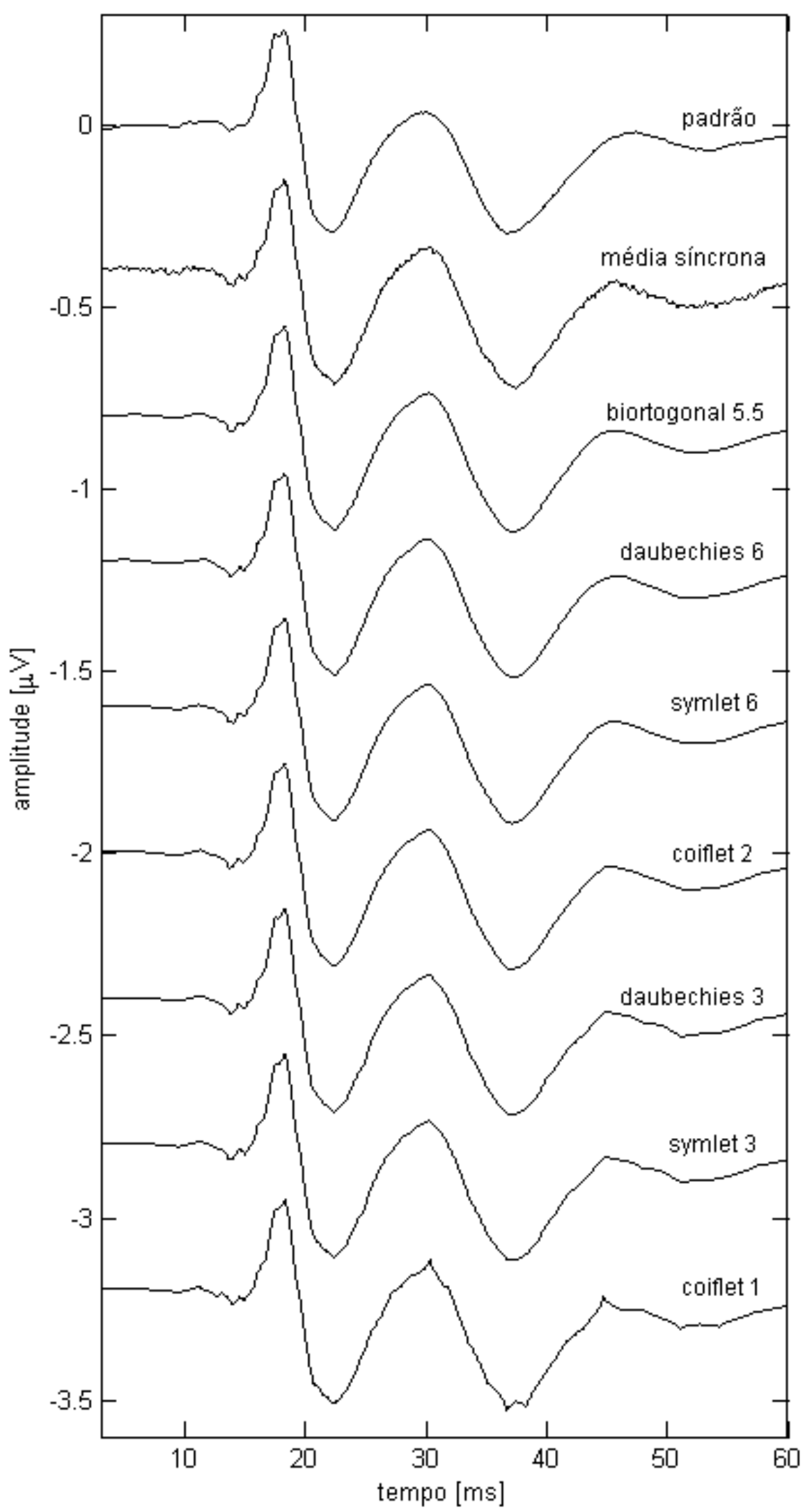

Figura 4.15: PE padrão, média síncrona de 100 respostas e estimativas por ondaletas utilizando as ondaletas-mãe biortogonal 5.5, daubechies 6 , symlet 6 , coiflet 2 , daubechies

3 , symlet 3 e coiflet 1 . As estimativas estão deslocadas de $0,4 \mu V$ para facilitar a visualização e foram calculadas para o primeiro conjunto de 100 respostas do sujeito 3. 


\subsection{Sinais experimentais}

A Figura 4.16 ilustra os sinais dos sujeitos 5 a 13, usados para a aplicação da metodologia. As médias das mil primeiras respostas individuais são representadas em linha contínua e as médias das últimas mil respostas, pela linha pontilhada. 

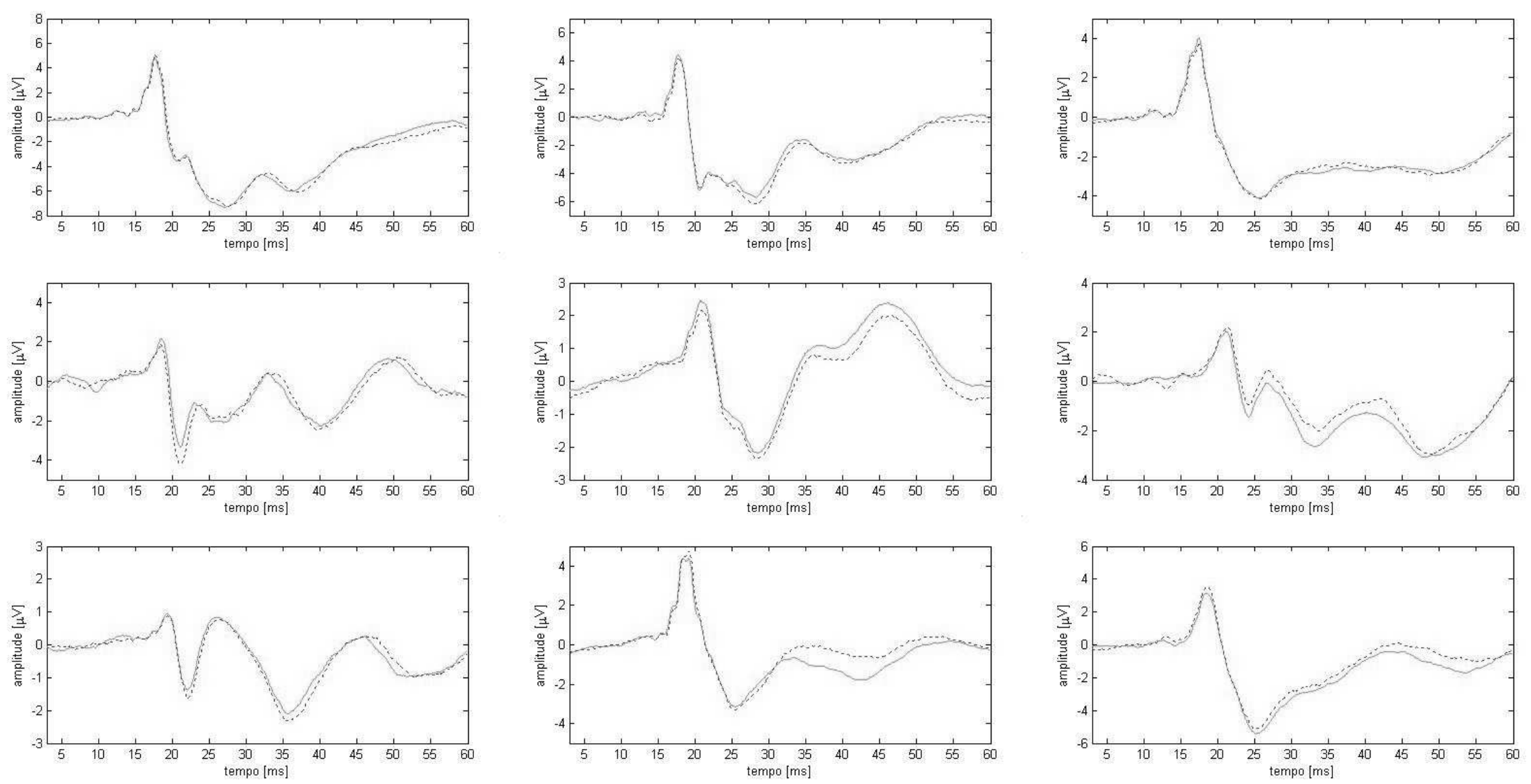

Figura 4.16: Médias das mil primeiras (linha contínua) e mil últimas (linha pontilhada) respostas inviduais, para os sujeitos a) 5, b) 6, c) 7, d) 8, e) 9, f) 10, g) 11, h) 12 e i) 13 . 
Nota-se que, de forma geral, as duas médias são parecidas para cada sujeito, validando a utilização desses sinais para a aplicação da metodologia. A média das mil primeiras respostas individuais (linha contínua) foi considerada o potencial evocado padrão do sujeito, e as mil respostas restantes foram divididas em 10 grupos de 100 respostas e, em seguida, utilizadas no processamento.

\subsection{Aplicação da metodologia}

Para cada conjunto de 100 respostas individuais, foram obtidas três estimativas: pela média síncrona, pelos filtros e pelas ondaletas, totalizando 10 grupos de 3 estimativas para cada sujeito.

A Tabela 4.2 apresenta os erros quadráticos normalizados, em porcentagem, para cada uma das estimativas. Nessa tabela, nota-se que, para cada um dos sujeitos, os erros das estimativas para um mesmo conjunto de respostas individuais (cada coluna da tabela) são próximos. Além disso, os erros podem variar bastante dependendo do conjunto de respostas estimado. As Figuras 4.17 a 4.25 apresentam o PE padrão e as três estimativas obtidas a partir de cada conjunto de 100 respostas, para os sujeitos 5 a 13. Elas também confirmam que as estimativas por ondaletas e por filtros dependem muito da própria média síncrona do conjunto. 
Tabela 4.2: Erros quadráticos normalizados percentuais das três estimativas para os conjuntos de 100 respostas individuais dos sujeitos 5 a 13.

Conjunto de 100 respostas

\begin{tabular}{|c|c|c|c|c|c|c|c|c|c|c|c|}
\hline ajeito & Técnica & 1 & 2 & 3 & 4 & 5 & 6 & 7 & 8 & 9 & 10 \\
\hline \multirow{3}{*}{5} & MS & 12,26 & 3,28 & 3,89 & 9,48 & 3,55 & 3,51 & 1,49 & 5,03 & 10,64 & 2,96 \\
\hline & $\mathrm{FC}$ & 12,22 & 3,26 & 3,86 & 9,32 & 3,42 & 3,41 & 1,45 & 4,99 & 10,45 & 2,94 \\
\hline & WT & 12,13 & 3,19 & 3,84 & 9,33 & 3,41 & 3,35 & 1,28 & 4,86 & 10,34 & 2,76 \\
\hline \multirow{3}{*}{6} & MS & 2,51 & 4,41 & 5,71 & 8,15 & 1,60 & 3,86 & 4,79 & 6,59 & 15,74 & 3,28 \\
\hline & $\mathrm{FC}$ & 2,41 & 4,29 & 5,66 & 8,05 & 1,54 & 3,66 & 4,77 & 6,34 & 15,64 & 3,16 \\
\hline & WT & 2,07 & 4,08 & 5,41 & 7,82 & 1,45 & 2,76 & 4,63 & 6,02 & 15,69 & 3,13 \\
\hline \multirow{3}{*}{7} & MS & 1,93 & 6,78 & 3,54 & 2,59 & 6,38 & 3,87 & 4,66 & 7,66 & 5,53 & 3,98 \\
\hline & $\mathrm{FC}$ & 1,86 & 6,76 & 3,53 & 2,55 & 6,35 & 3,82 & 4,63 & 7,62 & 5,48 & 3,96 \\
\hline & WT & 1,70 & 6,72 & 3,50 & 2,52 & 6,26 & 3,82 & 4,62 & 7,58 & 5,40 & 3,82 \\
\hline \multirow{3}{*}{8} & MS & 41,30 & 27,62 & 16,86 & 45,60 & 56,41 & 39,93 & 39,21 & 38,94 & 109,78 & 97,59 \\
\hline & $\mathrm{FC}$ & 38,69 & 27,02 & 16,40 & 44,94 & 54,93 & 38,42 & 37,75 & 36,65 & 105,24 & 94,84 \\
\hline & WT & 31,89 & 27,38 & 15,41 & 45,30 & 54,16 & 36,68 & 35,90 & 35,07 & 99,91 & 92,78 \\
\hline \multirow{3}{*}{9} & $\mathrm{MS}$ & 14,66 & 84,50 & 12,88 & 5,04 & 27,75 & 21,85 & 10,94 & 6,18 & 15,21 & 59,84 \\
\hline & $\mathrm{FC}$ & 14,01 & 84,29 & 12,78 & 4,97 & 27,53 & 21,61 & 10,82 & 6,05 & 15,09 & 59,64 \\
\hline & WT & 13,57 & 84,27 & 12,64 & 4,77 & 27,60 & 21,54 & 10,61 & 6,01 & 15,05 & 59,58 \\
\hline \multirow{3}{*}{10} & MS & 34,33 & 53,53 & 19,87 & 10,46 & 14,25 & 17,71 & 32,06 & 19,15 & 37,83 & 42,74 \\
\hline & $\mathrm{FC}$ & 33,79 & 52,98 & 19,54 & 10,22 & 14,04 & 17,53 & 32,04 & 19,12 & 37,74 & 42,61 \\
\hline & WT & 32,59 & 51,90 & 18,30 & 10,17 & 13,59 & 17,55 & 31,82 & 19,15 & 37,87 & 42,70 \\
\hline \multirow{3}{*}{11} & MS & 81,05 & 31,03 & 15,01 & 36,35 & 46,26 & 21,75 & 22,42 & 10,73 & 14,32 & 39,10 \\
\hline & $\mathrm{FC}$ & 80,31 & 30,50 & 14,69 & 35,88 & 45,54 & 21,10 & 22,02 & 10,34 & 13,86 & 38,23 \\
\hline & WT & 79,56 & 30,03 & 14,68 & 36,10 & 45,54 & 20,75 & 20,89 & 10,11 & 13,95 & 37,78 \\
\hline \multirow{3}{*}{12} & MS & 26,18 & 7,26 & 4,33 & 34,82 & 21,24 & 13,59 & 15,47 & 63,34 & 53,71 & 35,27 \\
\hline & $\mathrm{FC}$ & 25,99 & 7,12 & 4,23 & 34,65 & 21,10 & 13,41 & 15,27 & 63,11 & 53,31 & 35,07 \\
\hline & WT & 25,84 & 7,08 & 4,20 & 34,45 & 21,05 & 13,33 & 15,16 & 63,21 & 53,21 & 35,19 \\
\hline \multirow{3}{*}{13} & MS & 3,49 & 21,87 & 13,69 & 4,45 & 3,05 & 5,01 & 6,10 & 17,15 & 8,66 & 5,00 \\
\hline & $\mathrm{FC}$ & 3,29 & 21,61 & 13,45 & 4,43 & 3,02 & 4,87 & 5,99 & 16,87 & 8,54 & 4,88 \\
\hline & WT & 2,89 & 21,55 & 12,97 & 4,34 & 2,89 & 4,83 & 5,92 & 16,41 & 8,53 & 4,73 \\
\hline
\end{tabular}



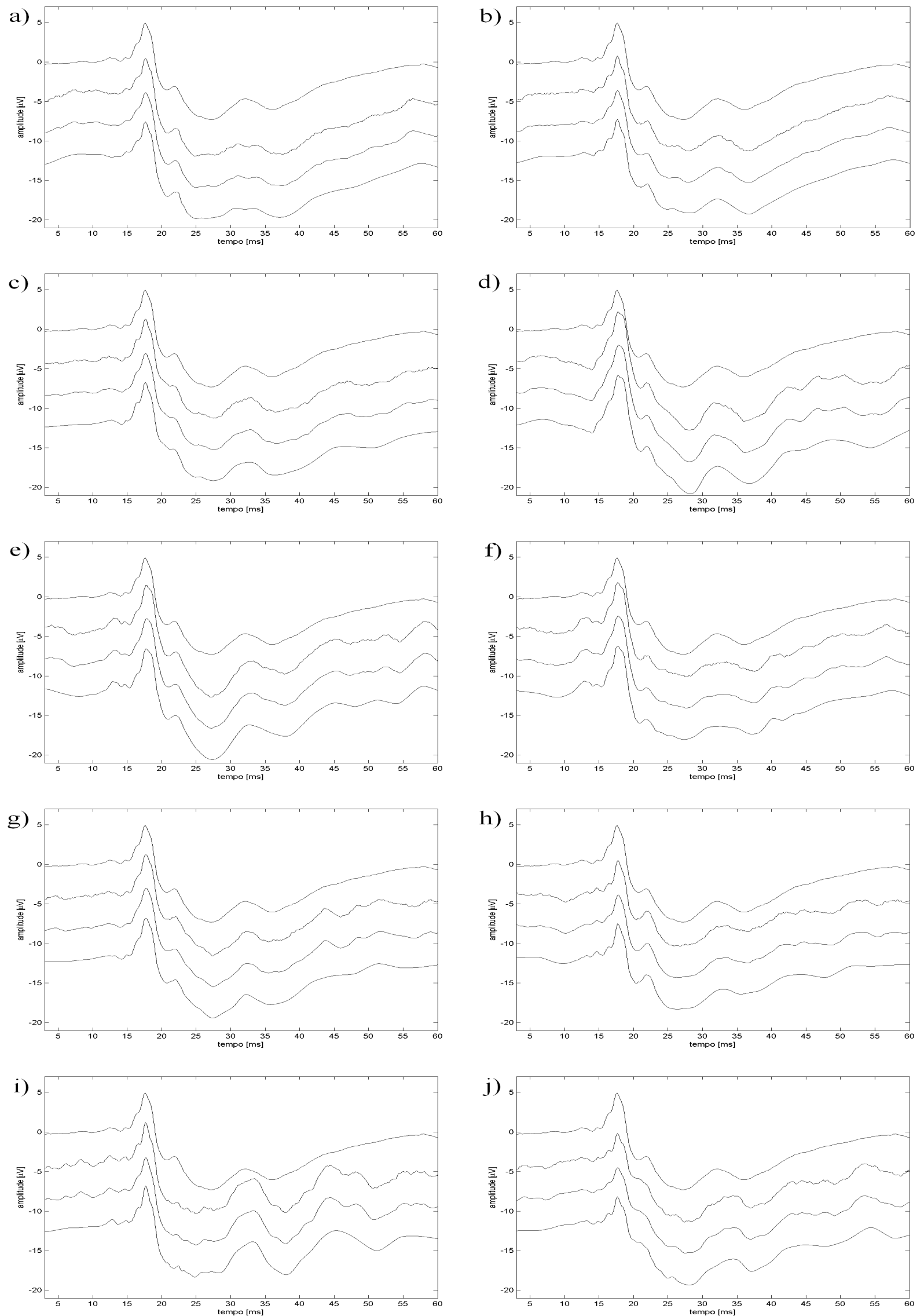

Figura 4.17: PE padrão e estimativas obtidas usando média síncrona, filtros e ondaletas (de cima para baixo, deslocadas de $4 \mu V$ ) para os conjuntos a) 1, b) 2, c) 3 , d) 4 , e) 5 , f) 6 , g) 7 , h) 8 , i) 9 e j) 10 do sujeito 5 . 

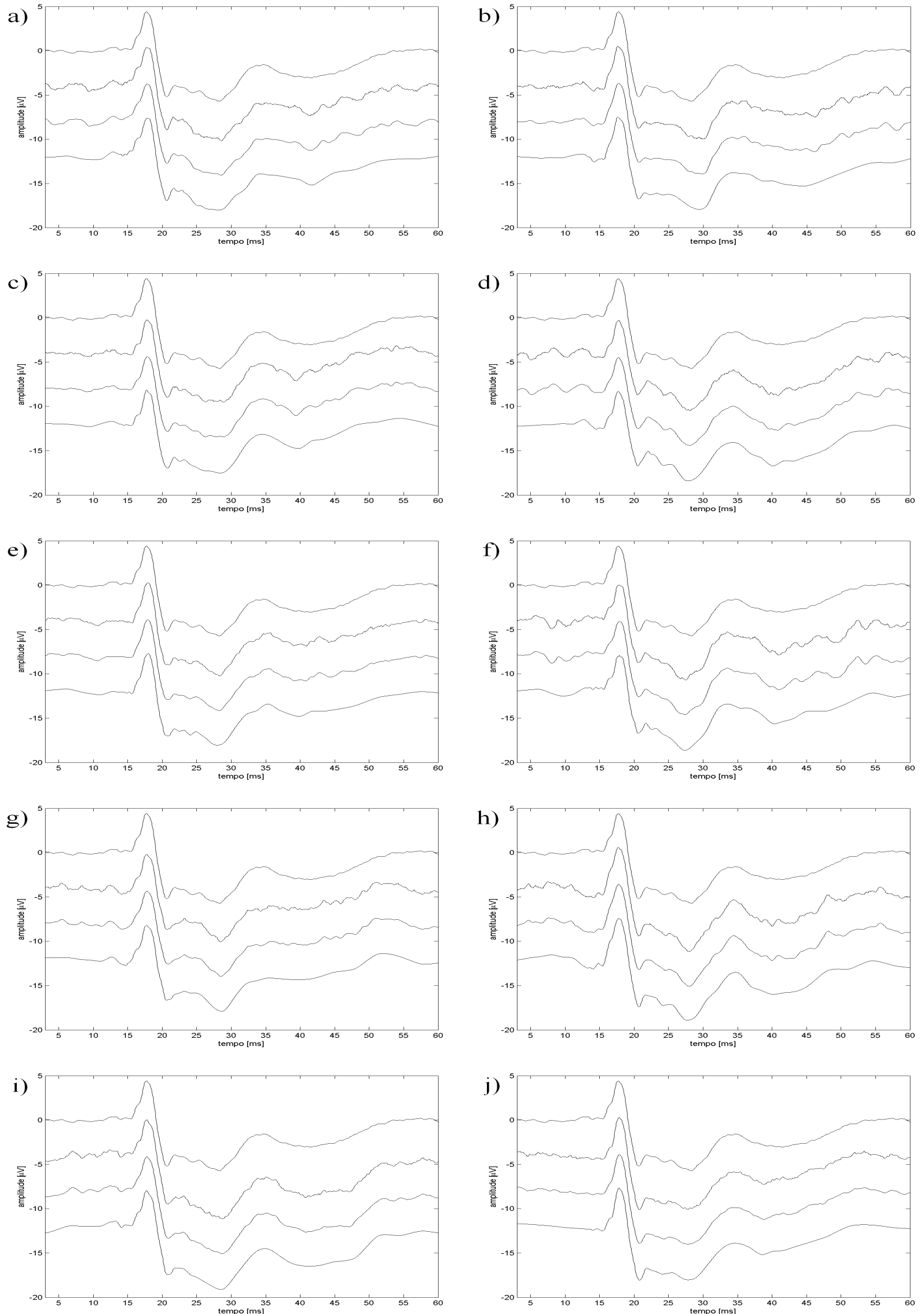

Figura 4.18: PE padrão e estimativas obtidas usando média síncrona, filtros e ondaletas (de cima para baixo, deslocadas de $4 \mu V$ ) para os conjuntos a) 1, b) 2, c) 3 , d) 4 , e) 5 , f) 6 , g) 7, h) 8 , i) 9 e j) 10 do sujeito 6 . 

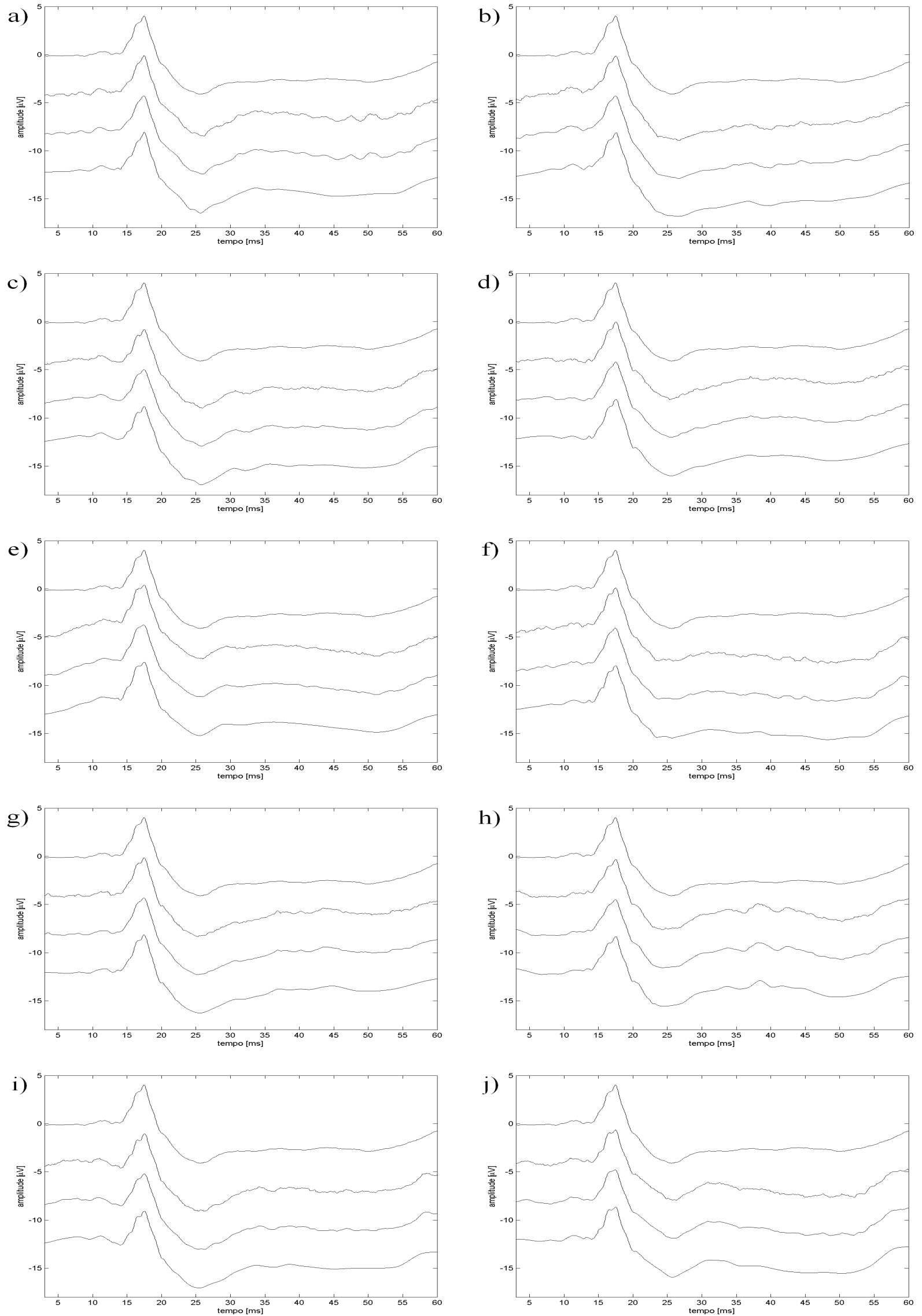

Figura 4.19: PE padrão e estimativas obtidas usando média síncrona, filtros e ondaletas (de cima para baixo, deslocadas de $4 \mu V$ ) para os conjuntos a) 1, b) 2, c) 3 , d) 4 , e) 5 , f) 6 , g) 7 , h) 8 , i) 9 e j) 10 do sujeito 7 . 

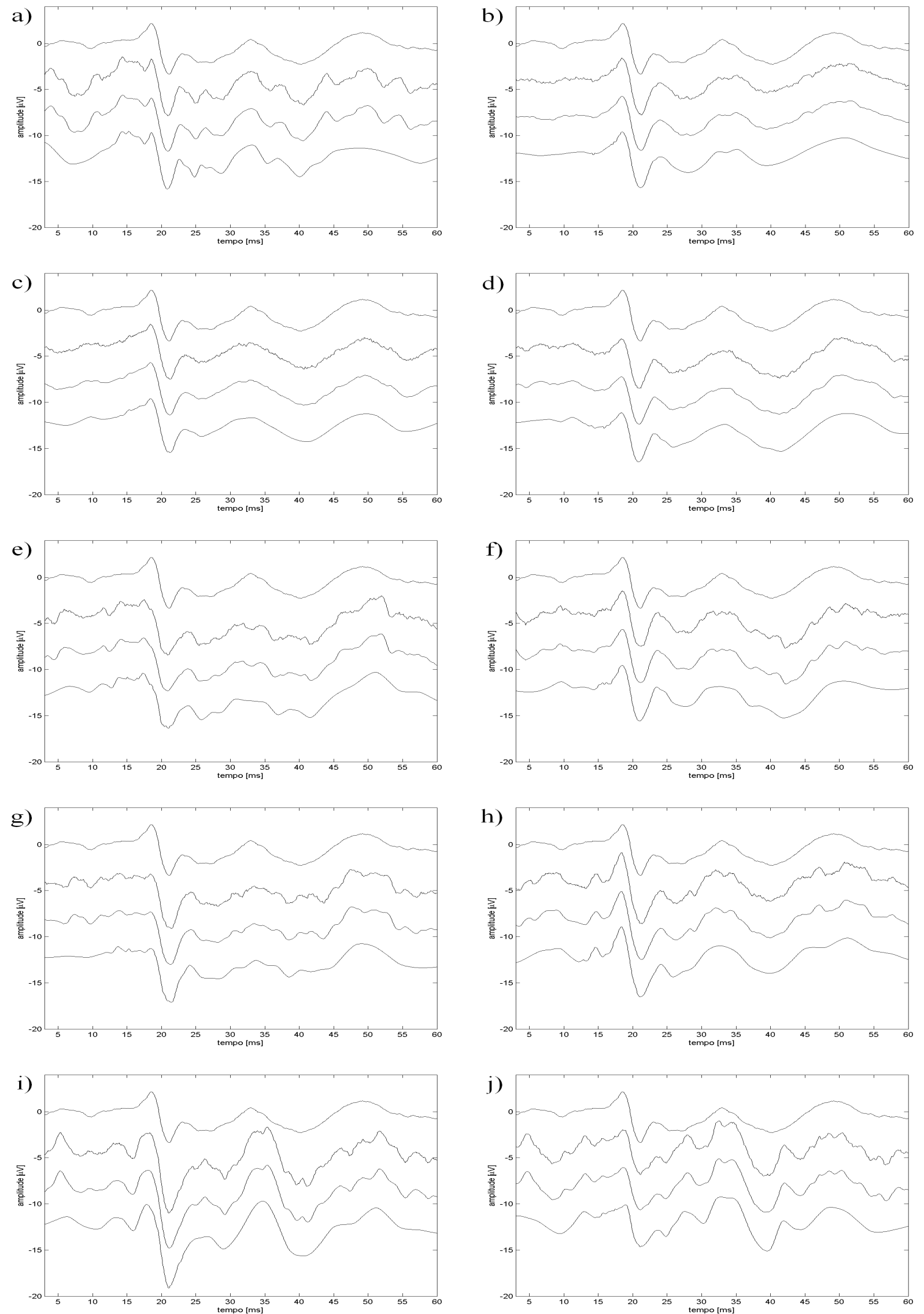

Figura 4.20: PE padrão e estimativas obtidas usando média síncrona, filtros e ondaletas (de cima para baixo, deslocadas de $4 \mu V$ ) para os conjuntos a) 1, b) 2, c) 3 , d) 4 , e) 5 , f) 6 , g) 7, h) 8 , i) 9 e j) 10 do sujeito 8 . 

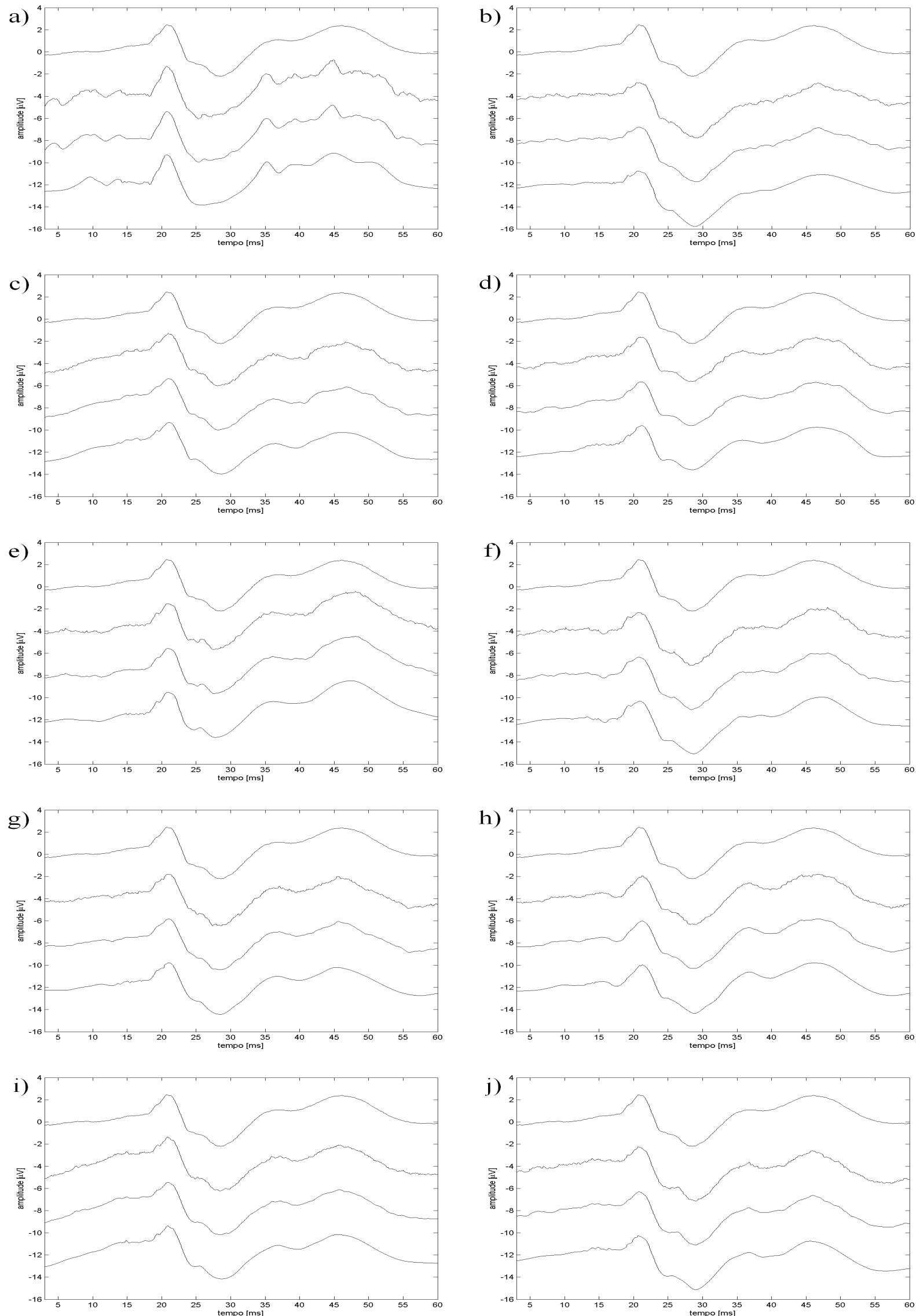

Figura 4.21: PE padrão e estimativas obtidas usando média síncrona, filtros e ondaletas (de cima para baixo, deslocadas de $4 \mu V$ ) para os conjuntos a) 1, b) 2, c) 3 , d) 4 , e) 5 , f) 6 , g) 7, h) 8 , i) 9 e j) 10 do sujeito 9 . 

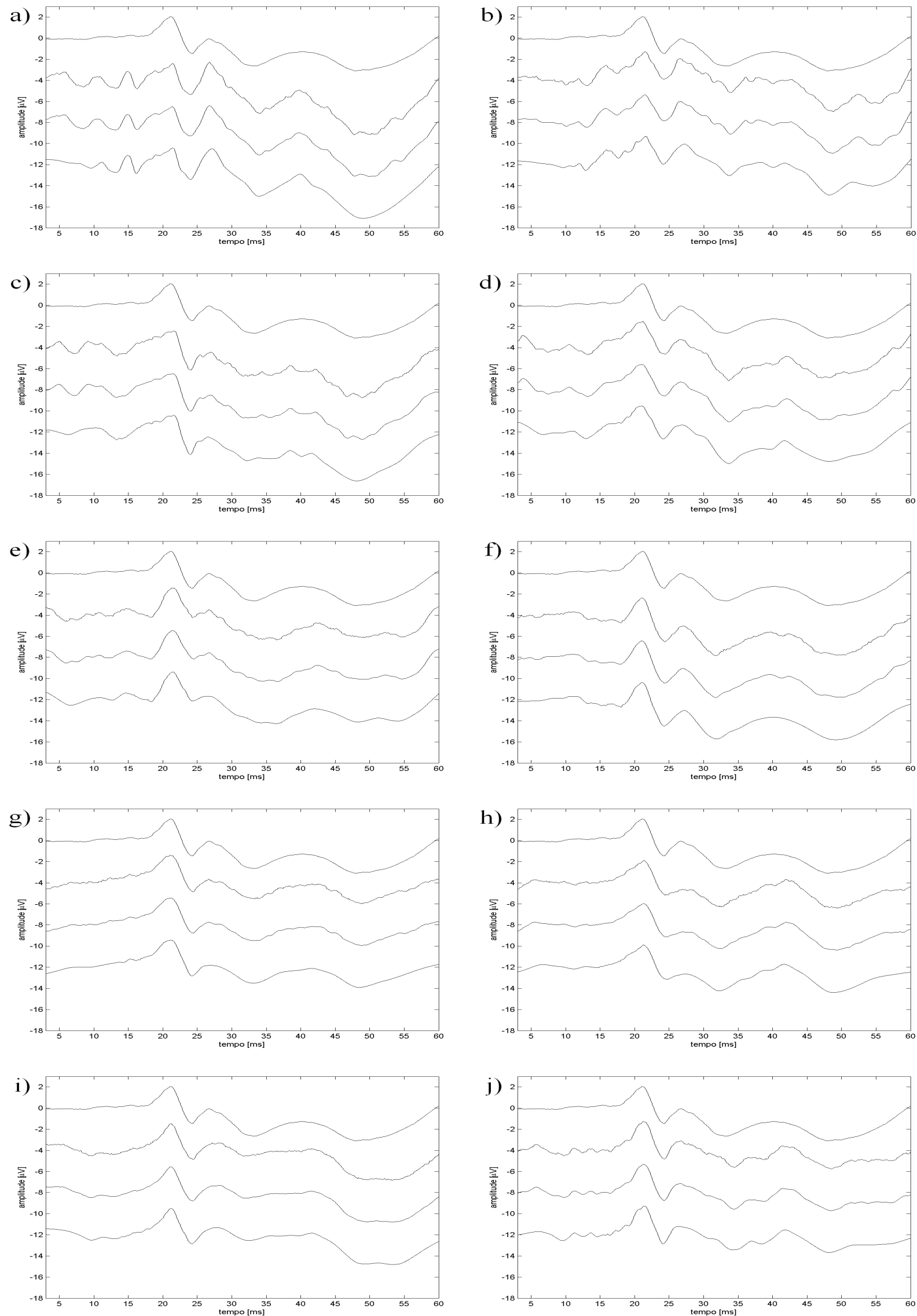

Figura 4.22: PE padrão e estimativas obtidas usando média síncrona, filtros e ondaletas (de cima para baixo, deslocadas de $4 \mu V$ ) para os conjuntos a) 1, b) 2, c) 3 , d) 4 , e) 5, f) 6 , g) 7, h) 8, i) 9 e j) 10 do sujeito 10. 

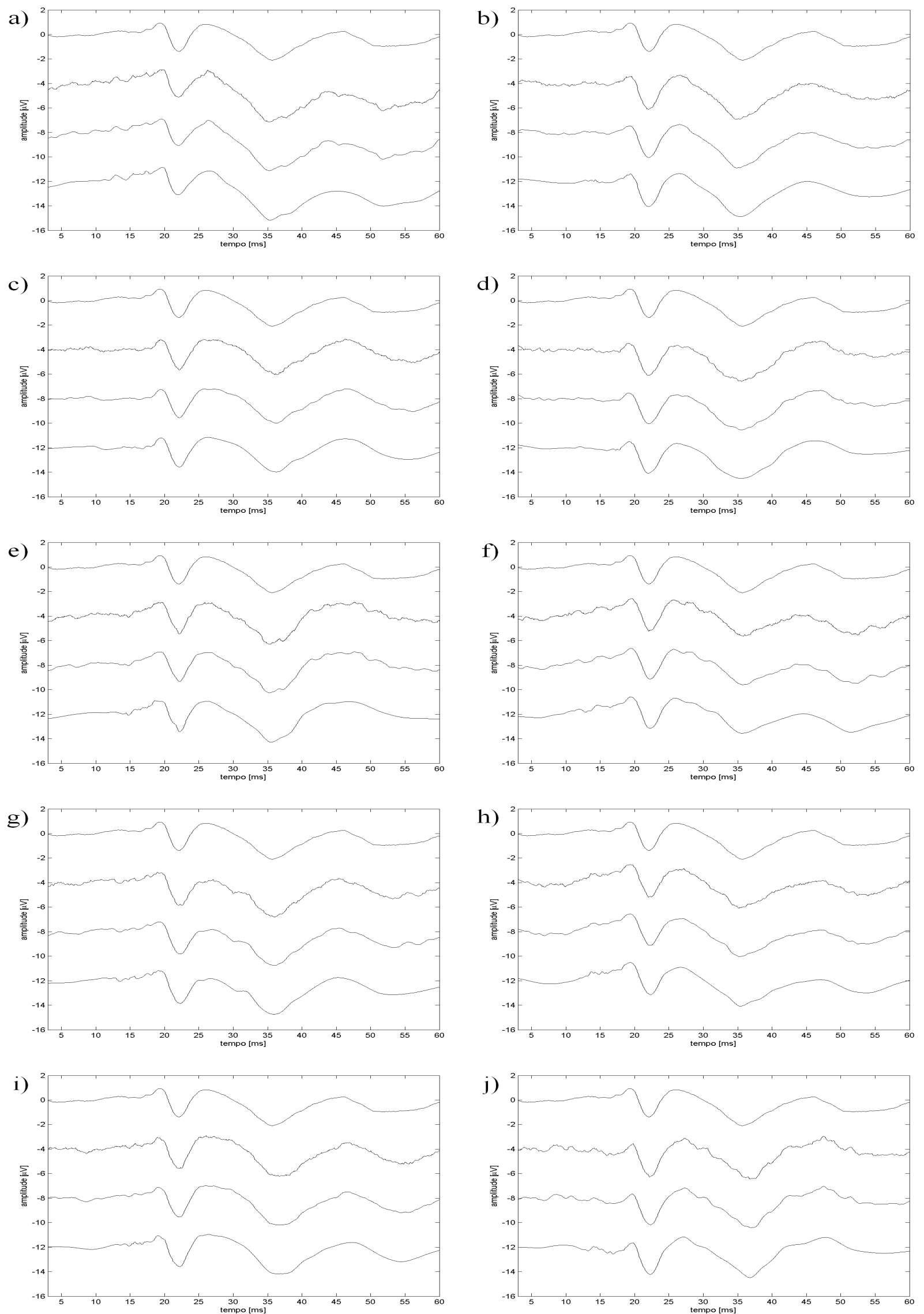

Figura 4.23: PE padrão e estimativas obtidas usando média síncrona, filtros e ondaletas (de cima para baixo, deslocadas de $4 \mu V$ ) para os conjuntos a) 1, b) 2, c) 3 , d) 4 , e) 5, f) 6 , g) 7, h) 8, i) 9 e j) 10 do sujeito 11. 

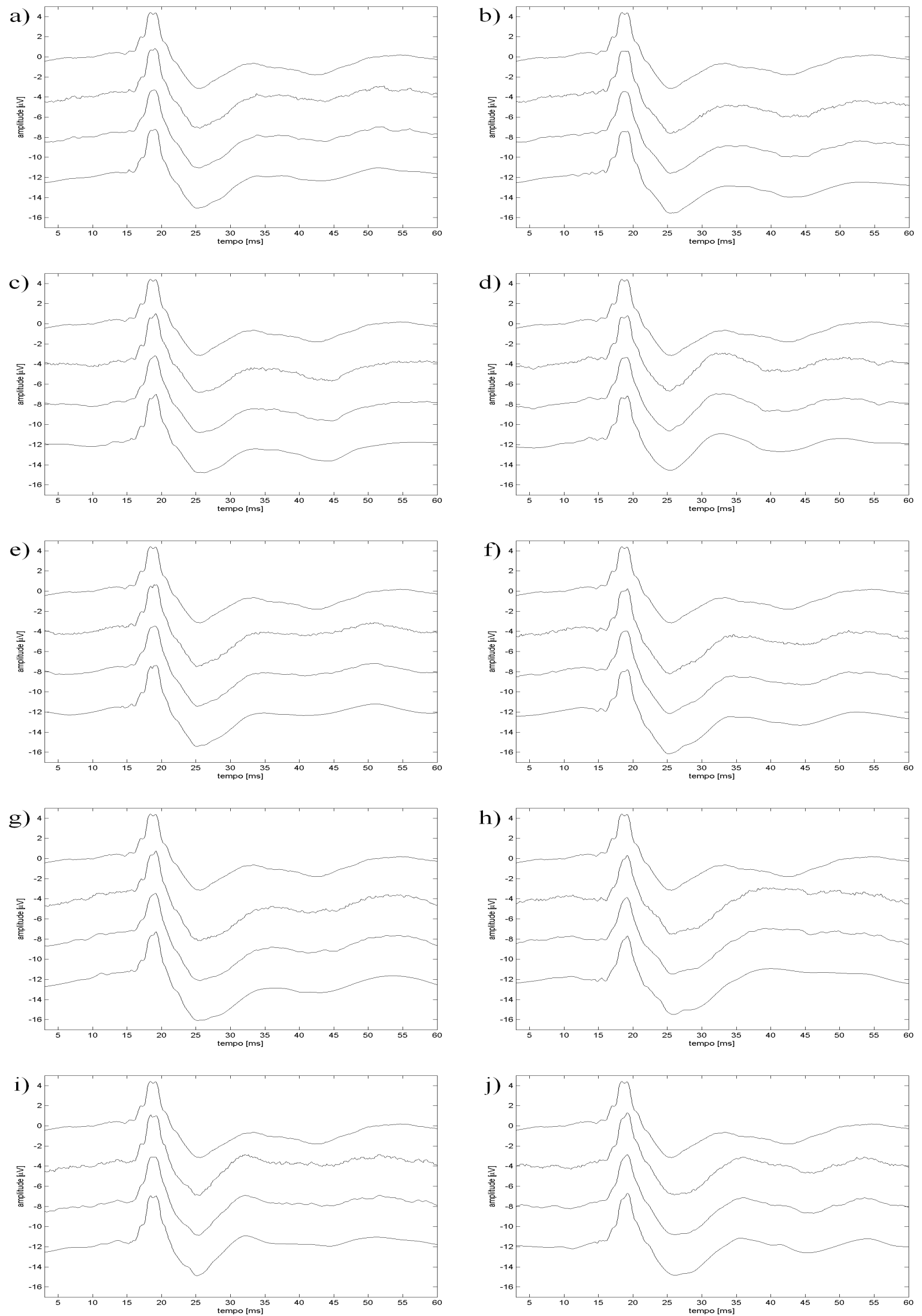

Figura 4.24: PE padrão e estimativas obtidas usando média síncrona, filtros e ondaletas (de cima para baixo, deslocadas de $4 \mu V$ ) para os conjuntos a) 1, b) 2, c) 3 , d) 4 , e) 5, f) 6 , g) 7, h) 8, i) 9 e j) 10 do sujeito 12 . 

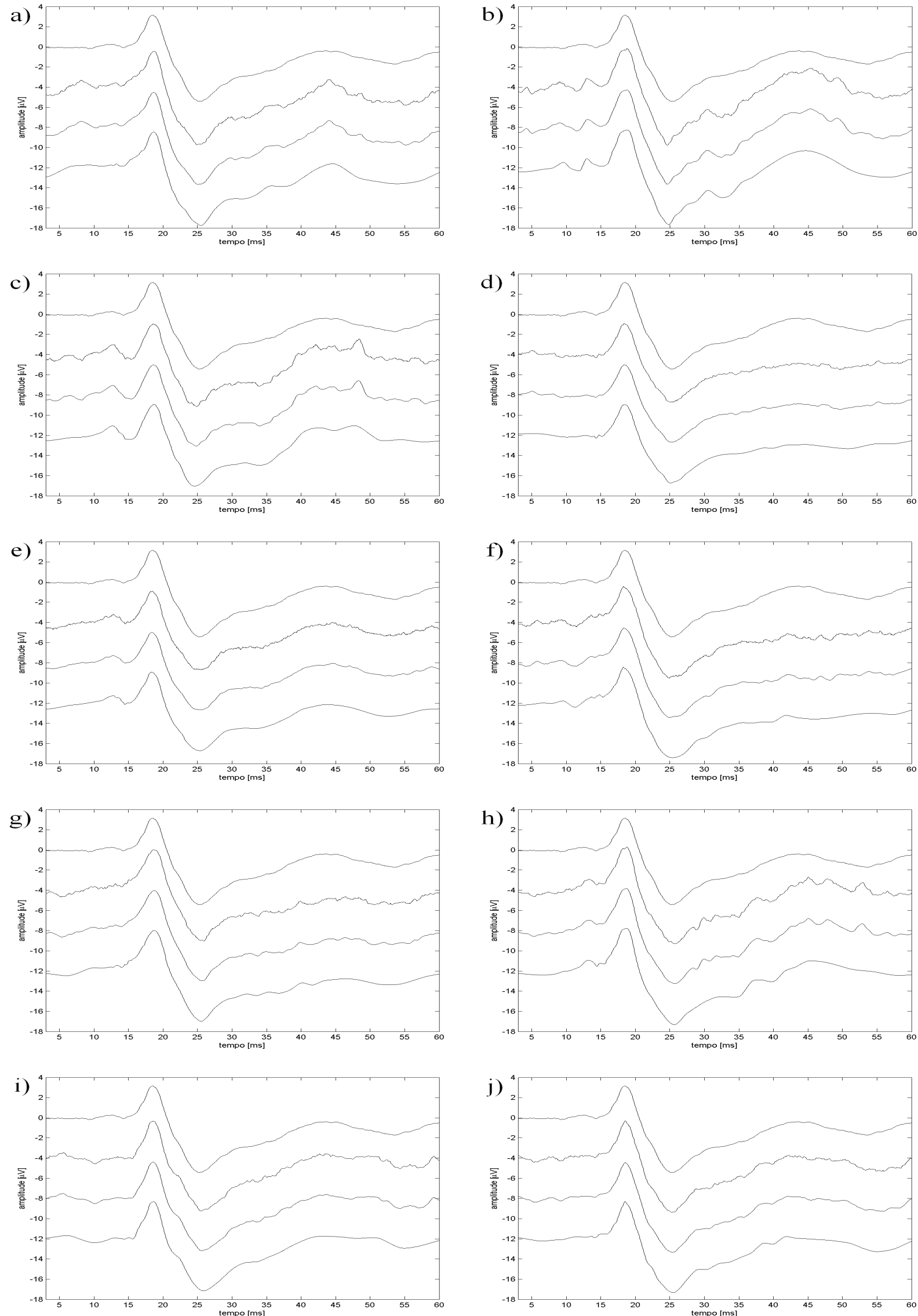

Figura 4.25: PE padrão e estimativas obtidas usando média síncrona, filtros e ondaletas (de cima para baixo, deslocadas de $4 \mu V$ ) para os conjuntos a) 1, b) 2, c) 3 , d) 4 , e) 5, f) 6, g) 7, h) 8, i) 9 e j) 10 do sujeito 13. 
A análise visual das figuras sugere que as estimativas por ondaletas sejam mais "limpas" ou alisadas que as estimativas por filtros e por simples média síncrona. No entanto, uma comparação quantitativa só pode ser fornecida pela análise estatística.

Para cada indivíduo, os valores médios dos erros obtidos por uma determinada técnica estão representados na Tabela 4.3. Também se encontram os postos de Friedman, entre parênteses.

Tabela 4.3: Média dos erros quadráticos normalizados das três estimativas para os sujeitos 5 a 13, em porcentagem, e postos de Friedman (entre parênteses).

\begin{tabular}{cccc} 
Sujeito & MS & FC & WT \\
\hline 5 & $5,61(3)$ & $5,53(2)$ & $5,45(1)$ \\
6 & $5,66(3)$ & $5,55(2)$ & $5,31(1)$ \\
7 & $4,69(3)$ & $4,66(2)$ & $4,59(1)$ \\
8 & $51,32(3)$ & $49,49(2)$ & $47,45(1)$ \\
9 & $25,88(3)$ & $25,68(2)$ & $25,56(1)$ \\
10 & $28,19(3)$ & $27,96(2)$ & $27,56(1)$ \\
11 & $31,80(3)$ & $31,25(2)$ & $30,94(1)$ \\
12 & $27,52(3)$ & $27,33(2)$ & $27,27(1)$ \\
13 & $8,85(3)$ & $8,70(2)$ & $8,51(1)$ \\
\hline
\end{tabular}

O teste de Page aplicado às médias dos erros quadráticos normalizados (Tabela 4.3) indicam que, com 0,1\% de significância, os erros das estimativas usando ondaletas são menores ou iguais aos erros das estimativas usando filtros. Estes, por sua vez, são menores ou iguais aos erros das estimativas pela média síncrona. O teste de Page garante que pelo menos uma dessas desigualdades seja estrita. Isso indica que as estimativas por ondaletas fornecem erros menores que as estimativas por média síncrona. No entanto, nada se poderia dizer quanto às estimativas por filtros.

Por isso, as técnicas foram comparadas duas a duas. O teste do sinal indicou que as estimativas por ondaletas fornecem erros estritamente menores que os associados às estimativas por filtros, com $0,1 \%$ de significância. O mesmo teste também confirmou que as estimativas por filtros resultam em erros estritamente menores que os resultantes da média síncrona, também com $0,1 \%$ de significância. 


\section{Discussão e Conclusão}

Neste capítulo é apresentada uma comparação entre a metodologia adotada e a literatura. Além disso, é feita a discussão dos resultados e a formulação da conclusão do trabalho.

\subsection{Escolha dos coeficientes}

Um dos interesses do uso das ondaletas no processamento de sinais é sua capacidade de separar faixas de freqüências e localizá-las no tempo. As escalas de decomposição representam diferentes intervalos de freqüências, e a seqüência de coeficientes de uma determinada escala está relacionada com o tempo. Essa forma de decomposição dos sinais permite que se selecionem determinadas faixas de freqüências em trechos de maior interesse. Para isso, basta escolher os coeficientes correspondentes.

Essa seleção tem sido feita de diversas formas na análise dos potenciais evocados. Alguns autores utilizam somente os coeficientes de aproximação e de decomposição de escalas mais altas. Scheller et al. (2006) usaram todos os coeficientes A5 e D5 para caracterizar o PE auditivo, enquanto Wilson (2004) usou todos os coeficientes A6, D6, D5 e D4. Já Thakor et al. (1993b) concluíram que os coeficientes A4 e D4 eram mais representativos do efeito da hipóxia em SEPs intracorticais.

Outra maneira de escolher os coeficientes é pela eliminação daqueles cujos valores ficam acima (ou abaixo) de uma certa referência. A eliminação dos maiores coeficientes é justificada quando se faz a detecção de PEs em respostas individuais ou nas médias de poucas respostas. Nesses casos, os maiores coeficientes estão relacionados com o EEG ou 
com outros sinais de origem biológica, que têm amplitude maior que o potencial evocado. Por outro lado, zerar coeficientes menores que um limiar é vantajoso para retirar ruídos de alta freqüência e obter estimativas mais alisadas (limpas). Uma dificuldade na aplicação desse tipo de eliminação de coeficientes reside na escolha do valor de referência, que pode afetar o resultado consideravelmente (CAUSEVIC et al., 2005). Valores muito conservadores, ou seja, que retém muitos coeficientes, podem não eliminar componentes indesejados, enquanto que valores muito arrojados podem eliminar coeficientes relacionados ao potencial evocado.

O meio-termo, em geral, é determinado heuristicamente e depende da finalidade do procesamento do PE. Hoppe et al. (2002) selecionaram 16 coeficientes, procurando minimizar a relação sinal-erro de estimativas de PE somato-sensitivo a partir da média síncrona de 200 respostas individuais. Bartnik, Blinowska e Durka (1992) escolheram os 5 coeficientes que mais permitiam diferenciar o potencial evocado auditivo do EEG, a partir de respostas individuais. Já Quiroga (2000) selecionou alguns coeficientes da DWT para obter PEs visuais de respostas individuais.

Neste trabalho, foi utilizada uma metodologia parecida com a de Zhang et al. (2004), que combinaram faixas de coeficientes relacionados ao potencial evocado com os maiores coeficientes de cada escala. Na decomposição do PE padrão do sujeito 3 (item 4.1.1), viu-se que os coeficientes das escalas mais altas são maiores que os coeficientes das escalas mais baixas. Isso mostra que as amplitudes dos componentes mais lentos (escalas mais altas) são maiores que as amplitudes dos componentes mais rápidos. Essa maior amplitude justifica o uso dos coeficientes das escalas mais altas e é coerente com alguns trabalhos da literatura (SCHELLER et al., 2006; WILSON, 2004). De fato, na reconstrução desse PE padrão, notou-se que os coeficientes A6 representam os componentes de freqüências mais baixas, que constituem a base do potencial evocado. A inclusão das escalas de detalhe em ordem decrescente foi acompanhada de contribuições cada vez menores, que alteram principalmente o trecho em torno de $20 \mathrm{~ms}$. De fato, os maiores coeficientes das escalas D3 a D6 estão concentrados nesse trecho específico. Por isso, além de restringir a escolha 
dos coeficientes dentre os $20 \%$ (ou 50\%) de maior amplitude, também se limitou a escolha ao trecho específico. Já os coeficientes D2 e D1, por apresentarem uma distribuição de caráter aleatório, não foram considerados. Um outro motivo para a eliminação dessas escalas é que elas representam freqüências altas, nas faixas de $5 \mathrm{kHz}$ a $10 \mathrm{kHz}$ (D1) e de $2,5 \mathrm{kHz}$ a $5 \mathrm{kHz}$ (D2). Uma vez que, na captação, foram utilizados filtros com freqüência de corte superior de $2 \mathrm{kHz}$, essas bandas (correspondentes às escalas D1 e D2) podem ser eliminadas.

Foram escolhidas faixas de coeficientes para as escalas D3 a D6. A porcentagem dos maiores coeficientes a serem utilizados na obtenção da estimativa do PE foi de $20 \%$ para as escalas D3, D4 e D5. Na escala D6, que essa porcentagem foi de 50\%. Os coeficientes considerados relevantes para a representação do potencial evocado, correspondiam, em número, a aproximadamente 11,8\% (D3), 16,1\% (D4), 19,6\% (D5) e 35,7\% (D6) dos coeficientes da respectiva escala. A escolha de reter uma porcentagem maior dos coeficientes que o número dentro da faixa considerada relevante, para depois escolher aqueles dentro da faixa, possibilita a exclusão de componentes de grande amplitude mas não relacionados ao PE. Além disso, a eliminação dos coeficientes pequenos dentro da faixa considerada relevante alterou muito pouco o erro quadrático (ver Seção 4.1.3), indicando o potencial da técnica.

\subsection{Seleção da ondaleta-mãe}

Uma outra decisão que precisa ser tomada antes da utilização da DWT é a seleção da ondaleta-mãe. No entanto, não há nenhuma ferramenta que auxilie nessa escolha, e também não há um consenso de como ela deve ser feita. Há vários trabalhos que não discutem essa questão ou a fazem de maneira muito supérflua (THAKOR et al., 1993b; BARTNIK; BLINOWSKA; DURKA, 1992; HOPPE et al., 2002).

Muitos autores dizem que o mais importante é que a ondaleta se pareça com o sinal que se quer analisar. Com esse argumento, Bartnik, Blinowska e Durka (1992) escolheram 
a ondaleta Battle-Lemarié de ordem 3 para PEs auditivos. Esse método de escolha parece ser bastante razoável na compressão de sinais, já que, dessa forma, a informação sobre o formato do sinal analisado se concentraria em poucos coeficientes. No entanto, esse não foi o objetivo desta dissertação. Além disso, como pode ser visto na Figura 4.16, os formatos dos PEs variam consideravelmente de sujeito para sujeito, dificultando a escolha de uma única ondaleta-mãe. Uma questão levantada por Bradley e Wilson (2004) relativa a esse critério de escolha é a dificuldade em quantificar a semelhança entre o PE e a ondaletamãe. Eles também ressaltam que o mesmo formato da ondaleta é utilizada para analisar diversas escalas, e que a semelhança entre a ondaleta e o sinal correspondente pode não ser válida em todas as escalas, tornando questionável a escolha inicial.

Bradley e Wilson (2004), por sua vez, testaram algumas ondaletas-mãe e recomendaram que a escolha fosse baseada nas suas propriedades, como a regularidade e a linearidade de fase. Esse mesmo argumento é utilizado por outros autores, como Causevic et al. (2005) e Zhang et al. (2004). Esses três trabalhos citam a linearidade de fase das ondaletas da família biortogonal como importante na escolha da ondaleta-mãe para aplicações em potenciais evocados.

Já Scheller et al. (2006) analisaram o uso de diversas ondaletas-mãe em duas medidas de informação. Nenhuma das ondaletas forneceu bons resultados para ambas as medidas. Dessa forma, esses autores recomendam que várias ondaletas sejam testadas para que a mais adequada possa ser escolhida, conforme a aplicação.

Neste trabalho, foram testadas algumas ondaletas. A biortogonal 5.5 foi incluída no teste graças à sua fase linear, e aos bons resultados obtidos em PEs auditivos (ZHANG et al., 2004). As famílias daubechies, symlet e coiflet foram testadas, pois são as mais utilizadas na literatura (WILSON, 2004; SCHELLER et al., 2006). Os resultados indicaram que, na média, as ondaletas associadas a filtros de comprimento maior (12 coeficientes) forneceram resultados melhores que aquelas associadas a filtros de comprimento menor (6 coeficientes). De fato, na Figura 4.15 é possível ver que as ondaletas de filtros menores (associadas a ordens mais baixas e menor regularidade) fornecem estimativas menos lisas 
do potencial evocado. A ondaleta biortogonal 5.5 foi a que resultou em menor erro quadrático. Essa melhor adequação da biortogonal 5.5 poderia ter sido causada pela escolha dos coeficientes usados na reconstrução do PE, já que, antes do teste das ondaletas, as faixas e as porcentagens de coeficientes foram ajustadas para a biortogonal 5.5. Esse ajuste inicial poderia ter prejudicado a avaliação do uso das outras ondaletas. No entanto, considerando os erros quadráticos, vê-se que os resultados obtidos para todas as ondaletasmãe são equivalentes. Por isso, em vez de se realizar um teste exaustivo, optou-se por usar a biortogonal 5.5, que tem uma importante característica: a fase linear.

\subsection{Métodos de estimação}

Após o estabelecimento das variáveis necessárias para utilizar as ondaletas, foi feito o processamento dos sinais obtidos durante este mestrado. Viu-se que o erro das estimativas pode variar consideravelmente para um mesmo sujeito, conforme ilustrado na Tabela 4.2. Essa diferença também pôde ser notada nas Figuras 4.17 a 4.25. Pode-se concluir que a 'qualidade' das estimativas obtidas depende fortemente do sinal processado, ou seja, do conjunto de respostas individuais utilizado (ver, por exemplo, 4.17 a 4.20). Esse resultado está de acordo com os obtidos por Bartnik, Blinowska e Durka (1992) e Quiroga (2000) (ver Figuras 7 e 3 nesses trabalhos, respectivamente), que estudaram a obtenção de potenciais evocados auditivos e visuais a partir de respostas individuais. Em ambos os trabalhos comenta-se que, a partir do sinal processado, é mais fácil detectar o PE. Quiroga (2000) sugere o uso dessa informação para escolher respostas individuais que melhorem a média síncrona, e para eliminar o efeito de sinais que apresentem muito ruído ou que não contenham PE.

Comparando os métodos de estimação, os resultados foram muito próximos. Nas Figuras 4.17 a 4.25, é possível notar que as estimativas obtidas com as ondaletas e os filtros são melhores que as médias síncronas, quando se considera a presença de ruído de alta freqüência. O processamento resultou em curvas mais lisas, mas sem alargar os picos (que seria conseqüência do corte excessivo de freqüências altas). Isso pode auxiliar na 
leitura das amplitudes e latências dos picos.

Por outro lado, as estimativas obtidas com os filtros muitas vezes não apresentam algumas oscilações de alta freqüência presentes antes do pico N19 (ver, por exemplo, 4.17 a 4.24). Esses componentes são resultantes da atividade do sistema nervoso (CURIO, 2000; VALENCIA et al., 2006). Por isso, não deveriam ser eliminados. Nesse aspecto, as ondaletas forneceram estimativas melhores que os filtros.

Essa diferença nas estimativas é compreensível analisando a decomposição feita pela DWT. Para um sinal amostrado a 20kHz, as escalas da DWT correspondem, aproximadamente, às seguintes faixas de freqüências: $5 \mathrm{kHz}$ a $10 \mathrm{kHz}$ (D1), $2,5 \mathrm{kHz}$ a $5 \mathrm{kHz}$ (D2), $1,25 \mathrm{kHz}$ a $2,5 \mathrm{kHz}$ (D3), $625 \mathrm{~Hz}$ a $1,25 \mathrm{kHz}$ (D4), $312,5 \mathrm{~Hz}$ a $625 \mathrm{~Hz}$ (D5), $156,25 \mathrm{~Hz}$ a $312,5 \mathrm{~Hz}$ (D6) e $0 \mathrm{~Hz}$ a $156,25 \mathrm{~Hz}$ (A6). Na reconstrução das estimativas usando ondaletas, foram usados coeficientes das escalas A6 e D6 a D3, que abrange as freqüências até 2,5kHz. Desse modo, no trecho em torno do pico N19, a estimativa por DWT considerou componentes de freqüência alta. No entanto, a estimativa por filtros utilizou uma freqüência de corte superior de $900 \mathrm{~Hz}$ nesse mesmo trecho. Como esse trecho do potencial evocado apresenta oscilações de alta freqüência, ou seja, componentes acima de 900Hz (VALENCIA et al., 2006), as diferentes bandas usadas pela DWT e pelos filtros justificaria o melhor desempenho da DWT.

Uma forma de melhorar a estimativa usando filtros seria aumentando a freqüência de corte superior para um valor maior que $900 \mathrm{~Hz}$. Mas essa mudança acarretaria na presença de ruído em todo o trecho correspondente, prejudicando principalmente a linha de base no início do PE. Outro modo seria incluir mais um filtro, até $2 \mathrm{kHz}$, no trecho em torno do pico N19. No entanto, o intervalo correspondente a esse filtro seria bastante estreito e dependeria da localização do pico, que pode variar consideravelmente (ver Tabela 2.1). Se fosse utilizado um intervalo que contivesse as latências consideradas normais para esse pico (aproximadamente $14 \mathrm{~ms}$ a $24 \mathrm{~ms}$ ) e o trecho da base imediatamente antes (onde estão as oscilações), o novo filtro quase que substituiria o primeiro filtro. Além disso, surgiriam problemas de concatenação entre os trechos dos diferentes filtros. 
Por isso, em termos de trabalhos futuros, seria mais interessante desenvolver uma técnica que determinasse esse trecho em torno do pico N19 de forma automática, com base nas características do PE de cada indivíduo. Tanto as faixas de coeficientes DWT quanto os trechos dos filtros poderiam ser ajustados para as particularidades de cada sujeito ou até mesmo para cada conjunto de sinais promediados. No entanto, deve-se ficar atento aos casos patológicos, em que os picos podem não estar presentes. Nesses casos, os métodos automáticos poderiam apresentar um péssimo desempenho. No entanto, esses casos geralmente não são tratados, pois fogem do escopo da maioria dos trabalhos da literatura.

\subsection{Avaliação das estimativas}

Em relação aos erros quadráticos, a estimativa por média síncrona apresenta os maiores valores (exceto para o conjunto 9 do sujeito 10) e a estimativa por ondaletas resulta, em geral, nos menores valores. A hipótese de que as três técnicas de estimação (usando a média síncrona, as ondaletas ou os filtros) fornecem o mesmo erro quadrático normalizado foi rejeitada com $0,1 \%$ de significância, de acordo com o teste de Page. Além disso, o teste do sinal indicou, com $0,1 \%$ de significância que as ondaletas forneceram as melhores estimativas.

Observando melhor os valores de erro da tabela 4.2, vê-se que eles são muito próximos para as três técnicas. Essas pequenas diferenças podem ser devidas ao fato de que a média síncrona de 100 respostas individuais já é uma estimativa razoavelmente livre de ruídos (limpa), e as ondaletas e os filtros pouco poderiam contribuir para melhorar o erro quadrático normalizado. Dessa forma, seria interessante aplicar essas técnicas a médias obtidas a partir de menos respostas individuais.

Uma outra questão que pode ser estudada é a medida de erro utilizada na avaliação das estimativas. Em processamento de sinais, o erro quadrático é uma boa medida da proximidade de duas curvas. No entanto, para aplicações na área médica, como foi feito 
neste trabalho, o valor do erro quadrático não reflete parâmetros clínicos (BESAR et al., 2000; MANIKANDAN; DANDAPAT, 2007). Recentemente, Manikandan e Dandapat (2007) propuseram uma medida para ECG, baseada em ondaletas. Em trabalhos futuros, seria interessante investigar a possibilidade de uso de medidas parecidas para potenciais evocados.

Com relação à estimação de PEs, a técnica que utiliza ondaletas poderia ser empregada conjuntamente com métodos que buscam melhorar a obtenção das estimativas, como a eliminação de artefatos de estímulo e de movimento.

Além disso, visando trabalhos futuros, a literatura tem apresentado melhores resultados quando se captam sinais com vários canais no escalpo e quando se faz a decomposição por análise de componentes independentes (ICA, do inglês Independent Component Analysis) (LEMM et al., 2006; DROZD et al., 2005). No entanto, esse tipo de montagem experimental não é comum em clínica, e por isso não foi abordado nesta dissertação.

\subsection{Variação do número de respostas individuais por média síncrona}

Para fins de ilustração, a Figura 5.1 mostra a média do erro quadrático para o sujeito 6 em função do inverso do número de respostas utilizadas no cálculo da média síncrona (foram usados valores submúltiplos de 1000, para que nenhuma resposta fosse descartada).

Na Figura 5.1, vê-se que os erros são muito parecidos para as três técnicas de estimação e aumentam com a diminuição do número de respostas utilizadas. Esse resultado é esperado, já que, promediando menos respostas individuais, o resíduo de EEG e outros sinais de origem biológica é maior. Esses sinais fazem com que a média síncrona varie consideravelmente de conjunto para conjunto, aumentando também os desvios-padrão. Também é possível notar que o gráfico se aproxima de uma reta, ou seja, o erro é proporcional a $1 / N$, em que $N$ é o número de respostas individuais utilizadas para obter a média síncrona. 
a)

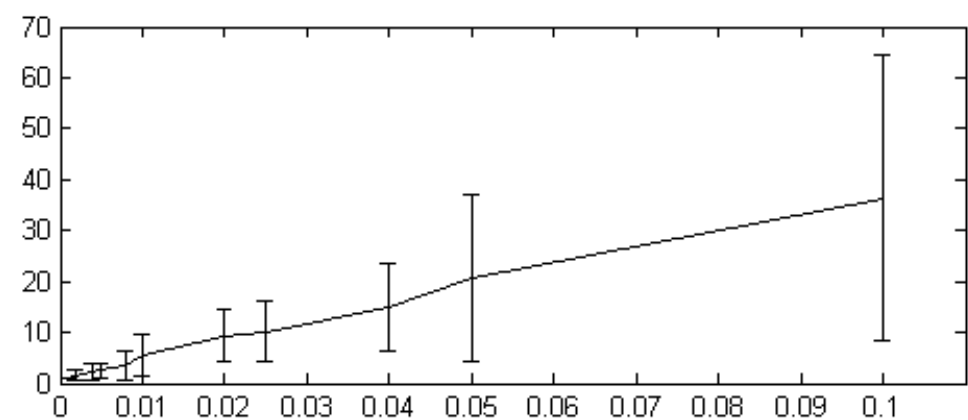

b)

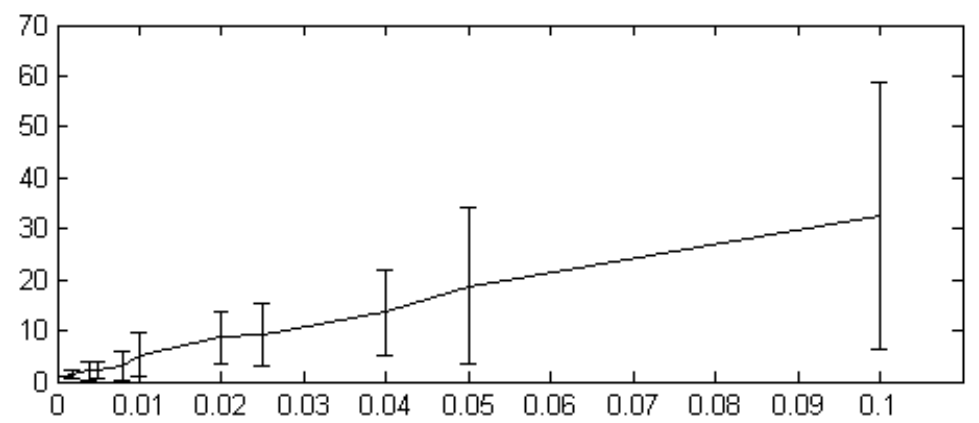

c)

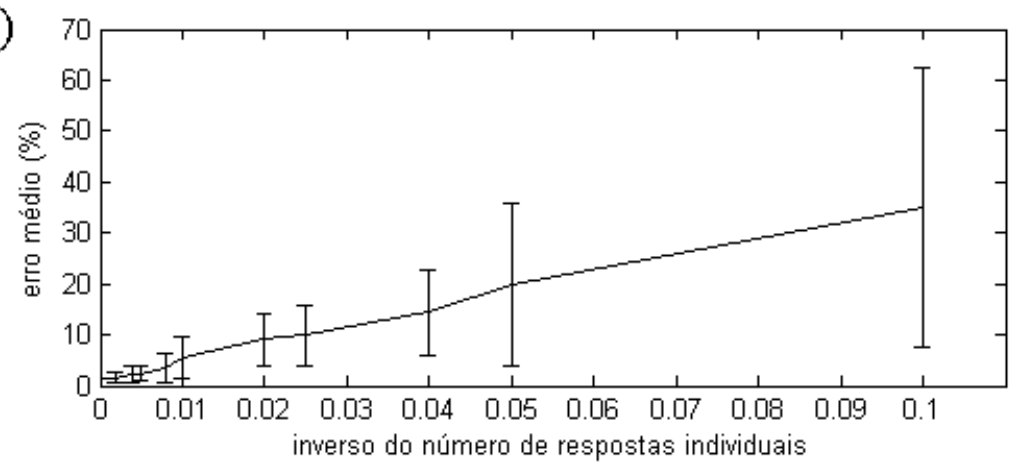

Figura 5.1: Variação da média do erro quadrático normalizado com o inverso do número de respostas individuais, para as estimativas por a) média síncrona, b) filtros e c) ondaletas, par ao sujeito 5 .

Algumas estimativas obtidas com a média síncrona de números diversos de respostas individuais são ilustradas na Figura 5.2. A análise visual confirma que um número menor de respostas individuais resulta em estimativas com mais "ruído". Curvas com as mesmas características são obtidas para todos os sujeitos. 

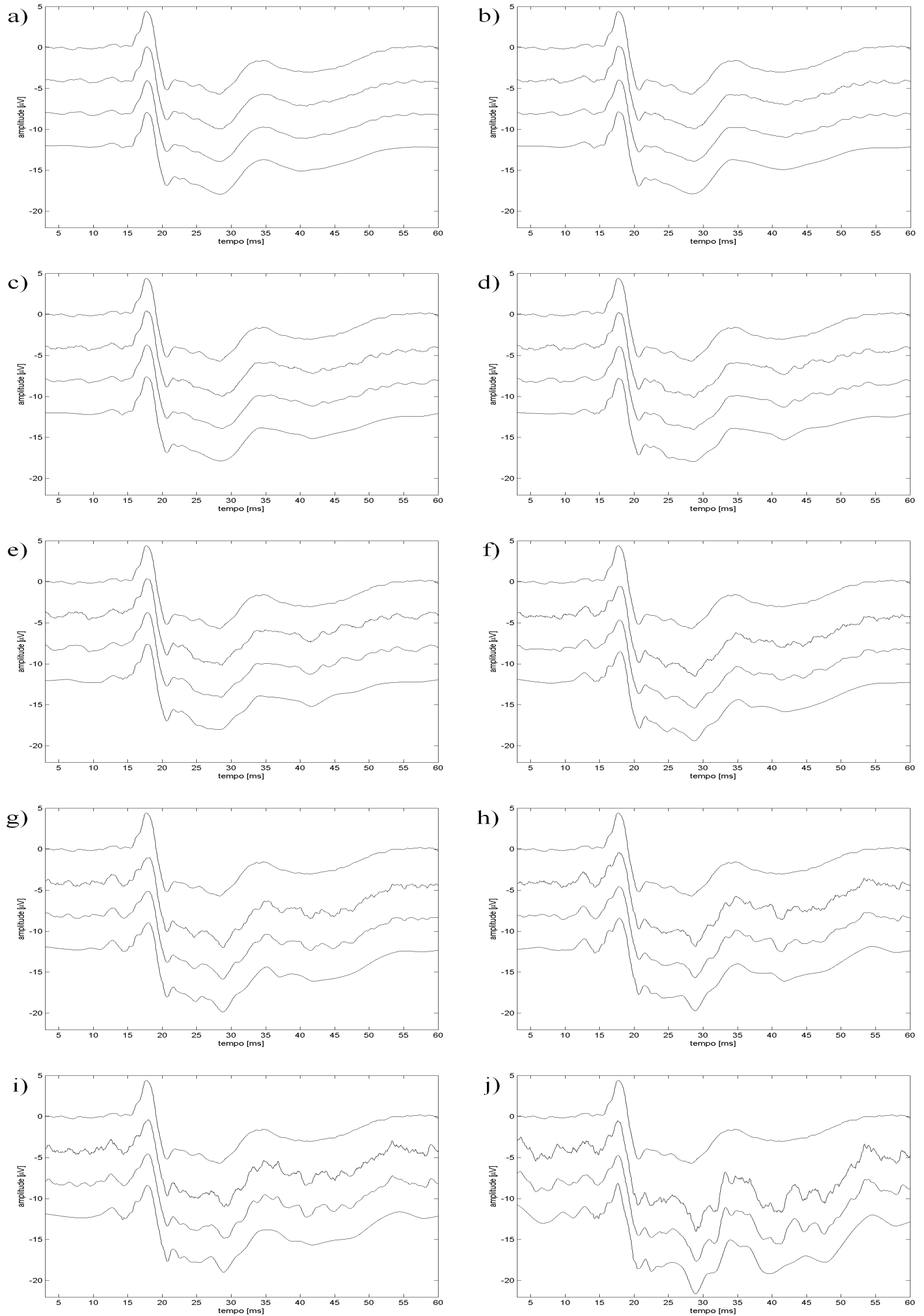

Figura 5.2: PE padrão e estimativas obtidas usando média síncrona, filtros e ondaletas (de cima para baixo, deslocadas de $4 \mu \mathrm{V}$ ) para os primeiros conjuntos de a) 500, b) 250, c) 200 , d) 125 , e) 100, f) 50, g) 40, h) 25, i) 20 e j) 10 respostas individuais do sujeito 6 . 
A Figura 5.3 apresenta o erro quadrático normalizado da média síncrona, em função do inverso do número de respostas individuais utilizadas. Nota-se que as curvas da Figura 5.3 se aproximam de retas, mostrando que o erro realmente é proporcional a $1 / N$. No entanto, elas variam quanto à inclinação. Essa diferença pode ser atribuída tanto à qualidade dos sinais analisados, quanto à presença de ruído. De fato, no caso extremo do sujeito 8, vê-se na Figura 5.4 que a média síncrona obtida para esse sujeito apresenta ruído de grande amplitude em relação ao PE padrão. Dessa forma, nota-se que as estimativas obtidas a partir de um número reduzido de respostas individuais dependem fortemente das condições em que os sinais foram captados. 


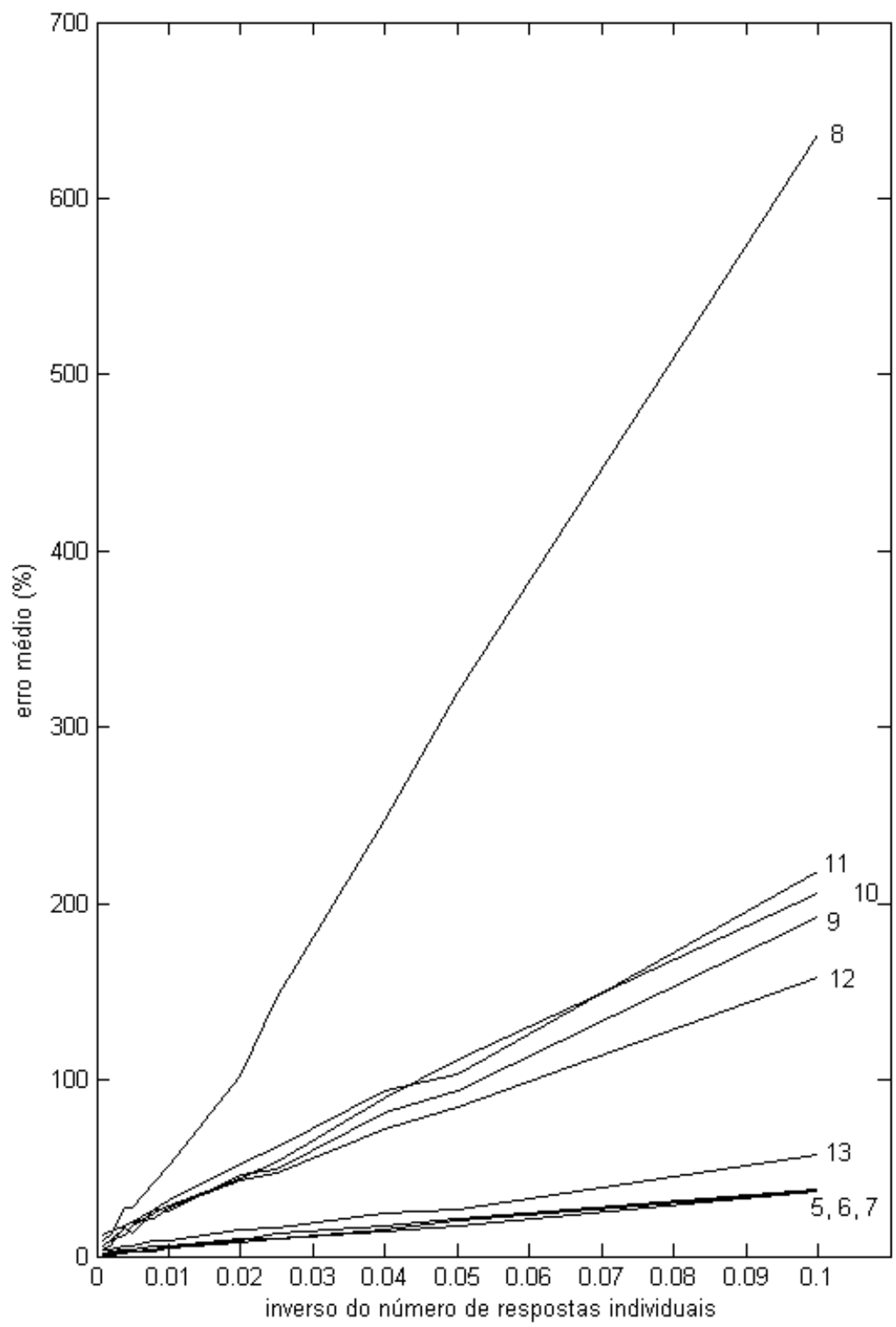

Figura 5.3: Variação da média do erro quadrático normalizado (da média síncrona) com o inverso do número de respostas individuais, para todos os sujeitos. 


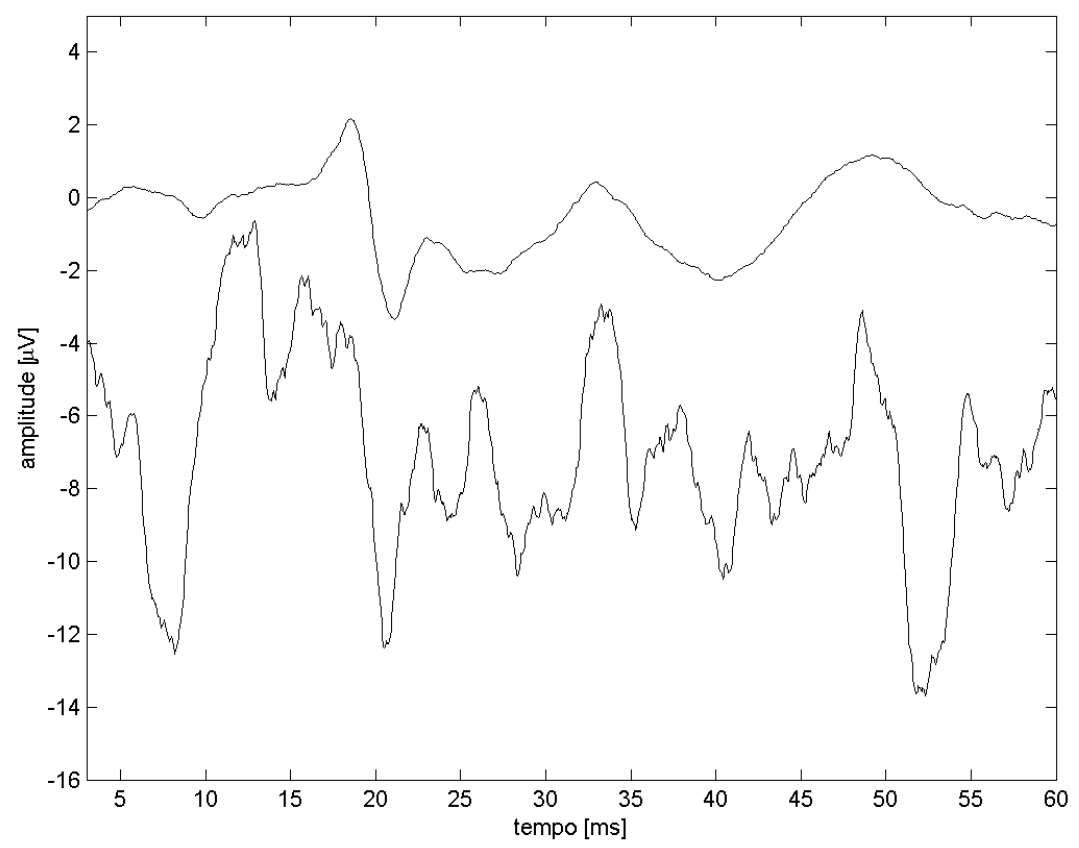

Figura 5.4: PE padrão e média síncrona das 10 primeiras respostas individuais do sujeito 8 . 


\subsection{Conclusão}

Neste trabalho, foi estudada a estimação de potenciais evocados somato-sensitivos a partir de um número reduzido de respostas individuais. Verificou-se que o erro quadrático de estimação é inversamente proporcional ao número de respostas individuais usadas na média síncrona. Portanto, a escolha do número de respostas usadas é um fator importante. No entanto, os resultados também indicam que a qualidade do sinal captado, associada a uma baixa impedância e a uma melhor relação sinal-ruído, pode reduzir muito o erro quadrático.

Duas técnicas de análise de tempo-freqüência foram comparadas com a simples média síncrona de 100 respostas individuais. O ajuste dos parâmetros das técnicas garante bons resultados.

Quanto aos filtros, sugere-se o uso de dois passa-baixas. O primeiro, com freqüência de corte em $900 \mathrm{~Hz}$, deve ser utilizado no trecho inicial de $3 \mathrm{~ms}$ a $35 \mathrm{~ms}$ e o segundo, com freqüência de corte em $200 \mathrm{~Hz}$, no trecho final de $25 \mathrm{~ms}$ a $60 \mathrm{~ms}$.

Em relação aos parâmetros da técnica baseada em ondaletas, recomenda-se a utilização da ondaleta-mãe biortogonal 5.5, pois ela fornece erros menores e apresenta curvas visualmente boas. Além disso, ela apresenta a vantagem de ter fase linear, que é mais adequada ao processamento de potenciais evocados. Os coeficientes 8 a 17 da escala D6, 11 a 19 da escala D5, 18 a 30 da escala D4, 33 a 50 da escala D3 e todos os coeficientes de aproximação de escala 6 são relevantes para a reconstrução do potencial evocado. A escolha baseada nessas faixas, em conjunto com um limiar de amplitude, mostra-se adequada para obter estimativas do potencial evocado.

As técnicas foram aplicadas a conjuntos de 100 respostas individuais. A análise estatística dos erros quadráticos normalizados indicou que a estimação por ondaletas é a melhor dentre as técnicas testadas. Também se verificou que ambas as técnicas resultaram na redução do erro quadrático normalizado, quando comparadas à média síncrona. 
Conclui-se que tanto as ondaletas quanto os filtros contribuem de forma positiva à obtenção de melhores estimativas do potencial evocado, mesmo quando um número reduzido de respostas individuais é utilizado. 


\section{Referências Bibliográficas}

ADDISON, P. Wavelet transforms and the ECG: a review. Physiological Measurement, v. 26, p. 155-199, 2005.

AMINOFF, M. (Ed.). Electrodiagnosis in Clinical Neurology. 2nd. ed. [S.l.]: New York: Churchill Livingstone, 1986.

AMINOFF, M.; EISEN, A. AAEM minimonograph 19: somatosensory evoked potentials. Muscle \& Nerve, v. 21, p. 277-290, 1998.

BAI, O. et al. Accurate identification of waveform of evoked potentials by component decomposition using discrete cosine transform modeling. Medical Engineering \& Physics, v. 23, p. $615-622,2001$.

BARTNIK, E.; BLINOWSKA, K.; DURKA, P. Single evoked potential reconstruction by means of wavelet transform. Biological Cybernetics, v. 67, p. 175-181, 1992.

BEAR, M.; CONNORS, B.; PARADISO, M. Neuroscience: Exploring the Brain. 2nd. ed. Baltimore: Lippincott Williams \& Wilkins, 2001.

BEAR, M.; CONNORS, B.; PARADISO, M. Neurociências: desvendando o sistema nervoso. 2. ed.. ed. [S.l.]: Porto Alegre: Artmed, 2002.

BERTRAND, O.; BOHORQUEZ, J.; PERNIER, J. Time-frequency digital filtering based on an invertible wavelet transform: an application to evoked potentials. IEEE Transactions on Biomedical Engineering, v. 41, n. 1, p. 77-88, January 1994.

BESAR, R. et al. On the choice of the wavelets for ECG compression. In: IEEE International Conference on Acoustics, Speech and Signal Processing, 2000. ICASSP'00. Proceedings. [S.l.: s.n.], 2000. v. 6, p. 3614-3617.

BOSTANOV, V. BCI competition 2003 - data sets ib and iib: feature extraction from event-related brain potentials with the continuous wavelet transform and the t-value scalogram. IEEE Transactions on Biomedical Engineering, v. 51, n. 6, p. 1057-1061, Junho 2004.

BRADLEY, A.; WILSON, W. On wavelet analysis of auditory evoked potentials. Clinical Neurophysiology, v. 115, p. 1114-1128, 2004.

BURRUS, S.; GOPINATH, R.; GUO, H. Introduction to Wavelets and Wavelet Transforms: A Primer. [S.l.]: Upper Saddle River: Prentice Hall, 1998.

CAUSEVIC, E. et al. Fast wavelet estimation of weak biosignals. IEEE Transactions on Biomedical Engineering, v. 52, n. 6, p. 1021-1032, June 2005. 
CERUTTI, S. et al. A parametric method of identification of single-trial event-related potentials in the brain. IEEE Transactions on Biomedical Engineering, v. 35, n. 9, p. 701-711, September 1988.

CHAN, F. et al. Evoked potential estimation using modified time-sequenced adaptive filter. Medical \& Biological Engineering $\&$ Computing, v. 36, p. 407-414, 1998.

CHAN, Y. Wavelet basics. [S.1.]: Boston: Kluwer Academic, 1995.

CHIAPPA, K. Evoked Potentials in Clinical Medicine. [S.l.]: New York: Raven Press, 1983.

COHEN, A.; KOVACEVIC, J. Wavelets: the mathematical background. Proceedings of the IEEE, v. 84, n. 4, p. 514-522, April 1996.

CRACCO, R.; BODIS-WOLLNER, I. (Ed.). Evoked Potentials. [S.l.]: New York: Alan R. Liss, 1986.

CURIO, G. Linking 600-hz "spikelike"EEG/MEG wavelets ("sigma-bursts") to cellular substrates - concepts and caveats. Journal of Clinical Neurophysiology, v. 17, n. 4, p. 377-396, 2000.

DAUBECHIES, I. Ten Lectures on Wavelets. [S.l.]: Philadelphia: Society for Industrial and Applied Mathematics, 1992. (CBMS-NSF Regional Conference Series in Applied Mathematics: 61).

DAVILA, C.; MOBIN, M. Weighted averaging of evoked potentials. IEEE Transactions on Biomedical Engineering, v. 39, n. 4, p. 338-345, April 1992.

DELISA, J.; MACKENZIE, K.; BARAN, E. Manual of Nerve Conduction Velocity and Somatosensory Evoked Potentials. 2nd. ed. New York: Raven Press, 1987.

DORLAND, W. Dicionário Médico Ilustrado. 28th. ed. [S.1.]: Editora Manole Ltda., 1999. Tradução de N.G. de Oliveira.

DROZD, M. et al. Detecting evoked potentials with SVD- and ICA-based statistical methods. IEEE Engineering in Medicine and Biology Magazine, p. 51-58, January/February 2005.

EFFERN, A. et al. Single trial analysis of event related potentials: non-linear de-noising with wavelets. Clinical Neurophysiology, v. 111, p. 2255-2263, 2000.

FREYE, E. Cerebral monitoring in the operating room and the intensive care unit: an introductory for the clinician and a guide for the novice wanting to open a window to the brain; part II: Sensory-evoked potentials (SSEP, AEP, VEP). Journal of Clinical Monitoring and Computing, v. 19, p. 77-168, 2005.

FUNG, K. et al. A tracing evoked potential estimatior. Medical $\mathscr{E}$ Biological Engineering \& Computing, v. 37, p. 218-227, 1999.

GIBBONS, H.; STAHL, J. Response-time corrected averaging of event-related potentials. Clinical Neurophysiology, v. 118, p. 197-208, 2007. 
HEINRICH, H. et al. Single-sweep analysis of event-related potentials by wavelet networks - methodological basis and clinical application. IEEE Transactions on Biomedical Engineering, v. 46, n. 7, p. 867-879, July 1999.

HOLLANDER, M.; WOLFE, D. Nonparametric Statistical Methods. [S.l.]: New York: John Wiley \& Sons, 1973.

HOPPE, U. et al. Representation of somatosensory evoked potentials using discrete wavelet transform. Journal of Clinical Monitoring and Computing, v. 17, p. 227-233, 2002 .

HU, Y. et al. Comparison of time-frequency analysis techniques in intraoperative somatosensory evoked potential (SEP) monitoring. Computers in Biology and Medicine, v. 32, p. 13-23, 2002.

HU, Y. et al. Application of time-frequency analysis to somatosensory evoked potential for intraoperative spinal cord monitoring. Journal of Neurology, Neurosurgery, and Psychiatry, v. 74, p. 82-87, 2003.

ILKHANI, M. et al. Accuracy of somatosensory evoked potentials in diagnosis of mild idiopathic carpal tunnel syndrome. Clinical Neurology and Neurosurgery, v. 108, p. 40-44, 2005.

JACOBS, M.; RAO, S.; JOSE, G. Parametric modeling of somatosensory evoked potentials. IEEE Transactions on Biomedical Engineering, v. 36, n. 3, p. 392-403, March 1989.

KANDEL, E.; SCHWARTZ, J.; JESSELL, T. (Ed.). Principles of Neural Science. 4th. ed. [S.l.]: New York: McGraw-Hill, 2000.

KIYMIK, M.; AKIN, M.; SUBASI, A. Automatic recognition of alertness level by using wavelet transform and artificial neural network. Journal of Neuroscience Methods, v. 139, p. 231-240, 2004.

KLEIN, A. et al. Conventional and wavelet coherence applied to sensory-evoked electrical brain activity. IEEE Transactions on Biomedical Engineering, v. 53, n. 2, p. 266-272, February 2006.

KOHLENBERG, A. Exact interpolation of band-limited functions. Journal of Applied Physics, v. 24, n. 12, p. 1432-1436, December 1953.

KRAFT, G. et al. Somatosensory evoked potentials: clinical uses. Muscle $\mathscr{G}$ Nerve, v. 21, p. 252-258, 1998.

LAGUNA, P. et al. Adaptive filter for event-related bioelectric signals using an impulse correlated reference input: comparison with signal averaging techniques. IEEE Transactions on Biomedical Engineering, v. 39, n. 10, p. 1032-1044, October 1992.

LANGE, D.; INBAR, G. A robust parametric estimator for single-trial movement related brain potentials. IEEE Transactions on Biomedical Engineering, v. 43, n. 4, p. 341-347, April 1996. 
LANGE, D.; PRATT, H.; INBAR, G. Segmented matched filtering of single event related evoked potentials. IEEE Transactions on Biomedical Engineering, v. 42, n. 3, p. 317-321, March 1995.

LANGE, D.; PRATT, H.; INBAR, G. Modeling and estimation of single evoked brain potential components. IEEE Transactions on Biomedical Engineering, v. 44, n. 9, p. 791-799, September 1997.

LEMM, S. et al. Enhancing the signal-to-noise ratio of ICA-based extracted ERPs. IEEE Transactions on Biomedical Engineering, v. 53, n. 4, p. 601-607, April 2006.

LIM, J.; OPPENHEIM, A. (Ed.). Advanced Topics in Signal Processing. [S.l.]: Englewood Cliffs: Prentice-Hall, 1988.

LINDQUIST, C. Adaptive 85 Digital Signal Processing with Digital Filtering Applications. [S.l.]: Miami: Steward \& Sons, 1989. (International Series in Signal Processing and Filtering, v. 2).

MAKINEN, V.; MAY, P.; TIITINEN, H. The use of stationarity and nonstationarity in the detection and analysis of neural oscillations. NeuroImage, v. 28, p. 389-400, 2005.

MALLAT, S. Une exploration des signaux en ondelettes. [S.l.]: Palaiseau: Les Éditions de l'École Polytechnique, 2000.

MANIKANDAN, M.; DANDAPAT, S. Wavelet energy based diagnostic distortion measure for ECG. Biomedical Signal Processing and Control, v. 2, p. 80-96, 2007.

MERLO, A.; FARINA, D.; MERLETTI, R. A fast and reliable technique for muscle activity detection from surface EMG signals. IEEE Transactions on Biomedical Engineering, v. 50, n. 3, p. 316-323, March 2003.

MISITI, M. et al. Wavelet Toolbox User's Guide. [S.1.], 2005. Disponível em: <http: //www.mathworks.com/access/helpdesk/help/pdf_doc/wavelet/wavelet_ug.pdf $>$.

MOORE, K. Clinically oriented anatomy. 3rd. ed. [S.l.]: Baltimore: Williams \& Wilkins, 1992.

NAIT-ALI, A.; SIARRY, P. A new vision on the averaging technique for the estimation of non-stationary brainstem auditory-evoked potentials: application of a metaheuristic method. Coomputers in Biology and Medicine, v. 36, p. 574-584, 2006.

NETO, P. C. Estatística. [S.l.]: São Paulo: Edgard Blücher, 2002.

NETTER, F. Interactive Atlas of Human Anatomy. 1995.

NIHON KOHDEN. Operator's Manual, Neuropack 8, Evoked Potential Measuring System MEB-4200 Series, Electromyograph MEM-4200 Series, Part I. OM.MEB/MEM4200-I-07. [S.l.], 1996.

NIHON KOHDEN. Operator's Manual, Neuropack 8, Evoked Potential Measuring System MEB-4200 Series, Electromyograph MEM-4200 Series, Part II (Examination Guide). OM.MEB/MEM4200-I-07. [S.l.], 1996. 
NISHIDA, S.; NAKAMURA, M.; SHIBASAKI, H. Method for single-trial recording of somatosensory evoked pontentials. Journal of Biomedical Engineering, v. 15, n. 3, p. 257-262, 1993.

NORTON, J. et al. A simple wavelet-based test for evoked responses. Journal of Neuroscience Methods, v. 138, p. 157-164, 2004.

OPPENHEIM, A.; SCHAFER, R. Discrete-time Signal Processing. [S.l.]: Englewood Cliffs: Prentice-Hall, 1989.

PARSA, V.; PARKER, P.; SCOTT, R. Adaptive stimuls artifact reduction in noncortical somatosensory evoked potential studies. IEEE Transactions on Biomedical Engineering, v. 45, n. 2, p. 165-179, February 1998.

QIU, W. et al. Real-time data-reusing adaptive learning of a radial basis function network for tracking evoked potentials. IEEE Transactions on Biomedical Engineering, v. 53, n. 2, p. 226-237, February 2006.

QUIROGA, R. Obtaining single stimulus evoked potentials with wavelet denoising. Physica D, v. 145, p. 278-292, 2000.

QUIROGA, R.; GARCIA, H. Single-trial event-related potentials with wavelet denoising. Clinical Neurophysiology, v. 114, p. 376-390, 2003.

REGAN, D. Human Brain Electrophysiology: Evoked Potentials and Evoked Magnetic Fields in Science and Medicine. [S.l.]: New York: Elsevier Science, 1989.

SCHELLER, B. et al. The influence of wavelets on multiscale analysis and parametrization of midlatency auditory evoked potentials. Biological Cybernetics, v. 95, p. 193-203, 2006.

SPEHLMANN, R. Evoked Potential Primer: Visual, Auditory and Somatosensory Evoked Potentials in Clinical Diagnosis. [S.l.]: Boston: Butterworth Publishers, 1985.

SPRECKELSEN, M. von; BROMM, B. Estimation of single-evoked cerebral potentials by means of parametric modeling and kalman filtering. IEEE Transactions on Biomedical Engineering, v. 35, p. 691-700, 1988.

THAKOR, N. et al. Orthonormal (Fourier and Walsh) models of time-varing evoked potentials in neurological injury. IEEE Transactions on Biomedical Engineering, v. 40, n. 3, p. 213-221, 1993.

THAKOR, N. et al. Multiresolution wavelet analysis of evoked potentials. IEEE Transactions on Biomedical Engineering, v. 40, n. 11, p. 1085-1094, November 1993.

UNSER, M.; ALDROUBI, A. A review of wavelets in biomedical applications. Proceedings of the IEEE, v. 84, p. 626-638, 1996.

VALENCIA, M. et al. High frequency oscillations in the somatosensory evoked potentials (SSEP's) are mainly due to phase-resetting phenomena. Journal of Neuroscience Methods, v. 154, p. 142-148, 2006.

WALSH, P.; KANE, N.; BUTLER, S. The clinical role of evoked potentials. Journal of Neurology, Neurosurgery and Psychiatry, v. 76, p. 16-22, 2005. 
WILSON, W. The relationship between the auditory brain-stem response and its resconstructed waveforms following discrete wavelet transformation. Clinical Neurophysiology, v. 115, p. 1129-1139, 2004.

YIN, H. et al. Application of adaptive noise cancellation with neural-network-based fuzzy interference system for visual evoked potentials estimation. Medical Engineering \&6 Physics, v. 26, p. 87-92, 2004.

ZHANG, J.; BöHME, J. Adaptive regularization network based neural modeling paradigm for nonlinear adaptive estimation of cerebral evoked potentials. Medical Engineering $\mathcal{E}$ Physics, v. 29, p. 1008-1018, 2007.

ZHANG, R. et al. Feature extraction and classification of the auditory brainstem response using wavelet analysis. In: Knowledge Exploration in Life Science Informatics. [S.l.]: Springer-Verlag Berlin Heidelberg, 2004. (Lecture Notes in Artificial Intelligence, v. 3303), p. 169-180. 